INSTITUTO DE PESQUISAS ENERGÉTICAS E NUCLEARES

Autarquia associada à Universidade de São Paulo

\title{
APLICAÇAO DE NANOTECNOLOGIA NO MEIO AMBIENTE: BIOSSORVENTE MAGNÉTICO NA REMOÇÃO DE URÂNIO
}

\section{AMANDA PONGELUPPE GUALBERTO YAMAMURA}

Dissertação apresentada como parte dos requisitos para obtenção do Grau de Mestre em Ciências na Área de Tecnologia Nuclear - Materiais.

Orientadora:

Dra. Mitiko Yamaura

São Paulo 
"A mente que se abre a uma nova idéia jamais voltará ao seu tamanho original." Albert Einstein 
Ao meu amor Wilson pelo incentivo, apoio, compreensão, amizade, companheirismo, paciência, dedicação, amor... Por me completar.

Ao meu querido e amado filho Luca Kenzo pela enorme alegria e sentido de vida.

Aos meus queridos e amados pais Vilma e Anízio pela vida, pelo exemplo de vida, apoio, compreensão, ensinamentos, carinho, amor...

Ao meu irmão Alisson pelo carinho e amizade.

À minha querida madrinha Leonilda Pongeluppe (in memoriam) pelo enorme aprendizado deixado.

A estes dedico este trabalho.

Muito obrigada. 


\section{AGRADECIMENTOS}

A Deus, pelo milagre da vida e por tudo que sou.

Ao Instituto de Pesquisas Energéticas e Nucleares. Ao Centro de Química e Meio Ambiente (CQMA) e à sua gerente Dra. Maria Aparecida Faustino Pires pela disponibilidade das instalações e laboratórios para a realização dos experimentos e desenvolvimento da pesquisa.

À $\mathrm{Dr}^{\mathrm{a}}$ Mitiko Yamaura pelo privilégio da sua orientação, incentivo, apoio, dedicação, profissionalismo e contribuições ao meu trabalho e por ter despertado em mim o gosto pela pesquisa.

À Dow Chemical Company pelo incentivo à pesquisa de inovação tecnológica por meio do $1^{\circ}$ Prêmio Dow de Sustentabilidade, no qual o trabalho foi classificado em primeiro lugar, em 2008.

Ao Dr. José Carlos Mierzwa e ao Dr. José Oscar Bustillos pelas observações.

Aos colegas de divisão que direta ou indiretamente colaboraram para a realização deste trabalho.

À minha amiga Jacinete pelo apoio, palavras de incentivo além, é claro, de sua valiosa amizade. À minha amiga Roseli pela amizade. À minha colega de laboratório Carol pelas conversas descontraídas e incentivo.

Ao meu marido por todo apoio, compreensão e incentivo. Ao meu filho pelos momentos de ausência. Aos meus pais e irmão pelo carinho. 


\section{SUMÁRIO}

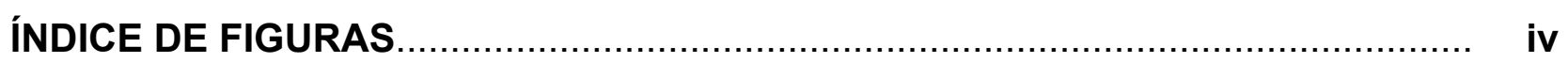

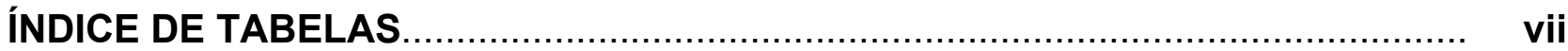

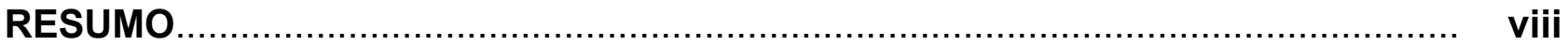

ABSTRACT

1. INTRODUÇÃO

2. OBJETIVOS

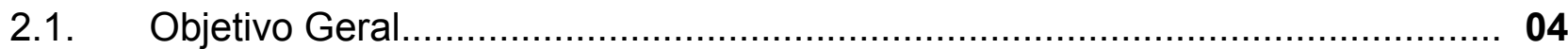

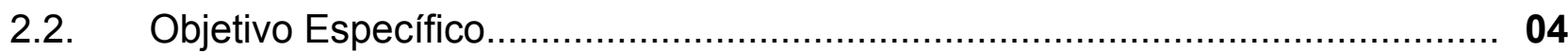

3. CONSIDERAÇÕES GERAIS E ASPECTOS TEÓRICOS ................................... 05

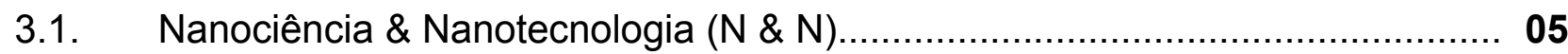

3.2. Introdução ao Magnetismo................................................................ 07

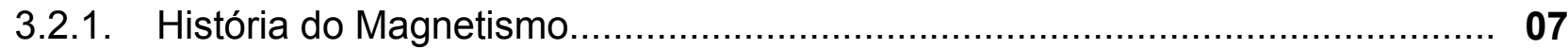

3.2.2. Momento Magnético........................................................................... 08

3.2.3. Comportamento Magnético dos Materiais.................................................... 09

3.2.4. Curvas de Magnetização e Histerese......................................................... 13

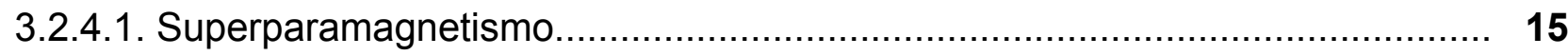

3.3. Aplicação Tecnológica de Nanopartículas Magnéticas................................. 17

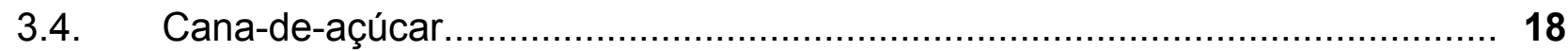

3.4.1. Bagaço de Cana-de-açúcar................................................................ 19

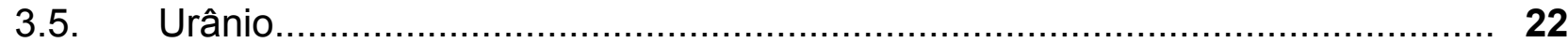

3.5.1. Rejeitos Radioativos Contendo Urânio...................................................... 23

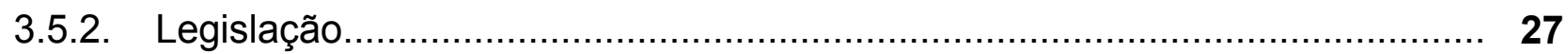

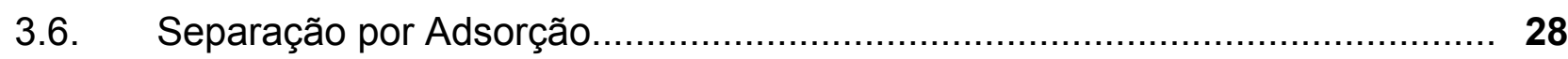

3.6.1. Modelos de Isotermas de Equilíbrio...................................................... 32 


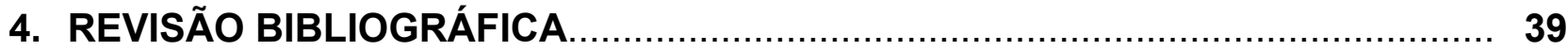

4.1. Exemplos de Biomassas como Biossorventes............................................ 39

4.2. Bagaço de Cana-de-açúcar como Material Biossorvente............................... 40

4.3. Adsorventes Magnéticos ................................................................. 43

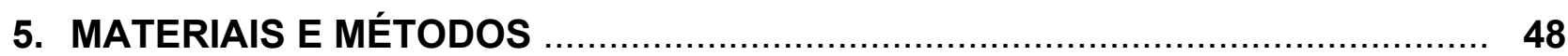

5.1. Materiais e Equipamentos de Laboratório................................................ 48

5.2. Preparação dos Biossorventes Magnético e de Bagaço................................ 49

5.2.1. Preparação do Biossorvente de Bagaço .................................................. 49

5.2.2. Preparação do Biossorvente Magnético..................................................... 50

5.3. Preparação das Soluções de Urânio........................................................ 54

5.3.1. Preparação das Soluções de Urânio em Diferentes Valores de $\mathrm{pH}$................ 54

5.3.2. Preparação das Soluções de Urânio com Concentrações Diferentes............... 54

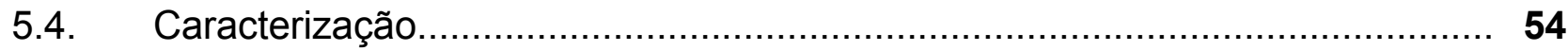

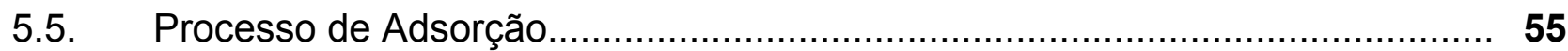

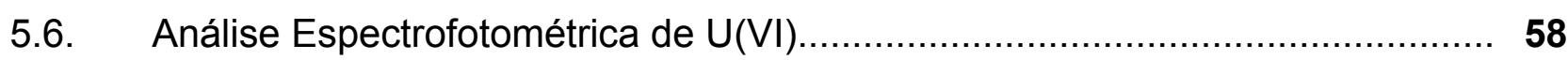

5.6.1. Determinação do Comprimento de Onda e Curva de Calibração para o Complexo U-Arsenazo III..................................................................... 58

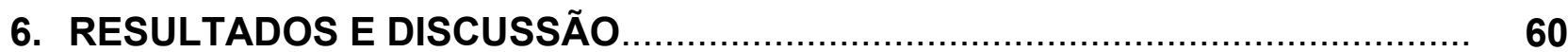

6.1. Caracterização do Biossorvente Magnético e do Biossorvente de Bagaço ..... 60

6.1.1. Microscopia Eletrônica de Varredura..................................................... 61

6.1.2. Espectro de Absorção na Região do Infravermelho...................................... 64

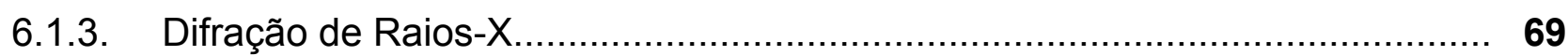

6.1.4. Análise de Termogravimetria (TGA) ...................................................... 70

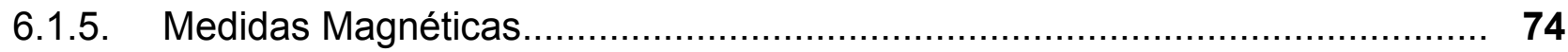

6.2. Avaliação do Processo de Adsorção......................................................... 75

6.2.1. Determinação do Tempo de Equilíbrio................................................... 75

6.2.2. Estudo do Tamanho dos Biossorventes...................................................... 77

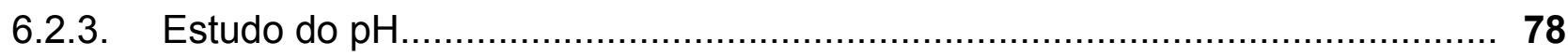

6.2.4. Estudo da Velocidade de Agitação....................................................... 80 


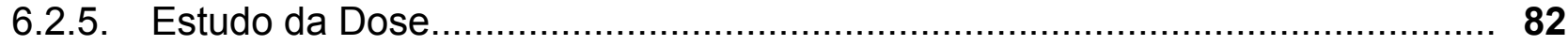

6.2.6. Isotermas de Equilíbrio....................................................................... 84

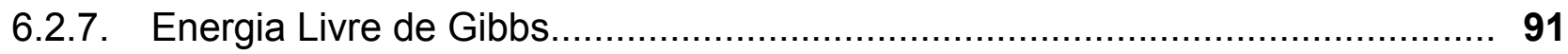

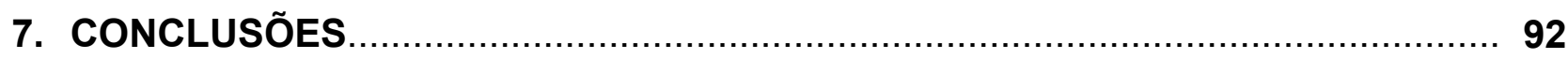

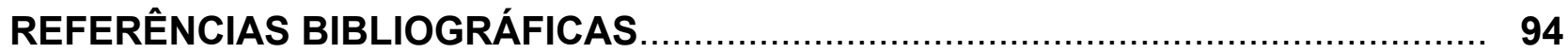




\section{ÍNDICE DE FIGURAS}

Página

FIGURA 3.1 Escala nanométrica......................................................................... 05

FIGURA 3.2 Movimentos dos elétrons no átomo.................................................... 08

FIGURA 3.3 Comportamento magnético dos materiais. .......................................... 11

FIGURA 3.4 Curva de magnetização com histerese, com modificações................... 14

FIGURA 3.5 Momento magnético de acordo com o número de domínios.

$D=$ diâmetro da partícula, $D_{c}=$ diâmetro crítico da partícula................ 16

FIGURA 3.6 Ciclo do combustível nuclear............................................................. 24

FIGURA 3.7 Fluxo do processo de extração de fósforo com ácido sulfúrico............... 25

FIGURA 3.8 Vista das imensas pilhas de rejeito de fosfogesso (Cajati, SP)............. 26

FIGURA 3.9 Classificação de isotermas de Brunauer................................................ 31

FIGURA 3.10 Energia de Gibbs em função da composição do sistema.................... 35

FIGURA 5.1 Processo de preparação do biossorvente de bagaço........................... $\quad \mathbf{5 0}$

FIGURA 5.2 Tratamento térmico do biossorvente.............................................. 51

FIGURA 5.3 Preparação do biossorvente magnético - $1^{\text {a }}$ etapa.............................. 52

FIGURA 5.4 Preparação do biossorvente magnético - $2^{\mathrm{a}}$ etapa.............................. 53

FIGURA 5.5 Foto da preparação do biossorvente magnético.................................. 54

FIGURA 5.6 Procedimento experimental para estudos de adsorção do biossorvente magnético..................................................................... 57

FIGURA 5.7 Relação entre absorbância e o comprimento de onda (nm) do complexo $\mathrm{UO}_{2}{ }^{2+}$ - arsenazo III........................................................ 59

FIGURA 6.1 Biossorvente de bagaço............................................................. $\quad 60$

FIGURA 6.2 Biossorvente magnético................................................................. 60

FIGURA 6.3 Biossorvente magnético sob a ação do campo magnético..................... $\mathbf{6 1}$

FIGURA 6.4 Micrografia eletrônica de varredura do biossorvente de bagaço.

Aumento de 100 e 2000 vezes......................................................... 62

FIGURA 6.5 Micrografia eletrônica de varredura do biossorvente magnético.

Aumento de 2000 vezes.................................................................... 
FIGURA 6.6 Espectro de energia dispersiva do biossorvente magnético................. 63

FIGURA 6.7 Espectro de energia dispersiva do biossorvente de bagaço................. 63

FIGURA 6.8 Espectro de absorção no infravermelho do biossorvente de bagaço na região de $4000 \mathrm{~cm}^{-1}$ a $400 \mathrm{~cm}^{-1}$.

FIGURA 6.9 Espectro de absorção no infravermelho do biossorvente magnético na região de $4000 \mathrm{~cm}^{-1}$ a $400 \mathrm{~cm}^{-1}$.

FIGURA 6.10 Difratogramas do biossorvente magnético e biossorvente de bagaço. (o) Picos característicos da magnetita para a radiação incidente CuKa (JCPDS - ICDD 19 - 29).

FIGURA 6.11 Curva termogravimétrica do biossorvente magnético e biossorvente de bagaço sob atmosfera de $\mathrm{O}_{2}$

FIGURA 6.12 Curva termogravimétrica do biossorvente magnético e biossorvente de bagaço sob atmosfera de $\mathrm{N}_{2}$.

FIGURA 6.13 Curva de magnetização do biossorvente magnético.

FIGURA 6.14 Influência do tempo sobre a adsorção de urânio pelo biossorvente magnético e biossorvente de bagaço. Concentração de $U=100$ mg. $\mathrm{L}^{-1}, \mathrm{pH} 3,5$

FIGURA 6.15 Principais espécies aquosas de urânio. Força iônica 0,1 mol.L-1, $[\mathrm{U}]=4,4 \cdot 10^{-7} \mathrm{~mol} \cdot \mathrm{L}^{-1}$

FIGURA 6.16 Efeito do pH sobre a adsorção de urânio pelos biossorventes magnético e de bagaço. Concentração de íons de $U=100 \mathrm{mg} \cdot \mathrm{L}^{-1} \ldots .$.

FIGURA 6.17 Influência da velocidade sobre a adsorção de urânio pelo biossorvente magnético e biossorvente de bagaço. Concentração de íons de $\mathrm{U}=100 \mathrm{mg} \cdot \mathrm{L}^{-1}, \mathrm{pH} 5$.

FIGURA 6.18 Variação da \% remoção de $\mathrm{UO}_{2}{ }^{2+}$ em função das doses do biossorvente magnético e do biossorvente de bagaço, em solução nítrica. $\left[\mathrm{UO}_{2}{ }^{2+}\right]=100 \mathrm{mg} \cdot \mathrm{L}^{-1}$ para o biossorvente magnético $\left[\mathrm{UO}_{2}{ }^{2+}\right]=177 \mathrm{mg} \cdot \mathrm{L}^{-1}$ para o biossorvente de bagaço................

FIGURA 6.19 Influência da dose de biossorvente magnético na capacidade de adsorção. $\left[\mathrm{UO}_{2}{ }^{2+}\right]=100 \mathrm{mg} \cdot \mathrm{L}^{-1}$ 
FIGURA 6.20 Isoterma de equilíbrio de adsorção de íons $\mathrm{UO}_{2}{ }^{2+}$ pelo biossorvente magnético. Temperatura $=27^{\circ} \mathrm{C} \pm 2^{\circ} \mathrm{C}$

FIGURA 6.21 Isoterma de equilíbrio de adsorção de íons $\mathrm{UO}_{2}{ }^{2+}$ pelo biossorvente de bagaço. Temperatura $=27^{\circ} \mathrm{C} \pm 2^{\circ} \mathrm{C}$

FIGURA 6.22 Representação da isoterma linear de Langmuir para o processo de adsorção de urânio pelo biossorvente magnético. Temperatura $=$ $27^{\circ} \mathrm{C} \pm 2^{\circ} \mathrm{C}$

FIGURA 6.23 Representação da isoterma linear de Freundlich para o processo de adsorção de urânio pelo biossorvente magnético. Temperatura = $27^{\circ} \mathrm{C} \pm 2^{\circ} \mathrm{C}$

FIGURA 6.24 Representação da isoterma linear de Langmuir para o processo de adsorção de urânio pelo biossorvente de bagaço. Temperatura = $27^{\circ} \mathrm{C} \pm 2^{\circ} \mathrm{C}$

FIGURA 6.25 Representação da isoterma linear de Freundlich para o processo de adsorção de urânio pelo biossorvente de bagaço. Temperatura $=$ $27^{\circ} \mathrm{C} \pm 2^{\circ} \mathrm{C}$

FIGURA 6.26 Isoterma de equilíbrio de adsorção de íons $\mathrm{UO}_{2}{ }^{2+}$ pelo biossorvente magnético e os modelos teóricos de Langmuir e Freundlich. Temperatura $=27^{\circ} \mathrm{C} \pm 2^{\circ} \mathrm{C}$

FIGURA 6.27 Isoterma de equilíbrio de adsorção de íons $\mathrm{UO}_{2}{ }^{2+}$ pelo biossorvente de bagaço e os modelos teóricos de Langmuir e Freundlich. Temperatura $=27^{\circ} \mathrm{C} \pm 2^{\circ} \mathrm{C}$ 


\section{ÍNDICE DE TABELAS}

Página

TABELA 3.1 Comportamento magnético dos materiais........................................... 12

TABELA 3.2 Reservas mundiais de urânio contabilizados em 2007........................ 23

TABELA 3.3 Classificação das águas doces e salinas (CONAMA 357, 2005,

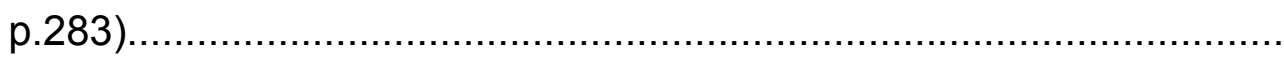

TABELA 6.1 Bandas de absorção na região do infravermelho do biossorvente de

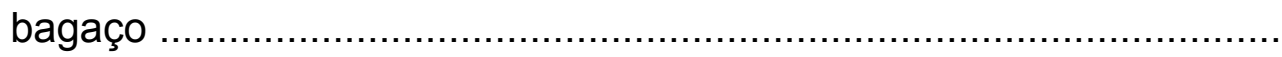

TABELA 6.2 Bandas de absorção na região do infravermelho do biossorvente

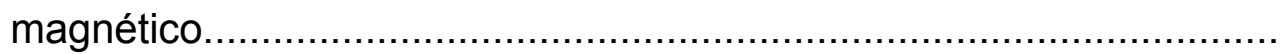

TABELA 6.3 Relação dos picos de difração do biossorvente magnético e do padrão de referência de magnetita (JCPDS - ICDD 19 - 629)

TABELA 6.4 Relação entre o tamanho do biossorvente e a adsorção de urânio por meio do biossorvente magnético.

TABELA 6.5 Relação entre o tamanho do biossorvente e a adsorção de urânio por meio do biossorvente de bagaço

TABELA 6.6 Parâmetros de Langmuir e Freundlich para a adsorção de íons uranilo pelo biossorvente magnético. Temperatura igual a $27^{\circ} \mathrm{C} \pm$ $2^{\circ} \mathrm{C}$

TABELA 6.7 Parâmetros de Langmuir e Freundlich para a adsorção de íons uranilo pelo biossorvente de bagaço. Temperatura igual a $27^{\circ} \mathrm{C} \pm$ $2^{\circ} \mathrm{C}$ 


\section{APLICAÇAO DE NANOTECNOLOGIA NO MEIO AMBIENTE: BIOSSORVENTE MAGNÉTICO NA REMOÇÃO DE URÂNIO}

\section{Amanda Pongeluppe Gualberto Yamamura}

\section{RESUMO}

O bagaço de cana-de-açúcar é um resíduo proveniente da agroindústria da cana-de-açúcar. Trata-se de um material biodegradável, com baixo custo e apresenta afinidade por compostos orgânicos e metais tóxicos. Neste trabalho preparou-se o bagaço de cana-de-açúcar combinado com nanopartículas de magnetita, o qual foi chamado de biossorvente magnético. $A$ magnetita foi sintetizada por precipitação simultânea adicionando-se uma solução de $\mathrm{NaOH}$ à solução aquosa contendo $\mathrm{Fe}^{2+}$ e $\mathrm{Fe}^{3+}$. O material foi caracterizado por microscopia eletrônica de varredura, espectrometria de infravermelho por transformada de Fourier, análise termogravimétrica, difratometria de raios- $X$ e medidas de magnetização. O biossorvente magnético apresentou uma alta magnetização de saturação sem histerese, comportamentos atribuídos aos materiais superparamagnéticos. Estudaram-se as variáveis do processo de adsorção de íons uranilo pelo biossorvente magnético em meio nítrico. $O$ estudo do tempo de equilíbrio indicou um aumento de adsorção em função do tempo. Verificou-se que quanto menor o tamanho do biossorvente, maior a porcentagem de remoção. A máxima remoção ocorreu em $\mathrm{pH}$ 5. O aumento da velocidade de agitação do sistema soluto mais biossorvente favoreceu a adsorção, sendo encontrado o equilíbrio a partir de 300 r.p.m. Verificou-se que o aumento da dose de biossorvente magnético aumentou a remoção até tornar-se constante a partir de $10 \mathrm{~g} \cdot \mathrm{L}^{-1}$. Estudou-se a isoterma de equilíbrio segundo os modelos de Langmuir e Freundlich. O modelo de isoterma de Langmuir correlacionou-se melhor aos dados experimentais. A capacidade máxima de adsorção encontrada foi de $17 \mathrm{mg}$ de $U$ por $g$ de biossorvente. Os mesmos estudos de adsorção foram realizados com o biossorvente de bagaço a fim de comparar os resultados. 


\title{
ENVIRONMENTAL NANOTECHNOLOGY APPLICATION: MAGNETIC BIOSORBENT FOR URANIUM REMOVAL
}

\section{Amanda Pongeluppe Gualberto Yamamura}

\begin{abstract}
Sugarcane bagasse is a residue from the sugarcane agroindustry. It is a biodegradable material, with low cost and presents affinity for organic compounds and toxic metals. In this work, the sugar cane bagasse combined with nanoparticles of magnetite was prepared and called magnetic biosorbent. The magnetite was synthesized by simultaneous precipitation by addition a solution of $\mathrm{NaOH}$ to the aqueous solution containing $\mathrm{Fe}^{2+}$ and $\mathrm{Fe}^{3+}$. The material was characterized by scanning electron microscopy, Fourier Transformer Infrared Spectroscopy, thermogravimetric analysis, X-ray diffractometry and measurements of magnetization. The magnetic biosorbent showed a high magnetization of saturation without hysteresis, behavior attributed to superparamagnetic materials. Variables of adsorption process of uranyl ions by magnetic biosorbent in nitric solutions were investigated. The study of the equilibrium time indicated an increase in the adsorption in function of time. Smaller biosorbent particle sizes resulted in greater removals. The maximum removal occurred at $\mathrm{pH} 5$. The increase of stirring speed of the solute plus biosorbent system favored the adsorption, reaching the equilibrium at 300 r.p.m. The increase of the biosorbent dosage increased the removal, which became constant for doses above of $10 \mathrm{~g} \cdot \mathrm{L}^{-1}$. The equilibrium isotherm was verified according to the Langmuir and Freundlich adsorption isotherm models. The results correlated better to the Langmuir isotherm model, being found a value of maximum capacity of adsorption of $17 \mathrm{mg}$ of $U$ per g biosorbent. The same studies of adsorption were performed with the bagasse biosorbent in order to compare the results.
\end{abstract}




\section{INTRODUÇÃO}

Atividades relacionadas com a civilização humana, especialmente as atividades industriais consomem recursos naturais e geram efluentes que provocam impacto ambiental afetando a biodiversidade do planeta e muitas vezes com deterioração de ecossistemas.

Efluentes industriais sólidos, líquidos ou gasosos, despejam cada vez mais metais pesados e tóxicos no meio ambiente comprometendo a qualidade das águas, do ar, do solo e dos alimentos e, conseqüentemente, ameaçando o equilíbrio e a estabilidade dos ecossistemas.

A contaminação se dá por meio de vários tipos de indústrias, como as de galvanoplastia e têxtil. Outras formas de contaminação são os incineradores de lixo urbano no qual o lixo é queimado em temperaturas elevadas gerando cinzas (sólidos inorgânicos) e gases. O problema de contaminação ambiental pode ser agravado caso o sistema funcione sem filtros adequados para reter os metais pesados oriundos da incineração.

Metais tóxicos estão presentes em fertilizantes à base de ácido fosfórico obtido de rochas fosfatadas e tem como subproduto o fosfogesso (sulfato de cálcio di-hidratado $\mathrm{CaSO}_{4} .2 \mathrm{H}_{2} \mathrm{O}$ ), o qual possui altos níveis de elementos radioativos, dentre eles, o $U$, o Th e o Ra-226. Calcula-se que para cada tonelada de ácido fosfórico há a geração de 5 a 6 toneladas de fosfogesso. A contaminação por meio da radioatividade se dá pelo seu armazenamento incorreto e pela aplicação dos fertilizantes fosfatados na lavoura, contaminando o solo, a água subterrânea e as plantações. O acúmulo de metais tóxicos nos solos agrícolas é freqüentemente causado pelo uso repetido e excessivo dos fertilizantes e dos pesticidas.

Os metais radioativos, como o urânio, são nocivos à saúde devido à sua 
toxicidade e porque são bioacumulados, ou seja, não são eliminados do organismo, sendo progressivamente depositados nos rins e nos ossos; a radiação exposta nos órgãos pode provocar efeitos biológicos graves como o desenvolvimento de câncer.

Segmentos industriais como usinas de mineração, hospitais e universidades geram volumes consideráveis de rejeitos líquidos radioativos contendo urânio que são lançados ao meio ambiente, muitas vezes sem um tratamento adequado, comprometendo a capacidade de regeneração natural do ciclo hidrológico e contaminando as águas.

A contaminação das águas pode comprometer a cadeia alimentar, os ecossistemas, alterando a biodiversidade.

Dessa forma torna-se imprescindível o desenvolvimento e implantação de tecnologias apropriadas de tratamento de águas de abastecimento e residuárias.

Os processos como precipitação [1], troca iônica [2], extração por solventes [3], osmose reversa [4], são comumente utilizados nos tratamentos das águas residuárias industriais. Em muitos casos, a complexidade de composição química associada às concentrações reduzidas dos contaminantes, torna estas tecnologias muitas vezes ineficazes. Além do mais, geram quantidades significativas de rejeitos secundários e suas aplicações são limitadas em função das restrições técnicas e econômicas.

O tratamento e a disposição efetiva e segura das águas residuárias contendo metais pesados e radioativos têm sido um desafio visto serem necessárias uma política e tecnologia efetivas e de baixo custo que possam ser aplicadas para o destino final dos resíduos gerados.

A necessidade de métodos aplicáveis economicamente e efetivos para a remoção dos contaminantes no tratamento de águas residuárias e remediação do meio ambiente tem resultado na busca de novas tecnologias de separação com a nanotecnologia. 
A nanotecnologia na área ambiental contribui com o desenvolvimento dos adsorventes magnéticos que agem na despoluição de águas residuárias.

Os adsorventes magnéticos possuem um núcleo constituído de nanopartículas de ferrita e em sua superfície externa uma matriz polimérica contendo grupos ativos capazes de se ligar a determinadas substâncias. Esse material combina duas técnicas de separação: química por meio de seus grupos funcionais, e magnética, mediante seu núcleo superparamagnético. Trata-se de uma tecnologia recente e alternativa às tecnologias tradicionais de separação, com eficiência adsortiva competitiva, baixo custo operacional, com fácil aplicabilidade, sem geração de efluentes secundários quando comparada com extração por solventes ou troca iônica, por exemplo. A separação magnética, por ser um processo físico que separa constituintes de uma mistura com base na susceptibilidade magnética dos materiais, gera o mínimo ou nenhum efluente secundário. A propriedade superparamagnética do material desenvolvido possibilita a retirada do adsorvente do meio líquido por aplicação de um campo magnético, sem que haja retenção da magnetização do adsorvente após cessada a ação do campo magnético. A técnica de adsorção destaca-se pela sua simplicidade e eficiência na remoção de contaminantes em baixas concentrações.

Este trabalho apresenta um biossorvente magnético inovador, o bagaço de cana-de-açúcar magnético, o qual se baseia em um composto de nanopartículas de magnetita $\left(\mathrm{Fe}_{3} \mathrm{O}_{4}\right)$ como núcleo magnético, associadas aos grupos funcionais do bagaço de cana atuando como uma matriz adsorvente. As nanopartículas de magnetita sintetizadas possuem baixo custo e são de fácil preparação. O uso do bagaço de cana-de-açúcar como adsorvente contribui duplamente com a redução do impacto ambiental: deixa de ser um possível poluente por não ser descartado e possibilita o tratamento de águas residuárias; é uma matéria-prima de baixo custo por se tratar de um subproduto do agronegócio de cana-de-açúcar. Um outro ponto relevante é a possibilidade de reutilização do biossorvente magnético e dos íons metálicos recuperados após passar pelo processo de dessorção. Ele também apresenta uma comparação entre o biossorvente magnético e o biossorvente preparado apenas a partir do bagaço de cana-de-açúcar. Este trabalho foi classificado em primeiro lugar no $1^{\circ}$ Prêmio Dow de Sustentabilidade, em 2008. 


\section{OBJETIVOS}

\subsection{Objetivo Geral}

O trabalho tem por objetivo apresentar um estudo inédito de preparação do biossorvente magnético, um novo material nanotecnológico, avaliar a potencialidade de adsorção de $\mathrm{U}(\mathrm{VI})$ em meio aquoso e comparar o biossorvente magnético com o biossorvente de bagaço.

\subsection{Objetivo Específico}

Caracterizar por microscopia eletrônica de varredura, espectroscopia na região de infravermelho, difratometria de raios- $X$ e análise por termogravimetria. Caracterizar o biossorvente magnético por meio de medidas de magnetização. Avaliar as propriedades adsortivas estudando-se as variáveis: tempo de contato, velocidade, tamanho das partículas do biossorvente, $\mathrm{pH}$ e dose. Aplicar os modelos de isoterma de equilíbrio de adsorção de Langmuir e de Freundlich à isoterma de equilíbrio experimental. 


\section{CONSIDERAÇÕES GERAIS E ASPECTOS TEÓRICOS}

\subsection{Nanociência \& Nanotecnologia ( $N \& N$ )}

Os dois neologismos derivam de nano, prefixo grego que significa anão. A palavra nano é usada na ciência para designar um bilionésimo de metro. Um átomo, por exemplo, mede cerca de $2 / 10$ de um nanômetro [5]. O fio de cabelo aproximadamente 100.000 nanômetros, conforme se observa na FIG. 3.1:

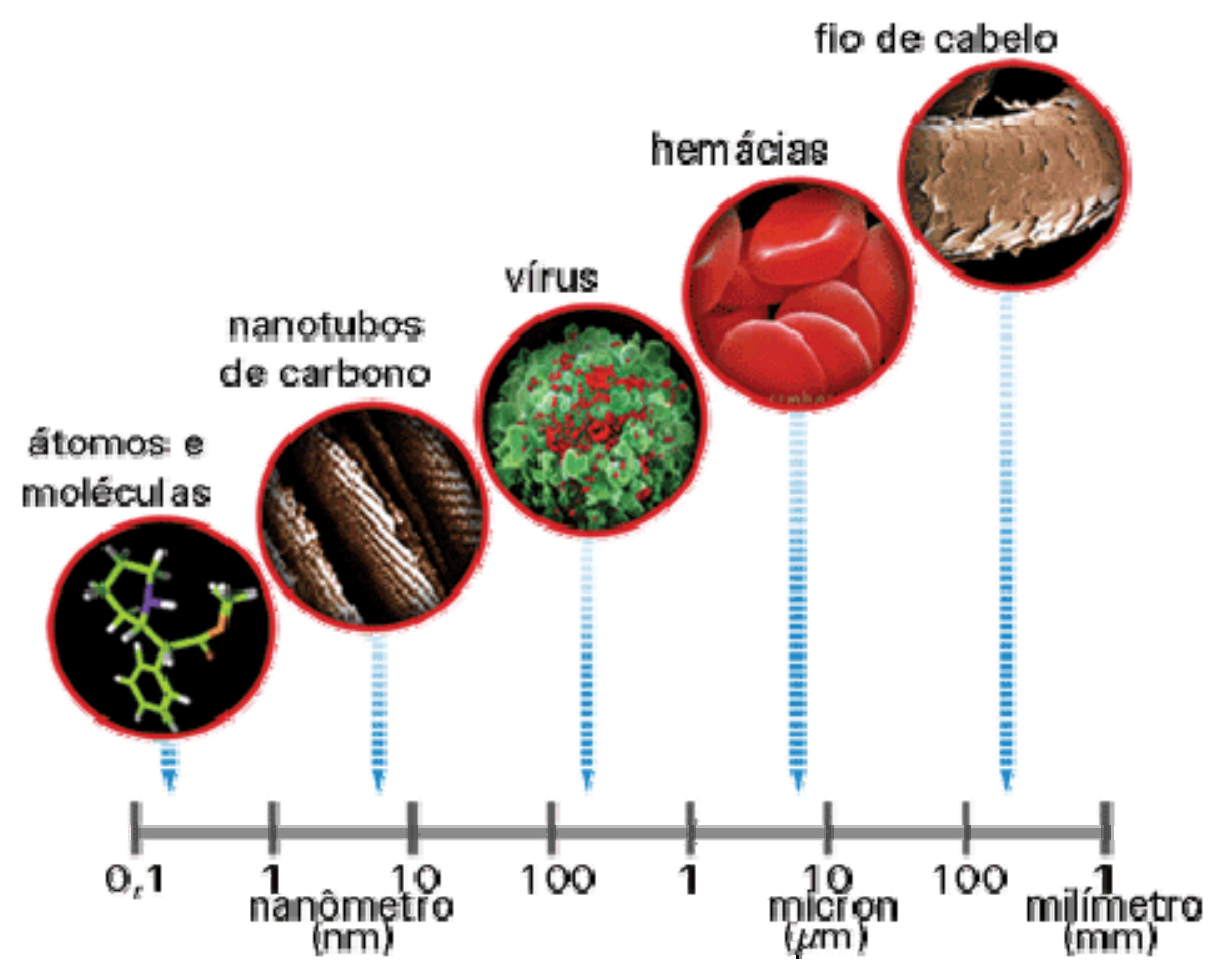

Figura 3.1 - Escala nanométrica [6].

A Nanociência visa a compreensão da matéria na escala nanométrica, escala que compreende valores inferiores a $100 \mathrm{~nm}$, com propriedades novas [7], enquanto a nanotecnologia tem por objetivo controlar a matéria nessa mesma escala e usar as propriedades únicas dos nanomateriais em aplicações tecnológicas. 
Trata-se de uma tecnologia multidisciplinar envolvendo várias áreas como: física, química, biologia, ciência e engenharia de materiais e computação.

Os primeiros conceitos de nanotecnologia foram propostos pelo físico americano Richard Feynman em 1959 em sua palestra entitulada: "Há muito espaço lá embaixo". Nessa palestra ele discutiu sobre a possibilidade de se escrever todos os 24 volumes da Enciclopédia Britânica na cabeça de um alfinete, bastando, para tanto, utilizar caracteres 25 mil vezes menores que os empregados na impressão da enciclopédia, algo em torno de $8 \mathrm{~nm}$ [8]. Segundo a proposta de Feynman, o objetivo da nanotecnologia é o de criar novos materiais e de desenvolver novos produtos e processos mediante a manipulação de átomos e moléculas.

Uma das invenções mais importantes para a Nanociência e Nanotecnologia, N \& N, aconteceu em 1981: o desenvolvimento do microscópio eletrônico de varredura por tunelamento por Gerd Binning Henrich Roher, do laboratório da IBM em Zurique. A partir desta invenção tornou-se possível uma extrema ampliação da superfície de um material. A invenção deu origem a uma série de instrumentos de visualização, denominados microssondas eletrônicas de varredura. Os instrumentos, além da visualização da superfície, permitem manipular átomos e moléculas que podem ser arrastados de um ponto a outro e ali depositados. Isso foi demonstrado quando Donald Eigler e Erhard Schweizer, do laboratório da IBM, na Califórnia, escreveram o logotipo IBM posicionando 35 átomos de xenônio sobre uma superfície de níquel [5, 9].

A nanotecnologia representa uma revolução tecnológica de grande abrangência e de impacto na história. Na área de materiais desenvolvem-se novos materiais com propriedades superiores aos existentes.

Nesta escala, os efeitos quânticos e de superfície são fundamentais para a definição das propriedades do material [10].

Dentre as várias pesquisas, há os nanotubos de carbono. Cada nanotubo corresponde a uma folha de grafite enrolada na forma de um cilindro, com diâmetro da ordem de $1 \mathrm{~nm}$ [11]. Os materiais constituídos de nanotubos de carbono 
possuirão vantagens em sua aplicação industrial. Sabe-se que a aplicação de apenas $2 \%$ dessas substâncias em determinados materiais será capaz de aumentar, em até 20 vezes, a resistência mecânica de sua estrutura. Eles também melhorarão a proteção térmica e a blindagem eletromagnética dos materiais, pois funcionarão como condutores ou semicondutores, o que ajudará dissipar a energia da descarga de raios [12]. Essas novas propriedades revolucionarão, em especial, as indústrias de veículos terrestres, aéreos e espaciais, tornando-os muito mais duráveis, leves e eficientes no consumo de energia.

Outras possíveis aplicações dos materiais nanotecnológicos incluem: aumentar a capacidade de armazenamento e processamento de dados em computadores; criar novos mecanismos para entrega de medicamentos, mais seguros e menos prejudiciais ao paciente; criar materiais mais leves e mais resistentes visando diversas aplicações; economizar energia e proteger o meio ambiente, dentre outras $[13,14]$.

\subsection{Introdução ao Magnetismo}

\subsubsection{História do Magnetismo}

Há muito tempo notou-se a propriedade que certos materiais têm de atrair outros materiais. A propriedade conhecida como magnetismo foi observada pela primeira vez com fragmentos de minério de Fe ao serem atraídos pela magnetita, um minério de composição química $\mathrm{Fe}_{3} \mathrm{O}_{4}$. A palavra magnetismo teve origem em uma cidade na região da Turquia, conhecida como Magnésia, a qual era rica em minério de ferro [15].

A primeira utilização prática do magnetismo foi a bússola, inventada pelos chineses na dinastia Han, em 200 d.C., baseada na propriedade que uma agulha magnetizada orienta-se na direção do campo magnético terrestre. A bússola foi empregada em navegação pelos chineses em 900 d.C., mas só foi descoberta e usada pelo mundo ocidental a partir do século 15 [16]. 
Até 1819 não havia sido percebida nenhuma relação entre os fenômenos elétricos e magnéticos. A partir de então, o cientista dinamarquês Hans Christian Oersted descobriu que a agulha de uma bússola, nas proximidades de uma corrente elétrica passando por um fio, mudava de orientação. Mais tarde Ampère formulou a lei que relaciona o campo magnético criado com a intensidade da corrente no fio. $O$ efeito recíproco, pelo qual um fio condutor sofre a ação de uma força, produzida pelo campo criado por um imã permanente, foi descoberto logo em seguida. Pouco depois, em 1831, Faraday na Inglaterra e Henry nos EUA descobriram que um campo variável podia induzir uma corrente elétrica num circuito [17]. Várias aplicações tecnológicas eram conhecidas no final do século XIX tais como o motor e o gerador elétrico.

\subsubsection{Momento Magnético}

O magnetismo possui natureza elétrica e está relacionado a uma carga em movimento. Ele provém da movimentação dos elétrons dos átomos.

Cada elemento químico presente na natureza possui um determinado número de prótons, nêutrons e elétrons que o tornam único. Os prótons e os elétrons são carregados eletricamente, de forma positiva e negativa, respectivamente. Há dois tipos de movimentos eletrônicos capazes de explicar a origem dos momentos magnéticos: o movimento do elétron ao redor de seu próprio eixo dando origem ao movimento semelhante a um pião, o spin, e o seu movimento ao redor do núcleo gerando o momento orbital, devido à carga elétrica que o elétron possui, de acordo com a FIG. 3.2:

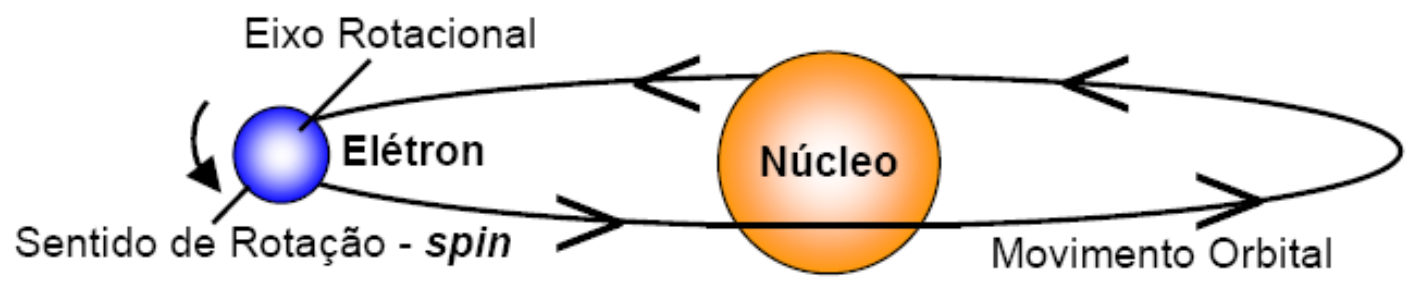

Figura 3.2 - Movimentos dos elétrons no átomo [18]. 
Esses dois momentos magnéticos, quando observados em uma escala macroscópica, são responsáveis pelas propriedades magnéticas dos materiais. $\mathrm{O}$ momento magnético total de um átomo difere bastante em relação ao seu arranjo global e em relação ao número de elétrons de cada átomo. Na natureza há a predominância de átomos com spin total nulo, ou seja, os elétrons ocupam orbitais de forma a satisfazer o princípio de Linus Pauling, ora com o spin num sentido e ora em outro. Para alguns elementos da tabela periódica, o spin total é diferente de zero, como é o caso dos elementos do grupo de transição do ferro como níquel, manganês e cobalto e como elementos de terras raras como gadolíneo e o európio. Neste caso, os átomos possuem momento magnético permanente.

Além desses dois momentos há uma força de origem quântica, chamada força de troca ou super-troca, a qual tende a alinhar os momentos magnéticos de átomos vizinhos de forma paralela ou anti-paralela. Dessa forma, cada átomo contribui para o momento total.

\subsubsection{Comportamento Magnético dos Materiais}

Cada átomo, individualmente, contribui para o momento magnético total de forma que todo material apresenta comportamento magnético. A magnetização dos materiais varia em intensidade de acordo com a sua susceptibilidade magnética $\left(X_{m}\right)$. A susceptibilidade magnética é a grandeza que caracteriza um material magnético segundo sua resposta a um campo magnético aplicado.

Os materiais podem ser classificados quanto ao comportamento magnético em diamagnético, paramagnético, ferromagnético, antiferromagnético e ferrimagnético.

DIAMAGNÉTICO - Os materiais diamagnéticos são aqueles repelidos pelos imãs. Essa repulsão ocorre porque o campo magnético gerado pelo imã faz com que o movimento dos elétrons se altere, como se houvesse a passagem de uma corrente elétrica. Dessa forma, gera um outro campo magnético, o qual está alinhado na direção oposta ao imã, causando a repulsão. Eles apresentam 
pequenos valores negativos de susceptibilidade magnética $\left(X_{m}\right)$ na faixa de $-10^{-6}$ a $10^{-5}$, e esta não varia com a temperatura.

PARAMAGNÉTICO - O paramagnetismo é uma forma muito fraca de magnetismo. Os átomos individuais possuem momentos magnéticos, mas suas orientações ao acaso resultam em magnetização nula para um grupo de átomos. Sem a presença de um campo magnético externo os spins dos elétrons do material estão alinhados de forma aleatória e, sob a ação de um imã, esses spins se movem na direção do campo magnético. Sem a presença do campo magnético os elétrons voltam a se orientar aleatoriamente, como mostra a FIG. 3.3. Os materiais paramagnéticos possuem susceptibilidade magnética positiva e de pequeno valor, na faixa de $+10^{-5}$ a $+10^{-3}$, a qual diminui com o aumento da temperatura. Os materiais diamagnéticos e paramagnéticos costumam ser classificados como nãomagnéticos pois seus efeitos, quando estão sob a influência de um campo externo, costumam ser muito pequenos.

ANTIFERROMAGNÉTICO - O protótipo é o óxido de manganês MnO. Possui estrutura cristalina do tipo CFC (cúbica de face centrada). Os íons manganês apresentam momento magnético permanente de forma que os adjacentes sejam antiparalelos em relação a eles, fazendo com que o momento magnético como um todo seja nulo. Possuem temperatura crítica, denominada temperatura de Néel $\left(\theta_{n}\right)$, acima da qual desaparece $\mathrm{o}$ efeito antiferromagnético dos materiais. A susceptibilidade dos materiais antiferromagnéticos é da mesma ordem dos paramagnéticos, ou seja, na faixa de $+10^{-5} \mathrm{a}+10^{-3}$.

FERROMAGNÉTICO - Como exemplo de materiais ferromagnéticos podemos citar o $\mathrm{Co}, \mathrm{Ni}$ e $\mathrm{Fe}_{\alpha}$ (CCC - estrutura cúbica de corpo centrado). Mesmo na ausência de campo externo esses materiais apresentam momento magnético, ou seja, os spins de seus elétrons permanecem alinhados na mesma direção e sentido. Isso é o que o diferencia das substâncias paramagnéticas. As substâncias ferromagnéticas possuem elevado nível de magnetização. Sua susceptibilidade magnética pode chegar a $10^{6}$. Após atingirem a temperatura crítica, chamada de temperatura de Curie $\left(\theta_{c}\right)$, tornam-se paramagnéticos, perdendo sua magnetização espontânea. Essa temperatura varia conforme o material. Por exemplo, o Co possui 
$\theta_{\mathrm{c}}=1130^{\circ} \mathrm{C}$, o Ni possui $\theta_{\mathrm{c}}=358^{\circ} \mathrm{C}$ e o $\mathrm{Fe}_{\alpha}=770^{\circ} \mathrm{C}$ [19]. Enquanto os materiais diamagnéticos e paramagnéticos são classificados como não magnéticos, devido à pequena influência do campo magnético, os ferromagnéticos são classificados como substâncias magnéticas.

FERRIMAGNÉTICO - Os spins dos elétrons se alinham de duas formas: paralelamente, como no caso do ferromagnético e parte no sentido anti-paralelo, sendo que o efeito destes mantém a força magnética geralmente menor que a dos sólidos puramente ferromagnéticos. Tal comportamento pode ser observado na FIG. 3.3. Esses materiais, chamados de ferritas, apresentam forte magnetização permanente. As ferritas podem ser representadas pela fórmula geral $\mathrm{MFe}_{2} \mathrm{O}_{4}$, onde $M$ é um elemento metálico. Um exemplo de material ferrimagnético muito conhecido é a magnetita, a qual possui a seguinte fórmula $\mathrm{FeO} \cdot \mathrm{Fe}_{2} \mathrm{O}_{3}$. Também apresenta temperatura crítica. Sua susceptibilidade magnética pode chegar a $10^{6}$ e diminui com a temperatura.

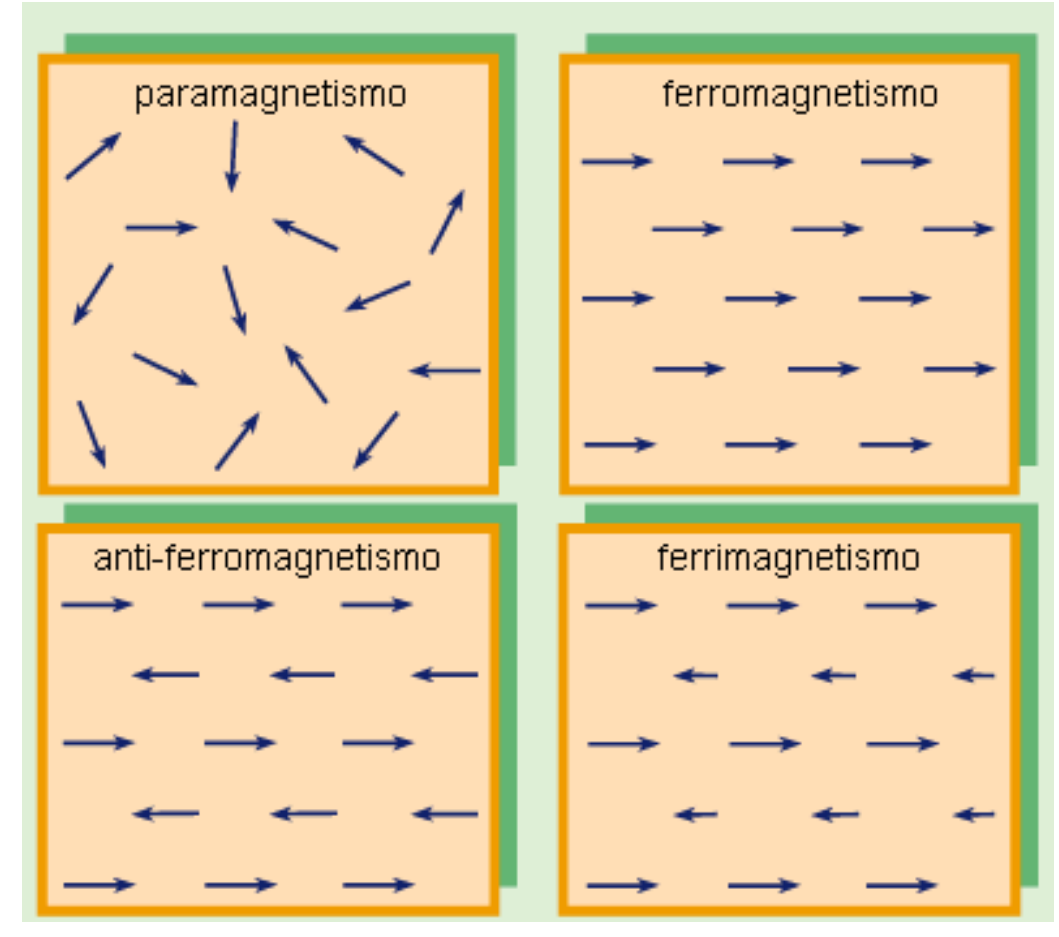

Figura 3.3 - Comportamento magnético dos materiais [20].

Na TAB. 3.1 apresenta-se um resumo do comportamento magnético dos materiais. 
TABELA 3.1 - Comportamento magnético dos materiais.

\begin{tabular}{|c|c|c|c|}
\hline $\begin{array}{l}\text { Comportamento } \\
\text { magnético }\end{array}$ & Magnetismo & $\begin{array}{c}\mathrm{Xm}_{\mathrm{m}} \\
\text { Susceptibilidade } \\
\text { magnética }\end{array}$ & Exemplos \\
\hline Diamagnetismo & $\begin{array}{l}\text { Magnetismo fraco, apenas } \\
\text { na presença de um campo } \\
\text { externo. Magnitude do } \\
\text { momento magnético } \\
\text { extremamente pequena e } \\
\text { na direção oposta ao } \\
\text { campo aplicado. }\end{array}$ & $\begin{array}{l}-10^{-6} \text { a }-10^{-5} \\
\text { Possui valor } \\
\text { negativo; } \\
\text { Não varia com a } \\
\text { temperatura. }\end{array}$ & $\begin{array}{c}\text { Gases } \\
\text { inertes; } \\
\text { Elementos } \\
\text { não } \\
\text { metálicos } \\
(\mathrm{B}, \mathrm{Si}, \mathrm{P}, \mathrm{S}) \\
\text { Moléculas } \\
\text { diatômicas } \\
\left(\mathrm{H}_{2} \mathrm{~N}_{2}\right)\end{array}$ \\
\hline Paramagnetismo & $\begin{array}{l}\text { A orientação ao acaso dos } \\
\text { momentos magnéticos de } \\
\text { alguns átomos resulta em } \\
\text { magnetização zero para } \\
\text { grupos de átomos. Os } \\
\text { dipolos podem ser } \\
\text { orientados na direção do } \\
\text { campo aplicado. }\end{array}$ & $\begin{array}{l}+10^{-5} \text { a }+10^{-3} \\
\text { Possui valor } \\
\text { positivo; } \\
\text { Diminui com a } \\
\text { temperatura. }\end{array}$ & $\begin{array}{l}\text { Alguns } \\
\text { metais Cr, } \\
\text { Mn; } \\
\text { Alguns } \\
\text { gases } \\
\text { diatômicos } \\
\mathrm{O}_{2}, \mathrm{NO} .\end{array}$ \\
\hline Ferromagnetismo & $\begin{array}{c}\text { Apresentam momento } \\
\text { magnético sem a } \\
\text { presença de campo } \\
\text { externo. }\end{array}$ & $\begin{array}{c}\text { Até } 10^{+6} \\
\text { TCurie (temperatura } \\
\text { crítica) varia de } \\
\text { acordo com o } \\
\text { material. }\end{array}$ & $\begin{array}{l}\text { Ferro a } \\
\text { (CCC); } \\
\text { Co; Ni; } \\
\text { Composto } \\
\text { de Mn } \\
\text { (MnBi). }\end{array}$ \\
\hline Ferrimagnetismo & $\begin{array}{l}\text { Apresenta magnetização } \\
\text { permanente. }\end{array}$ & $\begin{array}{c}\text { Até } 10^{+6} \\
\text { TCurie (temperatura } \\
\text { crítica) varia de } \\
\text { acordo com o } \\
\text { material. }\end{array}$ & $\begin{array}{c}\text { Ferritas, } \\
\mathrm{MFe}_{2} \mathrm{O}_{4} \\
\mathrm{M}=\mathrm{Fe}^{2+} \\
\mathrm{Ni}^{2+} \\
\mathrm{Co}^{2+}, \mathrm{Mn}^{2+} \\
\mathrm{Cu}^{2+}, \mathrm{Mg}^{2+}\end{array}$ \\
\hline $\begin{array}{c}\text { Anti- } \\
\text { ferromagnetismo }\end{array}$ & $\begin{array}{l}\text { O material como um todo } \\
\text { não apresenta momento } \\
\text { magnético porque dois } \\
\text { íons adjacentes têm } \\
\text { momentos anti-paralelos. }\end{array}$ & $\begin{array}{c}+10^{-5} \text { a }+10^{-3} \\
\text { Possui valor } \\
\text { positivo; } \\
\text { Apresentam } \\
\text { temperatura crítica - } \\
\mathrm{T}_{\text {Néel. }}\end{array}$ & $\begin{array}{l}\text { Material } \\
\text { cerâmico de } \\
\text { caráter } \\
\text { iônico } \\
\text { MnO, CoO, } \\
\text { NiO. }\end{array}$ \\
\hline
\end{tabular}




\subsubsection{Curvas de Magnetização e Histerese}

Segundo o comportamento magnético dos materiais, cada átomo, individualmente, contribui para o momento magnético total. Cada átomo na natureza pode ser imaginado como um minúsculo imã, denominado momento magnético $(\mu)$ pela física. De acordo com a sua configuração eletrônica, alguns elementos têm momentos mais fortes ou mais fracos [21].

Em elementos como o $\mathrm{Fe}$, o $\mathrm{Ni}$ e o $\mathrm{Co}$, do tipo ferromagnético, os momentos magnéticos de cada átomo tendem a se alinhar na mesma direção e sentido, de forma a obter um momento magnético efetivo, ou seja, a soma dos momentos magnéticos de todos os átomos. Isso ocorre com o sistema abaixo da temperatura de Curie, temperatura a partir da qual os átomos tendem a se desorganizar devido à agitação causada pelo aquecimento [19].

No entanto, o que se observa freqüentemente numa medida de magnetização é que o momento magnético é bem menor que o esperado ou, às vezes, é zero. A explicação para este efeito observado na magnetização de compostos ferromagnéticos é devido à existência de regiões microscópicas, constituídas de um agrupamento de átomos, denominadas domínios magnéticos $[22,23]$. Dentro de cada domínio há um momento magnético total grande pois os momentos magnéticos elementares estão alinhados em uma mesma direção. 0 aparecimento de domínios em compostos ferromagnéticos tende a um sistema energeticamente mais favorável, porque a configuração dos momentos magnéticos procura ficar em um estado de mínima energia potencial, levando à diminuição da energia magnetostática [24-26], que resulta em diferentes direções para os vários domínios, fazendo com que algumas direções cancelem-se mutuamente.

Os materiais ferromagnéticos podem ser magnetizados facilmente sob ação de um campo magnético indutor $\mathrm{H}$, fazendo com que haja um rearranjo da distribuição dos momentos magnéticos. Dessa forma ocorre mudança na estrutura dos domínios e na direção da magnetização de cada domínio de forma a obedecer ao estado de energia mínima [24]. 
Quando estes materiais são submetidos a um forte campo magnético, aproximam-se de um limite chamado saturação magnética ou magnetização de saturação. A magnetização de saturação representa um limite na orientação dos átomos.

Quando o campo magnético é removido e a magnetização não retorna ao seu valor original tem-se uma histerese. A FIG. 3.4, curva de cor azul, apresenta o modelo da curva de magnetização e desmagnetização, representando uma curva de histerese. A curva de cor laranja apresenta o modelo de curva de magnetização sem a presença de histerese.

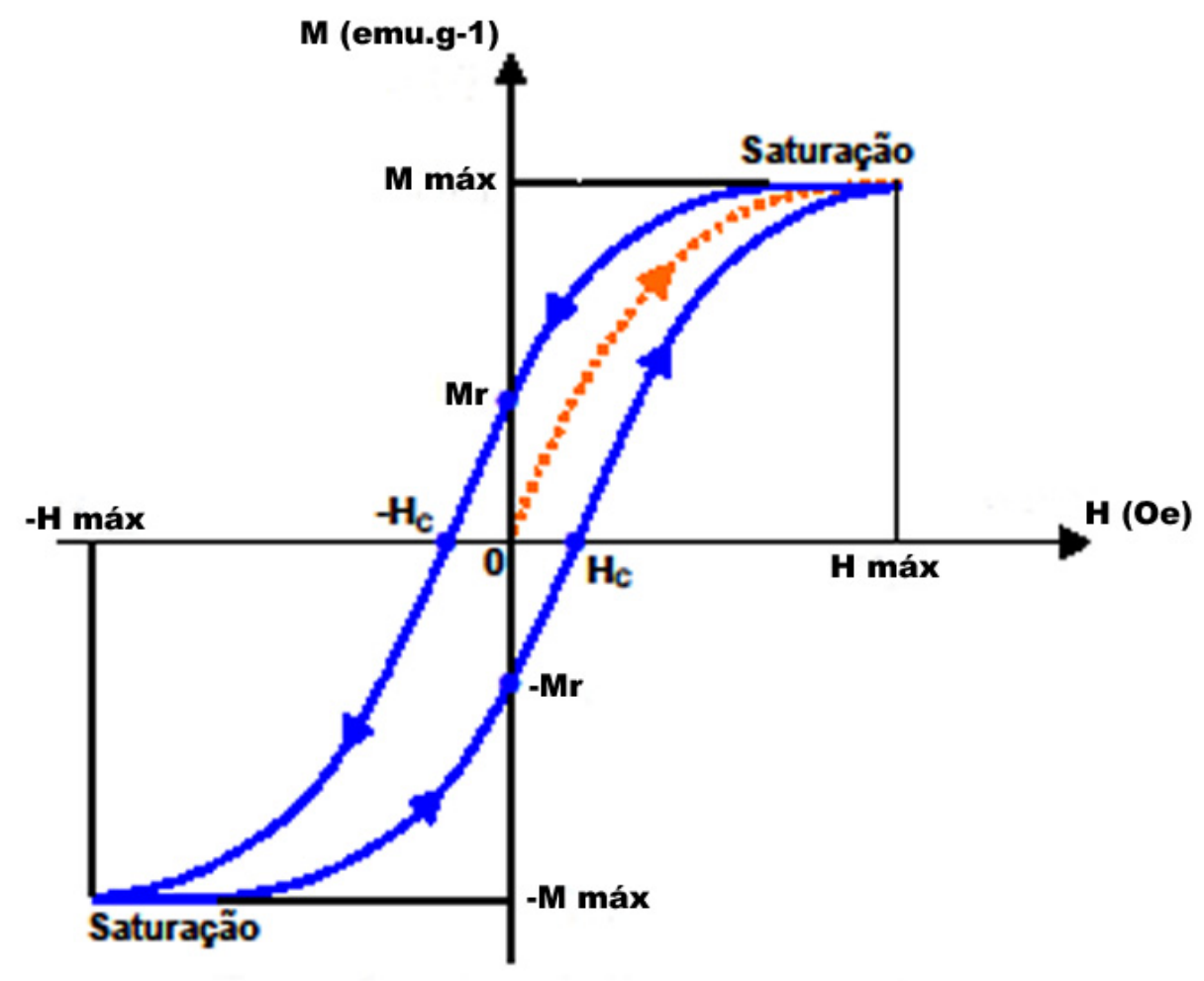

Figura 3.4 - Curva de magnetização com histerese, com modificações [18].

Sendo:

$M=$ magnetização, em unidade eletromagnética por grama (emu.g ${ }^{-1}$ );

$\mathrm{M}_{\text {máx }}$ ou $\mathrm{M}_{\mathrm{s}}=$ magnetização de saturação;

$\mathrm{M}_{\mathrm{r}}=$ magnetismo residual ou remanência;

$\mathrm{H}=$ campo indutor ou magnetismo aplicado, em Oersted $(\mathrm{Oe})$;

$\mathrm{H}_{\mathrm{C}}=$ coercitividade ou campo coercitivo. 
Por meio de uma análise da curva de magnetização é possível observar o aparecimento de histerese. No caso de haver histerese, quando o campo indutor $\mathrm{H}$ chega a zero ainda existirá um certo valor de densidade de fluxo $B$ ou o magnetismo residual $B_{R}$, também conhecido como retentividade. A fim de que o magnetismo residual chegue a zero é necessário aplicar um campo indutor negativo, chamado campo coercitivo $\mathrm{H}_{\mathrm{c}}$. Neste ponto a densidade de fluxo é nula. Aumentando negativamente o campo indutor o material irá se saturar novamente com orientação magnética contrária à anterior, ou seja, com polaridade oposta. Se o campo indutor for levado novamente a zero, aparecerá um magnetismo residual negativo $-B_{R}$. Aumentando-se ainda mais o campo indutor o material novamente satura e com a polarização inicial. Histerese é, portanto, o atraso do comportamento da densidade de campo magnético $B$ em relação ao campo magnético indutor $H$. Quanto maior o retardo, maior o magnetismo residual conservado pelo material.

O comportamento magnético observado nas curvas de magnetização varia em função do material, visto que cada um possui permeabilidades magnéticas diferentes. A permeabilidade está relacionada à facilidade com que as linhas de campo podem atravessar um dado material. Materiais com baixa permeabilidade, ou seja, de difícil magnetização, apresentam uma curva de histerese mais larga havendo, portanto, alta retentividade, coercitividade e alto magnetismo residual. Enquanto os materiais com alta permeabilidade magnética apresentam uma curva de histerese mais estreita havendo, portanto, baixos retentividade, força coerciva e magnetismo residual [22].

Em se tratando de nanomateriais ferromagnéticos ou ferrimagnéticos, observa-se que estes deixam de ser magnetos permanentes e passam a ter propriedades superparamagnéticas, sendo estas caracterizadas, de uma forma simplificada, pela alta magnetização de saturação e ausência de histerese [27].

\subsubsection{Superparamagnetismo}

Na escala nanométrica há o surgimento de novas propriedades físicas e químicas não observadas na escala macroscópica ou mesmo na microscópica, levando a novos materiais. Tais propriedades surgem em função do confinamento 
quântico e dos efeitos de superfície, ou seja, do aumento da área superficial. Estes materiais apresentam uma elevada magnetização de saturação o qual permite um controle do seu movimento mediante a ação de um campo magnético sem que haja a retenção do magnetismo pelo material, após cessada a aplicação do campo [22].

Trabalhar em escala nanométrica é muito complexo pois é necessário considerar a contribuição de milhões e milhões de partículas de diferentes formas e tamanhos, além das interações entre elas. E dependendo da distância entre as partículas, o campo magnético gerado por uma pode ser sentido por outras.

A direção dos eventos no universo procura o estado de menor energia, compatível com as condições do sistema de maneira que os domínios magnéticos ficam dispostos em direções aleatórias. Porém, embora os domínios vizinhos apontem para direções diferentes, quando as dimensões do material são reduzidas para a nanoescala $\left(10^{-9}\right.$ metros) os domínios são fundidos em um só (monodomínio), abaixo de um determinado diâmetro crítico $\left(D_{c}\right)$ e passam a apontar para uma única direção [24], conforme a FIG. 3.5.

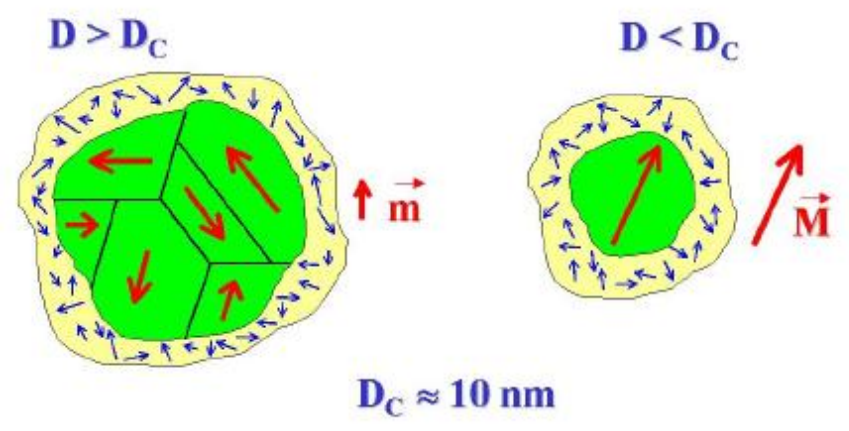

\section{Multidomínio \\ Monodomínio}

Figura 3.5 - Momento magnético de acordo com o número de domínios [24]. $D=$ diâmetro da partícula, $D_{c}=$ diâmetro crítico da partícula.

No interior dessas partículas, o material magnético permanece espontaneamente magnetizado em uma só direção, o que leva à formação de um 
momento magnético gigante, ou supermomento. O momento magnético total de uma partícula nanométrica poderá ser até 10000 vezes maior que os momentos atômicos dos átomos constituintes [28].

Existe um tipo de energia cuja tendência é desordenar os momentos a qual chamamos de energia térmica. Essa energia faz com que os momentos oscilem constantemente em todas as direções. Em partículas cujo tamanho é igual ou inferior ao tamanho crítico o momento magnético torna-se altamente influenciado pela variação da temperatura. Quanto maior a temperatura, ou mesmo quanto menor o volume, menor o tempo que uma partícula levará para passar de um estado de equilíbrio a outro. Nessas condições o sistema passa a estar no estado superparamagnético. Dessa forma, estar no estado superparamagnético significa diminuir o tempo de relaxação, ou seja, o tempo médio que uma partícula leva para passar de um estado de equilíbrio a outro. Se a temperatura é baixa o suficiente ou se as partículas são maiores que o tamanho crítico, diz-se que o sistema está no estado bloqueado.

No comportamento superparamagnético não há histerese, ou seja, a retentividade e a coercitividade são nulas. A susceptibilidade magnética destes materiais situa-se entre a dos ferromagnéticos e dos paramagnéticos [22].

\subsection{Aplicação Tecnológica de Nanopartículas Magnéticas}

As nanopartículas magnéticas são aplicadas, por exemplo, nas áreas médica e ambiental.

$\mathrm{Na}$ área médica há o tratamento por magnetohipertermia. Com a conexão de nanopartículas magnéticas a células cancerosas, será possível aplicar um campo alternado suficientemente forte para movimentar essas partículas e aquecer localmente o tumor, provocando a eliminação do câncer sem os indesejados efeitos colaterais da quimioterapia e da radioterapia [29]. As nanopartículas magnéticas, com o auxílio de nanocápsulas, são estudadas com o objetivo de confinar um fármaco, efetuar o seu transporte e depois liberá-lo sobre o alvo, minimizando os efeitos colaterais associados à circulação das drogas pelo organismo. 
Outra aplicação está relacionada à área ambiental, em que partículas magnéticas poderão ser utilizadas na eventualidade de um vazamento de óleo, facilitando a coleta, recuperação e limpeza da área afetada [29]. Neste sentido, compósitos magnéticos produzidos a partir da agregação de nanopartículas magnéticas a polímeros tratados quimicamente permitirão que o material se una ao óleo e seja separado da fase aquosa se comportando de forma hidrofóbica e possibilitando a retirada da água por meio da aplicação de um campo magnético.

As nanopartículas magnéticas podem ser associadas a resíduos agroindustriais para compor a tecnologia dos adsorventes magnéticos que combina as técnicas de adsorção e separação magnética nos processos de tratamento de águas residuárias. O uso dessa biomassa residual tem um duplo impacto positivo pois deixa de ser mais um poluente pelo acúmulo e permite a remoção de substâncias tóxicas.

\subsection{Cana-de-Açúcar}

A cana-de-açúcar pertence ao gênero Saccharum spp. Ela é cultivada nas regiões tropicais e subtropicais sendo proveniente do sudeste Asiático. Entre as substâncias encontradas na cana-de-açúcar, a mais importante é a sacarose, que é um dissacarídeo formado por uma molécula de glicose e uma de frutose [30].

A cana-de-açúcar tem contribuído durante séculos e de forma expressiva para o desenvolvimento econômico de nosso país. O Brasil ocupa a $1^{a}$ posição na produção mundial. Durante a safra de 2006/2007 o Brasil moeu 425 milhões de toneladas de cana. Desse valor, foi produzido 29,8 milhões de toneladas de açúcar e 17,7 bilhões de litros de álcool. Para a safra de 2012/2013, a projeção do setor é de que haverá uma produção de 727,8 milhões de toneladas de cana-de-açúcar [31].

A produtividade de álcool é de 80-85 litros de álcool por tonelada de canade-açúcar e a produtividade nacional de açúcar é de 140-145 kg por tonelada de cana-de-açúcar [32]. De 5 mil a 7 mil litros de bioetanol são produzidos por hectare [33]. 
Os processos de fabricação de açúcar e álcool são simples e obedecem as seguintes etapas: a cana de açúcar após passar por uma análise feita em laboratório para se averiguar a quantidade de sacarose é lavada, picada e desfibrada. Após passar pelo processo de moagem é enviada para os decantadores. A partir desta etapa parte vai para a produção de açúcar e parte para a produção de álcool. Na fabricação de açúcar, após passar por um rigoroso processo de decantação, o caldo obtido é enviado aos evaporadores, e em seguida, aos flotadores. O processo todo inclui as etapas de cozimento, cristalização, secagem e centrifugação.

O Estado de São Paulo, o qual responde por cerca de $60 \%$ da produção nacional da cana, açúcar e álcool, possui 124 usinas em operação de acordo com o último levantamento da UNICA feito em 06/2006 [34].

\subsubsection{Bagaço de Cana-de-Açúcar}

O bagaço de cana-de-açúcar é um polímero natural de parede celular composta de celulose, hemicelulose e lignina, com aproximadamente $41 \%, 25 \%$ e $20 \%$, respectivamente, baseado no peso seco de bagaço. A estrutura da hemicelulose é constituída de monômeros de glucose e outros monossacarídeos tais como xilose, manose, arabinose e galactose [35]. A lignina é um polímero muito complexo de unidades de fenilpropano interligadas por éster, éter e ligações C-C [36].

Da cana-de-açúcar produzida, cerca de $30 \%$ de sua massa, corresponde ao bagaço, o que equivale a 127,5 milhões de toneladas de bagaço. Em 2007, cada tonelada possuia um valor aproximado de $\mathrm{R} \$ 25,00$ [37].

Como ele possui um poder calorífico de $1850 \mathrm{kcal} / \mathrm{kg}$, cerca de $90 \%$ da quantidade gerada é destinada às usinas de cogeração, na produção de energia térmica e elétrica para o consumo da própria indústria sucro-alcooleira. O bagaço é queimado em caldeiras e gera vapor. O vapor de alta pressão alimenta uma turbina que produz energia elétrica. 
As vantagens na geração de energia elétrica no setor sucro-alcooleiro podem ser estratégicas devido à geração de energia descentralizada, próxima aos pontos de carga; econômicas, com o crescimento do setor de máquinas e equipamentos, devido ao uso de combustível e equipamentos nacionais com conseqüente aumento da arrecadação de impostos; sociais com a utilização de mãode-obra na zona rural; e ambientais ao se utilizar combustível com caráter renovável [32], sendo possível avaliar as emissões evitadas com a substituição da energia gerada a partir de termelétricas a combustíveis fósseis por eletricidade produzida a partir de biomassa levando a um balanço de carbono praticamente nulo (quando utilizada de forma sustentável) [38].

Uma outra parcela desse material é destinada à alimentação animal. Em épocas secas em determinadas regiões do país há dificuldade de se adquirir alimentos volumosos em quantidade suficiente para o gado. Coincidentemente, nesta época de escassez, a oferta de subprodutos e resíduos oriundos da cana, como o bagaço, é abundante. O bagaço de cana é um produto de baixo valor nutricional e qualquer tentativa do seu uso na alimentação animal deve estar associada a algum tipo de tratamento físico (pressão e vapor) ou químico (amônia, soda cáustica) [39].

Segundo dados fornecidos por Coelho [40] "ainda há uma grande parte do bagaço que não é usada para geração de eletricidade apesar de não existirem estatísticas confiáveis com relação à quantidade e destino do bagaço vendido pelas usinas".

Estima-se que, além da quantidade de bagaço processado e utilizado para alimentar caldeiras, haja um excedente de bagaço de cana-de-açúcar correspondente a $8 \%$ nas destilarias anexas e $12 \%$ nas autônomas, que poderia ter outros destinos, inclusive ser empregado de forma a melhorar a qualidade do meio ambiente, citado por Albertini et. al [41].

Atualmente pesquisas sobre o aproveitamento do bagaço para produção de papel e etanol estão em desenvolvimento. 
O bagaço da cana-de-açúcar constitui um bom material em termos de fibras para a produção de papel e papelão. O papel artesanal é obtido com o resíduo cozido, alvejado, lavado, batido, tingido, peneirado e prensado de acordo com as dimensões e formato do papel requerido [42]. O papel produzido é utilizado para a fabricação de rótulos, embalagens para cachaça, cartões, convites e artesanatos em geral [42]. Os fatores limitantes na utilização do bagaço como matéria-prima para a indústria de papel envolvem, além do tamanho das fibras de celulose, o teor e a composição da lignina. A lignina altera a qualidade do papel, modificando suas características físicas e diminuindo seu brilho e opacidade. Por esta razão, é necessário submeter a matéria-prima, durante o processo de cozimento (delignificação), a altas temperaturas e a tratamentos alcalinos, seguidos de um processo de alvejamento com soda cáustica, peróxidos, hipoclorito e hiposulfito, dentre outros. Esses tratamentos não apenas aumentam o custo de obtenção da polpa como danificam a fibra de celulose, o que altera as propriedades mecânicas do papel e leva ao aparecimento de amarelamento [43].

O bagaço de cana-de-açúcar pode servir de matéria-prima para a produção de etanol, mediante processos de hidrólise seguida de fermentação, ainda em desenvolvimento. Diversas rotas ácidas e enzimáticas estão sendo testadas, sempre em busca de processos eficientes para converter a celulose e a hemicelulose de resíduos respectivamente em hexoses e pentoses fermentáveis. Uma das dificuldades da hidrólise é que a lignina restringe o acesso dos reagentes à celulose e eventualmente sua remoção ataca o açúcar formado, impondo técnicas complexas e multifásicas. Atualmente se obtém cerca de $100 \mathrm{~L}$ de etanol por tonelada de bagaço hidrolisado, esperando-se atingir uma produtividade $80 \%$ superior com o aperfeiçoamento da tecnologia. O estágio atual não recupera para etanol os açúcares derivados de hemicelulose [44].

Estudos do bagaço como biossorvente de contaminantes também estão sendo realizados. Devido à presença de grupos funcionais tais como hidroxila, carbonila, carboxila e fenol na sua composição química, o bagaço apresenta uma capacidade de se combinar com compostos orgânicos [45] e íons metálicos [46-48], a qual é chamada biossorção. 
A biossorção é o fenômeno de adsorção observado em materiais biológicos vivos ou não, e portanto, denominados biossorventes. Uma breve revisão bibliográfica sobre biossorventes foi relatada no capítulo 4 .

\subsection{Urânio}

O Urânio foi descoberto em 1789 pelo alemão Martin Heinrich Klaproth. Ele percebeu a presença de uma substância semi-metálica na uraninita, a qual, mais tarde, notou-se tratar do óxido e não do metal. Em 1896 o renomado físico francês Antoine Henri Becquerel descobriu a radioatividade natural do urânio e em 1903 recebeu o Prêmio Nobel em Física pela descoberta [49]. O urânio foi o primeiro elemento radioativo descoberto.

O urânio é o elemento químico radioativo mais pesado existente na natureza, com 92 prótons. Ele possui os isótopos U-235, com 143 nêutrons, U-238 com 146 nêutrons e U-234 com 142 nêutrons. Estes aparecem nas respectivas porcentagens: $0,71 \%, 99,2845 \%$ e $0,0055 \%$ [50].

É encontrado nas rochas da crosta terrestre e as maiores reservas do mundo (ano 2007) considerando o quilo de urânio possível de ser obtido a custos inferiores a U\$ 130,00 estão na Austrália, seguida do Cazaquistão, e da Rússia, como mostra a TAB. 3.2. Em $7^{\circ}$ lugar encontra-se o Brasil, com cerca de 309.370 toneladas de $\mathrm{U}_{3} \mathrm{O}_{8}$ [51]. Há ocorrências de urânio nos estados da Bahia, Ceará, Minas Gerais, dentre outras. A jazida de Santa Quitéria, localizada no Ceará, por exemplo, possuía em 2001 uma reserva de 142,5 mil toneladas de urânio associado ao fosfato. 
TABELA 3.2 - Reservas mundiais de urânio contabilizados em 2007 [51].

\begin{tabular}{ll}
\hline País & $\mathbf{t ~}_{\mathbf{3}} \mathbf{O}_{\mathbf{8}}$ \\
\hline Austrália & 1.462 .000 \\
Cazaquistão & 961.000 \\
Rússia & 641.000 \\
África do Sul & 512.000 \\
Canadá & 497.000 \\
Estados & 399.000 \\
Unidos & \\
Brasil & 309.370 \\
\hline
\end{tabular}

\subsubsection{Rejeitos Radioativos Contendo Urânio}

A aplicação mais importante do urânio é a energética. No Brasil, a geração de energia elétrica a partir do urânio aumentou de 9,9 TWh em 2005 para 13,8 TWh em 2006, devido à operação continuada da Central Nuclear Almirante Álvaro Alberto [52]. Com esta finalidade o minério urânio passa por uma série de etapas até sua utilização como combustível dentro de uma usina nuclear. Esse conjunto de etapas é uma parte do Ciclo do Combustível Nuclear.

O ciclo do combustível pode ser aberto ou fechado. No ciclo aberto o urânio após ser utilizado no reator é armazenado em depósitos geológicos. No ciclo fechado o urânio não consumido e o plutônio produzido no combustível queimado são extraídos quimicamente e convertidos em uma mistura de óxidos para uso em um novo combustível nuclear. Países como a França utilizam o ciclo fechado. A FIG. 3.6 mostra esquematicamente os dois ciclos. 


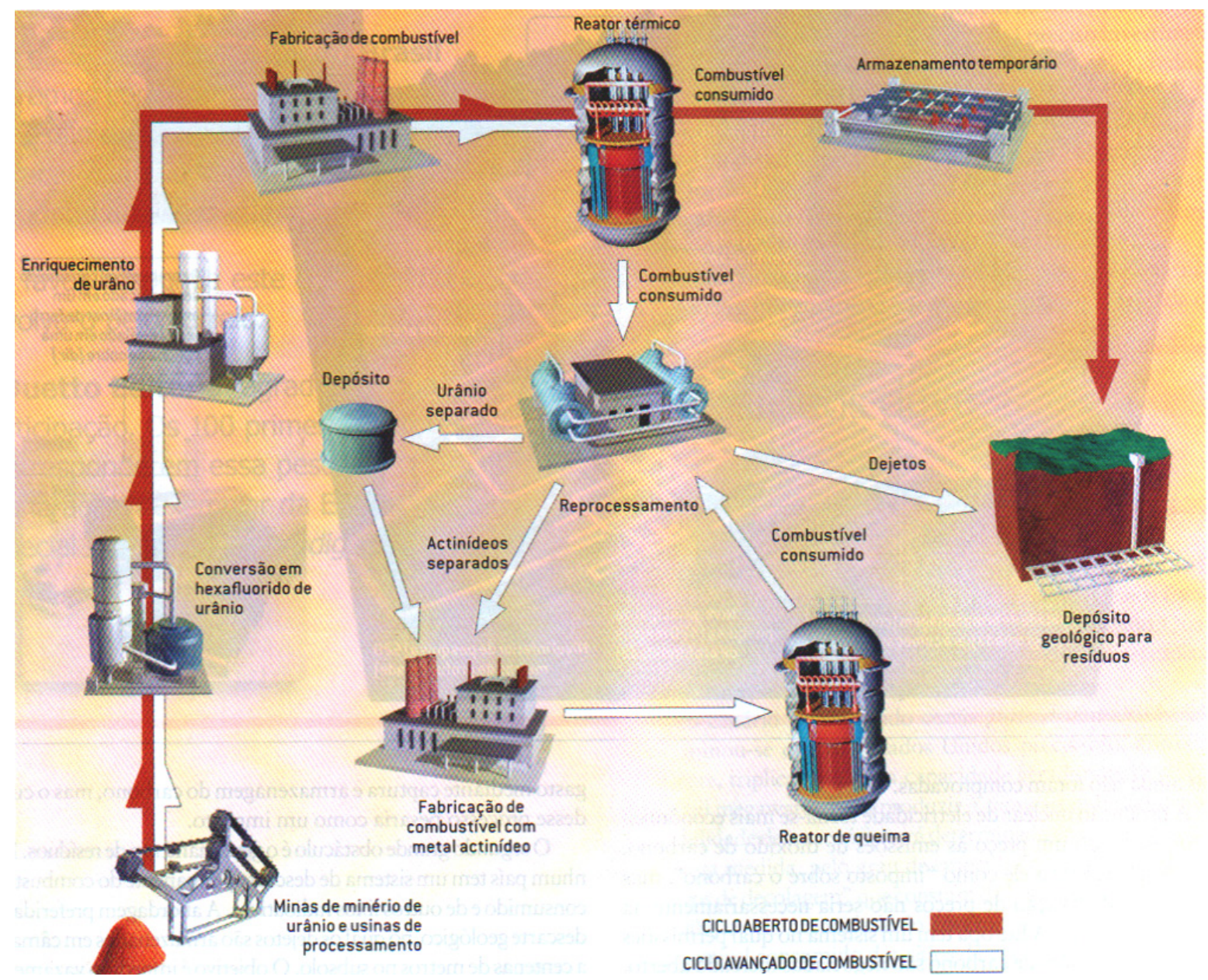

Figura 3.6 - Ciclo do combustível nuclear [53].

A fim de ser utilizado nos reatores o urânio é extraído de minérios, concentrado, purificado e processado. Os rejeitos do ciclo do combustível ou rejeito radioativo são gerados em todas as etapas do ciclo como efluentes sólidos e líquidos e classificados segundo o nível de radioatividade [54], de alto, intermediário e baixo nível.

No Brasil os rejeitos gerados pela indústria nuclear, ao longo de mais de 40 anos, encontram-se armazenados em instalações pertencentes ou supervisionados pela Comissão Nacional de Energia Nuclear (CNEN) [55].

O urânio está também relacionado à produção de radioisótopos. Os radioisótopos ou isótopos radioativos são caracterizados por apresentar um núcleo atômico instável e que tende à estabilização pela emissão de radiação. Eles são 
produzidos em reatores nucleares e em aceleradores de partículas tipo Cíclotron. Neste processo bem como em todas as atividades que envolvem o uso de materiais radioativos são gerados os rejeitos radioativos. Os radioisótopos têm aplicações na medicina, na agricultura e na indústria [56,57].

Na indústria de fosfato [58] para produção do ácido fosfórico, a questão dos impactos radiológicos se relaciona com a geração de fosfogesso e com a presença de elementos radioativos, como o urânio. A produção de ácido fosfórico $\left(\mathrm{H}_{3} \mathrm{PO}_{4}\right)$ é feita por meio do processamento químico do minério de fosfato por lixiviação ácida. A maioria do processamento utiliza o ácido sulfúrico com a formação do fosfogesso. O fosfogesso é formado por cristalização durante o ataque da rocha fosfática com ácido sulfúrico $\left(\mathrm{H}_{2} \mathrm{SO}_{4}\right)$, via úmida. Embora o fosfogesso seja composto principalmente por sulfato de cálcio di-hidratado $\left(\mathrm{CaSO}_{4} \cdot 2 \mathrm{H}_{2} \mathrm{O}\right)$, ele pode apresentar níveis elevados de impurezas tais como radionuclídeos naturais de $U$ e Th, provenientes da rocha fosfática em questão. A produção de 1 tonelada de fosfato $\left(\mathrm{P}_{2} \mathrm{O}_{5}\right)$ resulta na formação de 4 a 5 toneladas de fosfogesso [59]. Oitenta por cento do ${ }^{226} \mathrm{Ra}, 14 \%$ do ${ }^{232} \mathrm{Th}$ e $30 \%$ do ${ }^{238} \mathrm{U}$ se depositam no fosfogesso, conforme se observa na FIG. 3.7, e o restante acompanha a produção de ácido fosfórico e fertilizante.

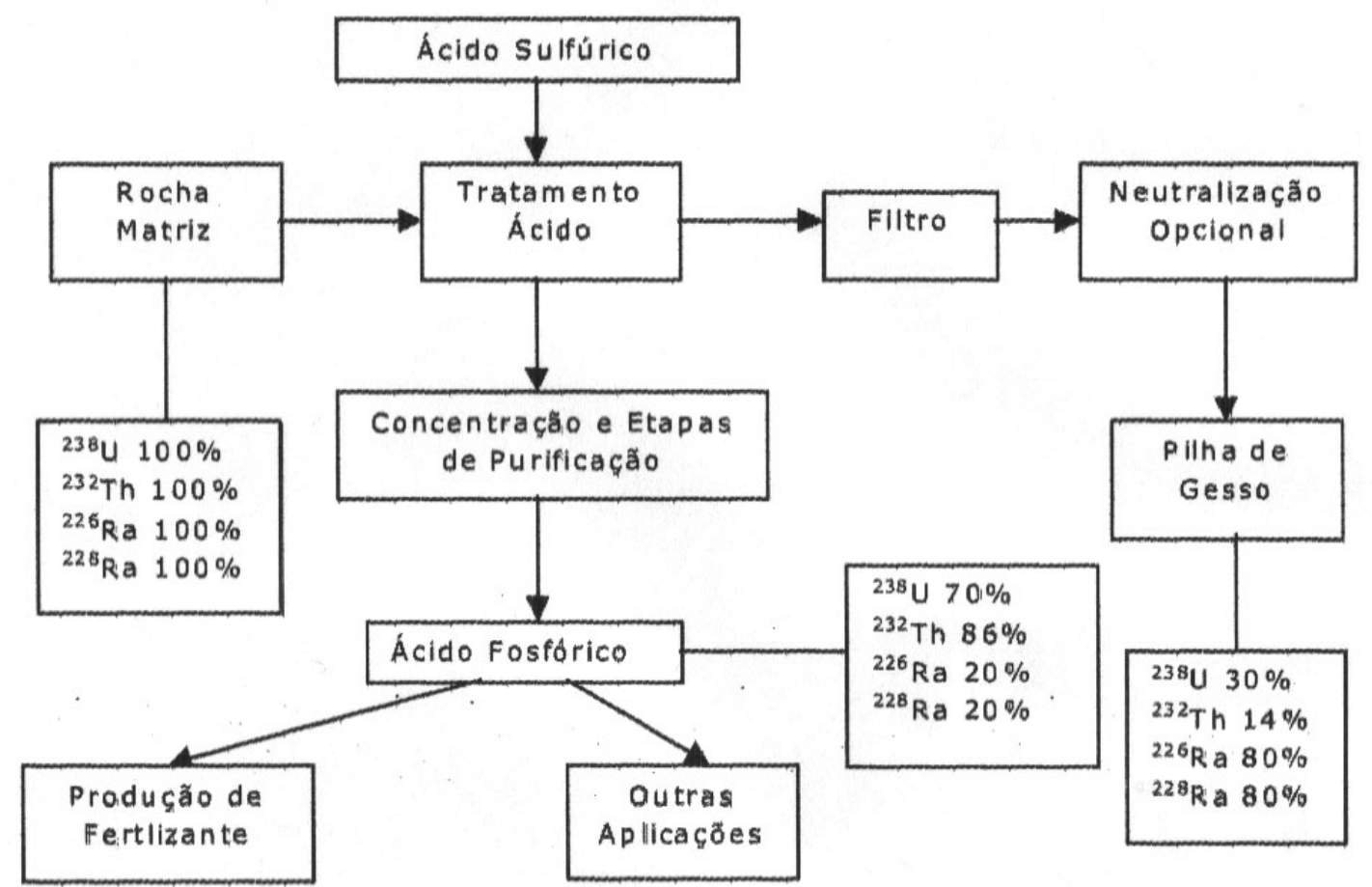

Figura 3.7 - Fluxo do processo de extração de fósforo com ácido sulfúrico [59]. 
Apesar do risco, o fosfogesso é armazenado em pilhas, como mostra a FIG. 3.8 [60], nas proximidades das fábricas. A indústria nacional de ácido fosfórico produz anualmente cerca de 69 milhões de toneladas de fosfogesso, sendo que 3 milhões de toneladas são estocadas a céu aberto [59]. O problema desse tipo de armazenagem decorre do fato das impurezas do fosfogesso ficarem disponíveis para percolarem através da pilha, possibilitando a infiltração pelo solo, atingindo as fontes hídricas superficiais e subterrâneas. As vias críticas de contaminação aos indivíduos do público referentes aos radionuclídeos do fosfogesso estão relacionadas às inalações de ar, às ingestões de água contaminada, além da exposição externa ao fosfogesso e à radiação gama.

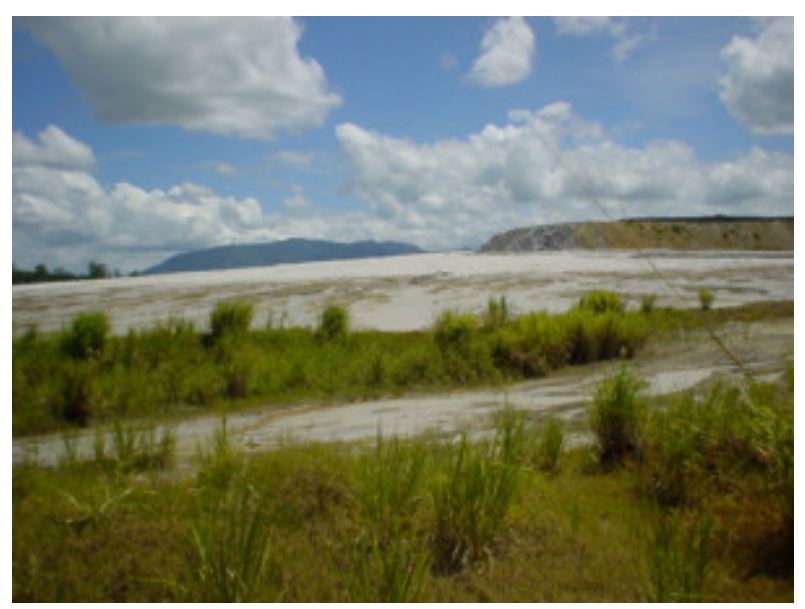

FIGURA 3.8 - Vista das imensas pilhas de rejeito de fosfogesso. (Cajati, SP) [60]

Os fertilizantes fosfatados no cultivo de legumes e verduras bem como os alimentos de fosfato bicálcico em criações de gado e frango contaminam os alimentos de origem vegetal e animal [61].

A ingestão diária de alimentos que contenham urânio, leva ao acúmulo deste no organismo. Em estudos realizados, citado por Silva et al. [62], foi verificada a retenção de urânio no corpo humano por meio de necropsia em seres humanos. $O$ osso foi o local onde houve a maior deposição de urânio. O urânio deposita-se a partir da superfície do osso, redistribuindo-se lentamente em direção à medula óssea. Numa ingestão crônica, ou seja, com pequenas doses diárias, o urânio 
atinge a medula óssea, podendo causar, a longo prazo, leucemia e osteosarcoma, ou câncer nos ossos [63].

Um outro exemplo de liberação de urânio ao meio ambiente com impacto está relacionado à queima do carvão mineral. Estima-se que em todo o mundo sejam queimados anualmente 2,8 bilhões de toneladas de carvão, liberando 9 mil toneladas de tório e 3,6 mil toneladas de urânio por meio das partículas presentes na fumaça e nas cinzas para o meio ambiente. Por meio da queima são multiplicadas as concentrações de elementos radioativos nas cinzas gerados pelo decaimento natural dos isótopos 238 no urânio e 232 no tório. Uma avaliação da queima do carvão vem sendo realizada pelo National Radiological Protection Board (NRPB), no Reino Unido. Resultados preliminares indicam que as exposições mais elevadas resultam da liberação na atmosfera contaminando a vegetação local [64].

Depoi F. S. et al. [65] estudaram a composição química do carvão mineral e das cinzas do carvão mineral presentes em Figueira, no Paraná. Foi encontrada uma concentração de $U$ de $71,6 \mathrm{mg} \cdot \mathrm{kg}^{-1}$ e $609 \mathrm{mg} \cdot \mathrm{kg}^{-1}$, para o carvão e para as cinzas de carvão, respectivamente.

\subsubsection{Legislação}

De acordo com os padrões de qualidade das águas determinados pela Resolução do Conselho Nacional do Meio Ambiente (CONAMA) 357 (2005) [66], os limites máximos estabelecidos para o $U$ é de $0,02 \mathrm{mg} \cdot \mathrm{L}^{-1}$ e $0,5 \mathrm{mg} \cdot \mathrm{L}^{-1} \mathrm{em}$ águas doces (classes 1 e 3) e salinas (classe 1), respectivamente. Na concentração apresentada, o risco é, principalmente, químico. A Tabela 3.3 descreve as especificações das águas doces e salinas, classes 1 e 3.

O limite de urânio permitido nos alimentos é de 3 p.p.m [61, 67]. Porém, no Brasil a fiscalização alimentar é feita exclusivamente em relação à possibilidade do alimento causar intoxicação, não havendo controle do material radiológico [61]. 
Tabela 3.3 - Classificação das águas doces e salinas (CONAMA 357, 2005, p. 283) [66]

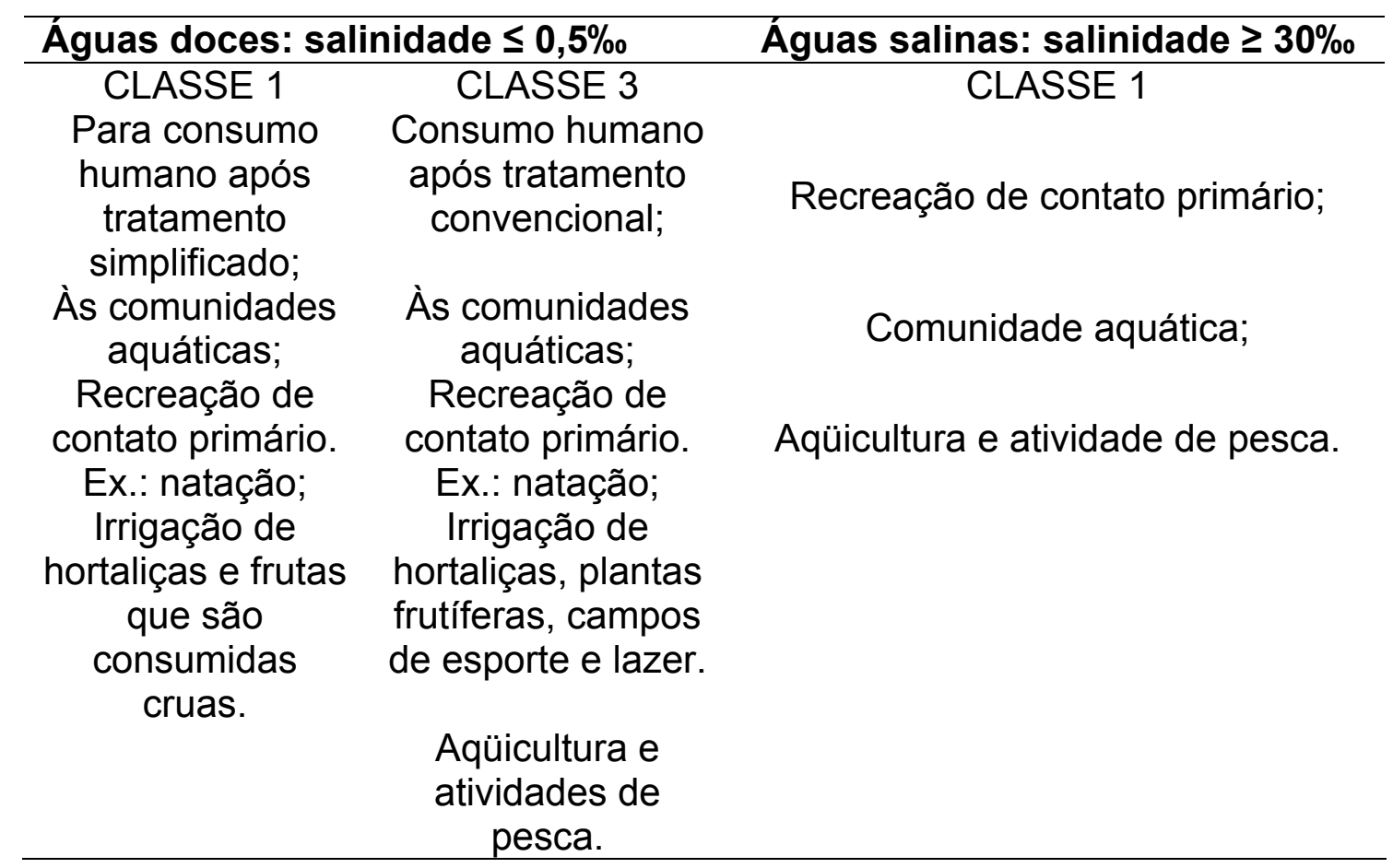

Com relação ao descarte de $U$ e de outros radionuclídeos como rejeito radioativo líquido em esgoto sanitário, de rejeito sólido como lixo urbano, e de rejeito gasoso, os limites são estabelecidos pela Norma CNEN-NE 6.05:

- líquidos solúveis ou fácil dispersão em água: quantidade anual total de radionuclídeos, excluindo o $\mathrm{H}-3$ e o $\mathrm{C}-14$, não deve exceder $3,7 \times 10^{10} \mathrm{~Bq}(1 \mathrm{Ci})$;

- sólidos: atividade específica limitada a $2 \mu \mathrm{Ci} / \mathrm{kg}$;

- gasosos: necessitam previamente de autorização da CNEN.

É necessário ressaltar que o descarte de todo rejeito radioativo está sujeito à aprovação da CNEN (Comissão Nacional de Energia Nuclear), em conformidade com normas específicas para cada tipo de instalação.

\subsection{Separação por Adsorção}

Rejeitos líquidos radioativos lançados ao meio ambiente, muitas vezes sem um tratamento adequado, comprometem a capacidade de regeneração natural 
do ciclo hidrológico. Dessa forma torna-se imprescindível o desenvolvimento e implantação de tecnologias apropriadas de tratamento de águas de abastecimento e residuárias.

Processos como precipitação [1], troca iônica [2], extração por solventes [3], osmose reversa [4] são comumente utilizados nos tratamentos de águas residuárias industriais e rejeitos radioativos. Em muitos casos, a complexidade de composição química associada às concentrações reduzidas dos contaminantes, torna estas tecnologias muitas vezes ineficazes. Além do mais, geram quantidades significativas de rejeitos secundários indesejáveis. Neste aspecto, o processo por adsorção se destaca por ser efetivo para efluentes com baixas concentrações de contaminantes e apresenta versatilidade operacional.

O fenômeno da adsorção é conhecido desde o século XVIII, quando se observou que certa espécie de carvão retinha em seus poros grandes quantidades de vapor de água, o qual era liberado quando submetido ao aquecimento. Com o avanço das pesquisas e do acentuado desenvolvimento da indústria petroquímica, a adsorção passou a ser utilizada como uma operação unitária importante dentro da engenharia química, sendo que atualmente a adsorção é aplicada em processos de purificação e separação, apresentando-se como uma alternativa importante e economicamente viável em muitos casos. Como exemplo mais comum tem-se os chamados processos de purificação, onde utiliza-se geralmente uma coluna de leito fixo empacotada com adsorvente para remover impurezas de uma corrente líquida, como o de um efluente industrial [68].

A adsorção pode ser entendida como o acúmulo de moléculas ou íons presentes na fase fluida (adsorbato) para a superfície de uma fase sólida (adsorvente), citado por Peruzzo et. al [69]. É um fenômeno de transporte no qual a transferência de massa se dá quando existe uma superfície de contato entre um sólido e um líquido ou mesmo um gás. Dessa forma, a adsorção está intimamente ligada à tensão superficial das soluções e a intensidade deste fenômeno depende da temperatura, da natureza e a concentração da substância adsorvida (o adsorbato), da natureza e estado de agregação do adsorvente e do fluido em contato com o adsorvente. 
As moléculas ou íons são atraídos para a zona interfacial devido aos diferentes tipos de forças de atração a fim de se atingir o equilíbrio de adsorção. De acordo com essas forças os fenômenos adsortivos classificam-se em: adsorção física e química.

A adsorção física não envolve o compartilhamento ou transferência de elétrons e dessa maneira sempre mantém a individualidade das interações das espécies. As interações são completamente reversíveis, permitindo ocorrer dessorção na mesma temperatura, embora o processo possa ser lento devido aos efeitos de difusão. A adsorção física não ocorre em sítios específicos; as moléculas adsorvidas estão livres para cobrir a superfície inteira. Isto permite medir a área superficial do sólido adsorvente. O calor de adsorção física é baixo se comparado ao da quimissorção; entretanto, o calor de adsorção não é um critério definido. $O$ limite superior para adsorção física pode ser maior que $20 \mathrm{kcal} \cdot \mathrm{mol}^{-1} \mathrm{em}$ adsorventes com poros muito estreitos [70].

A adsorção química ou quimissorção envolve ligações químicas entre o adsorvente e o adsorbato. As moléculas adsorvidas estão fixadas em sítios específicos. O calor de quimissorção abrange valores acima de $100 \mathrm{kcal}^{\mathrm{mol}}{ }^{-1} \mathrm{a}$ menores de $20 \mathrm{kcal}^{\mathrm{mol}}{ }^{-1}$. A quimissorção é caracterizada principalmente por grandes potenciais de interação que levam a altos calores de adsorção os quais aproximam dos valores das ligações químicas. Este fato associado a outras medidas espectroscópicas, ressonância de spin eletrônico, e medidas de susceptibilidade magnética, confirmam que a quimissorção envolve a transferência de elétrons e a formação de ligação química verdadeira entre o adsorbato e a superfície sólida. Como a quimissorção envolve ligações químicas, ela frequentemente ocorre em altas temperaturas e está normalmente associada com energia de ativação. Além disso, as moléculas adsorvidas estão localizadas em sítios específicos e, portanto, não estão livres para migrar sobre a superfície [70].

Quanto ao modo operacional, o processo de adsorção é dividido em dois tipos de ensaios: ensaio em batelada e ensaio em coluna. Nos ensaios em batelada, 
a solução de adsorbato em concentrações diferentes é colocada em contato com o adsorvente por um tempo determinado que pode variar de minutos a dias, sendo, posteriormente, a solução separada por filtração ou centrifugação. Nos ensaios contínuos, o adsorvente é colocado em coluna e a solução de adsorbato passa por meio desta. A determinação da quantidade de adsorbato adsorvido é feita indiretamente pela concentração de adsorbato remanescente na solução [70].

O estudo de adsorção, ou seja, o estudo de equilíbrio de adsorção envolve um equilíbrio de fases. O equilíbrio do adsorbato entre a fase fluida e a fase adsorvida é governado pelos princípios da termodinâmica. Os dados de equilíbrio geralmente são reportados sob a forma de isotermas.

As isotermas de adsorção apresentam a relação entre a quantidade adsorvida e a concentração do adsorbato em solução. A partir da determinação experimental das isotermas é possível estimar a quantidade total de adsorvente necessário para um determinado processo $e$, conseqüentemente, 0 dimensionamento dos equipamentos a serem utilizados no processo.

As isotermas de equilíbrio de adsorção foram classificadas por Brunauer em cinco formas básicas, conforme mostra a FIG 3.9. As isotermas do tipo 1 estão associadas com sistemas em que a adsorção não continua além da camada monomolecular. Os outros tipos de isotermas envolvem formações de multicamadas. As isotermas para adsorção de solução que seguem o tipo 1, embora sob certas condições, também podem ocorrer adsorção em multicamada [70].

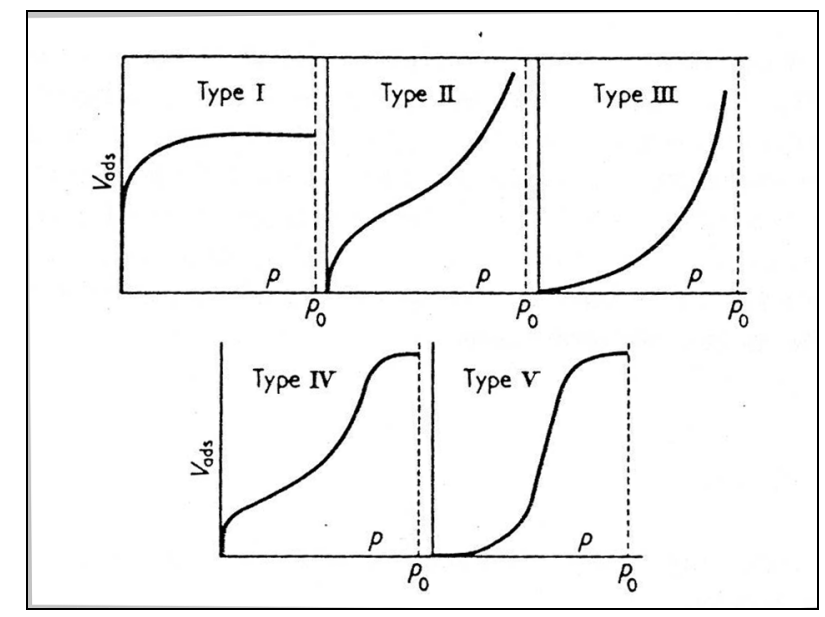

FIGURA 3.9- Classificação de isotermas de Brunauer [70]. 
Existem muitos modelos matemáticos utilizados para correlacionar dados de equilíbrio para os vários tipos de isotermas existentes.

\subsubsection{Modelos de Isotermas de Equilíbrio}

As relações estabelecidas entre as concentrações de equilíbrio do soluto ou adsorbato entre as fases líquida e sólida tornam possível a quantificação do processo de adsorção. O comportamento do sistema em equilíbrio pode ser investigado por meio das isotermas de equilíbrio. Existem diversos modelos para isotermas, sendo o modelo de adsorção de Langmuir o mais utilizado para adsorção de uma solução, bem como o de Freundlich [70].

\section{Modelo de Isoterma de Langmuir}

O modelo de Langmuir é um dos modelos mais utilizados no tratamento matemático de dados experimentais de processos de adsorção e é aplicado na adsorção ocorrida em superfícies homogêneas. Ele pressupõe as seguintes hipóteses [71]:

\footnotetext{
a) Todos os íons são adsorvidos em sítios definidos na superfície do adsorvente;
}

b) A superfície sólida contém um número fixo de sítios de adsorção e cada sítio ativo pode manter apenas uma molécula adsorvida, formando uma monocamada de íons adsorvidos sobre a superfície sólida;

c) A energia de adsorção é igual em todos os sítios;

d) Os íons adsorvidos por sítios vizinhos não interagem entre si.

e) Todos os sítios de adsorção são equivalentes e a superfície é uniforme. 
Neste modelo, a adsorção aumenta linearmente com o aumento de concentração do soluto e aproxima-se de um valor constante devido ao número limitado de sítios de adsorção.

O modelo de adsorção pode ser representado pela equação 3.1:

$$
Q_{e q}=Q K_{L} \cdot C_{e q} /\left(1+K_{L} \cdot C_{e q}\right)
$$

Sendo:

$\mathrm{C}_{\mathrm{eq}}=$ concentração de íons na fase fluida, no equilíbrio [mg. $\left.\mathrm{L}^{-1}\right]$;

$\mathrm{Q}_{\mathrm{eq}}=$ quantidade de íons adsorvidos por unidade de adsorvente [mg. $\mathrm{g}^{-1}$ ];

$\mathrm{K}_{\mathrm{L}}=$ constante de Langmuir relacionada com a energia de adsorção $\left[\right.$ L.mg $\left.{ }^{-1}\right]$;

$\mathrm{Q}=$ capacidade máxima de adsorção $\left[\mathrm{mg} \cdot \mathrm{g}^{-1}\right]$.

A equação 3.1 pode ser rearranjada e representada pela equação linear 3.2, com o propósito de se obter os parâmetros $Q$ e $k_{L}$ por meio dos coeficientes angular e linear, respectivamente. Normalmente utiliza-se o coeficiente de correlação linear encontrado para verificar se houve um bom ajuste dos dados experimentais ao modelo de Langmuir.

$$
C_{e q} / Q_{\text {eq }}=1 / Q K_{L}+C_{e q} / Q \quad(\text { Linear })
$$

\section{Modelo de Isoterma de Freundlich}

O modelo de Freundlich é considerado um modelo empírico e pressupõe que os íons são infinitamente acumulados na superfície do adsorvente, pois o número de sítios de adsorção é muito maior do que a quantidade de moléculas de soluto. Além disso pressupõe que a adsorção ocorre em superfície energeticamente heterogênea. Este modelo é representado pela equação 3.3

$$
Q_{\text {eq }}=K_{F} \cdot C_{e q}^{1 / n}
$$


Sendo:

$\mathrm{K}_{\mathrm{F}}\left[\left(\mathrm{mg} \cdot \mathrm{g}^{-1}\right) \cdot\left(\mathrm{L} \cdot \mathrm{mg}^{-1}\right)^{1 / n}\right]$ e $1 / \mathrm{n}$ são constantes características do sistema e indicam a intensidade de adsorção;

A equação de Freundlich sob a forma linear pode ser representada pela equação 3.4 a fim de se verificar os valores de $1 / n$ e $k_{F}$ por meio dos coeficientes angular e linear, respectivamente. A forma linear permite também verificar o ajuste dos dados experimentais ao modelo de acordo com o valor de coeficiente de correlação linear.

$$
\log Q_{e q}=\log K_{F}+1 / n \cdot \log C_{e q} \quad \text { (linear) }
$$

Valor de $1 / \mathrm{n}$ muito próximo de 1 indica alta capacidade adsortiva $\left(Q_{\mathrm{eq}}\right)$ em altas concentrações de equilíbrio $\left(\mathrm{C}_{\text {eq }}\right)$ que diminui rapidamente em concentrações de equilíbrio menores. Valores muito menores que 1 indicam que a capacidade adsortiva $\left(Q_{e q}\right)$ varia pouco entre as concentrações de equilíbrio $\left(C_{\text {eq }}\right)$ maiores e menores [70].

\section{Energia Livre de Gibbs}

A energia livre de Gibbs é a medida da energia do sistema disponível para realização de trabalho útil. É a medida da quantidade de trabalho que pode ser extraído de algum processo operando à pressão constante [72]. Seu estudo é importante para determinação da espontaneidade de uma reação.

A energia de Gibbs da reação $\left(\Delta_{\mathrm{r}} \mathrm{G}\right)$ é a energia de Gibbs dividida pela variação da composição $(\Delta n)$, conforme a equação 3.5:

$$
\Delta_{\mathrm{r}} \mathrm{G}=\frac{\Delta \mathrm{G}}{\Delta \mathrm{n}}
$$

Ela também pode ser entendida como o coeficiente angular do gráfico de G contra a composição do sistema, de acordo com a FIG 3.10: 


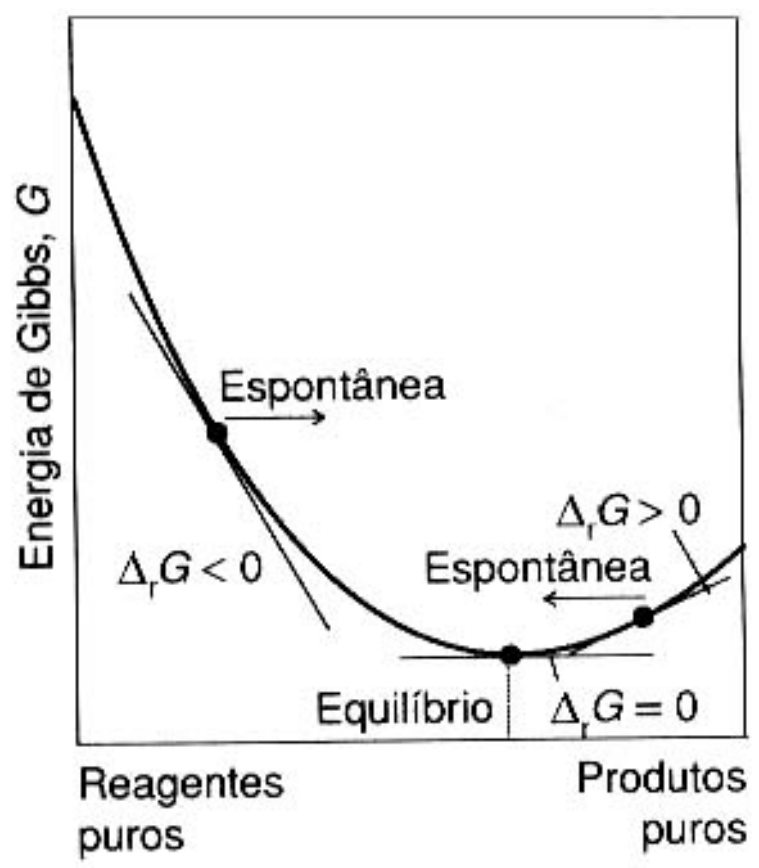

FIGURA 3.10 - Energia de Gibbs em função da composição do sistema [73].

Nas composições que correspondem a $\Delta_{r} G<0$ a reação tende a formar mais produtos e a reação direta é espontânea. Nas composições onde $\Delta_{r} G>0$ a reação inversa é espontânea e os produtos tendem a se transformarem em reagentes. Quando $\Delta_{\mathrm{r}} \mathrm{G}=0$, à pressão e temperatura constantes, a reação está no equilíbrio e não tem nenhuma tendência para formar produtos ou reagentes.

Uma reação geral pode ser representada pela equação 3.6:

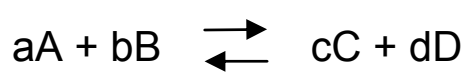

Onde A e B são os reagentes e C e D os produtos. E a,b,c e d as respectivas quantidades em mols.

A Lei de Ação das Massas ou quociente reacional ( $Q$ ) é um quociente que tem como numerador a multiplicação das concentrações dos produtos e como denominador a multiplicação das concentrações dos reagentes. Para uma reação 
química genérica como da equação 3.6, a aplicação da Lei de ação das massas é representada pela Equação 3.7 [74]:

$$
Q=\frac{[C]^{c}[D]^{d}}{[A]^{a}[B]^{b}}
$$

No início de uma reação a concentração dos reagentes é máxima, a velocidade da reação direta tem o seu valor máximo, a concentração dos produtos é zero e a velocidade da reação inversa é nula. À medida que o tempo passa, a concentração dos reagentes vai diminuindo bem como a velocidade da reação direta, a concentração dos produtos e a velocidade da reação inversa vão aumentando até o momento em que as velocidades das reações direta e inversa ficam iguais [75] e a reação atinge um estado de equilíbrio. O equilíbrio químico de uma reação depende da temperatura, pressão e da natureza dos reagentes e produtos.

O valor da expressão da Lei de Ação das Massas (Q) para uma certa reação em equilíbrio a uma dada temperatura é uma constante conhecida como constante de equilíbrio, k, de acordo com a equação 3.8:

$$
Q=k
$$

De forma geral, os estados padrões se referem às substâncias puras.

A energia de Gibbs da reação pode ser representada por meio da energia de Gibbs padrão da reação $\left(\Delta_{\mathrm{r}} \mathrm{G}^{\Theta}\right)$, conforme a equação 3.9:

$$
\Delta_{\mathrm{r}} \mathrm{G}=\Delta_{\mathrm{r}} \mathrm{G}^{\Theta}+\text { R.T.In } \mathrm{Q}
$$

Onde:

$\mathrm{R}=$ constante universal dos gases perfeitos $8,314 \mathrm{~J} \cdot \mathrm{K}^{-1} \cdot \mathrm{mol}^{-1}$

$\mathrm{T}=$ temperatura absoluta $(\mathrm{K})$

$Q=$ quociente reacional 
Quando a reação atinge o equilíbrio $\left(\Delta_{\mathrm{r}} \mathrm{G}=0\right)$, a composição não tem mais nenhuma tendência em mudar e conseqüentemente a reação não é mais espontânea em nenhuma direção. Neste caso o quociente reacional é substituído pela constante de equilíbrio k, conforme a equação 3.10 .

$$
0=\Delta_{r} G^{\Theta}+\text { R.T.In } k
$$

$E$, portanto, obtem-se a equação 3.11 que determina a energia livre de Gibbs padrão de reação em equilíbrio.

$$
\Delta_{\mathrm{r}} \mathrm{G}^{\Theta}=- \text { R.T.In } \mathrm{k}
$$

Essa é uma das equações mais importantes de toda a termodinâmica química. Ela é usada para prever o valor da constante de equilíbrio de qualquer reação a partir dos dados termodinâmicos tabelados, ou determinar $\Delta_{\mathrm{r}} \mathrm{G}^{\Theta}$ medindo a constante de equilíbrio de uma reação [73].

Uma característica importante da equação 3.11 é que por meio dela é possível verificar que $\mathrm{k}>1$ se $\Delta_{\mathrm{r}} \mathrm{G}^{\Theta}<0$. De modo geral, $\mathrm{k}>1$ indica que os produtos são dominantes no equilíbrio. Assim pode-se concluir que uma reação é termodinamicamente possível, ou espontânea, se $\Delta_{\mathrm{r}} \mathrm{G}^{\Theta}<0$. Por sua vez, $\mathrm{k}<1$ se $\Delta_{\mathrm{r}} \mathrm{G}^{\Theta}>0$, ou seja, os reagentes serão dominantes numa mistura reacional no equilíbrio se $\Delta_{\mathrm{r}} \mathrm{G}^{\ominus}>0$. Em outras palavras uma reação com $\Delta_{\mathrm{r}} \mathrm{G}^{\Theta}>0$ não é termodinamicamente possível, ou não espontânea. Entretanto, essas regras devem ser consideradas com ressalvas, pois os produtos só serão significativamente mais abundantes que os reagentes se $\mathrm{k}$ >> 1 (maior do que, aproximadamente, $10^{3}$ ) e até mesmo uma reação com $\mathrm{k}<1$ pode ter uma abundância razoável de produtos no equilíbrio.

A constante $\mathrm{K}_{\mathrm{L}}$ obtida pelo modelo de isoterma de Langmuir tem sido freqüentemente considerada como a constante de equilíbrio e utilizada em cálculos da variação da energia livre de Gibbs padrão de reação de adsorção $[76,77]$. 
Liu [78] demonstrou a importância de se calcular a energia de Gibbs utilizando a unidade mol. $\mathrm{L}^{-1}$ para as concentrações das espécies envolvidas pois somente neste caso é possível igualar a constante do modelo de Langmuir com a constante de equilíbrio. 


\section{REVISÃO BIBLIOGRÁFICA}

\subsection{Exemplos de Biomassas como Biossorventes}

Diversos materiais alternativos de natureza vegetal têm sido estudados para a remoção de metais pesados de águas residuárias industriais. A seguir um breve resumo de alguns trabalhos utilizando a casca da castanha, do amendoim, da cebola, da laranja, do pomelo, da banana, o bagaço de uva e a madeira do pé de mamão foram descritos.

Nakajima et al. [79] estudaram a adsorção de urânio presente em água não-salina e na água do mar, em 7 resíduos de plantas: as cascas interna e externa da castanha e do amendoim, a casca da cebola, da laranja e do pomelo. Os resíduos foram secos e triturados para obter um pó. Exceto a casca externa do amendoim, todos os adsorventes apresentaram bons resultados de remoção de urânio presente em água não salina, com valores entre $72 \%$ e $81 \%$. As cascas externa e interna da castanha apresentaram remoção de 59,7\% e 79,6\%, respectivamente, para o $U$ na água do mar. Este resultado foi atribuído à presença de tanino na composição das cascas como responsável pela remoção de urânio. A alta remoção de urânio em baixos pH pela casca da laranja e do pomelo foi associada aos grupos carboxílicos, os quais possuem bastante afinidade por espécies como $\mathrm{UO}_{2}{ }^{2+}$ e $\mathrm{UO}_{2}(\mathrm{OH})^{+}$, presentes em pH ácidos. Nakajima estudou ainda a modificação das biomassas com formaldeído. A capacidade de adsorção dos resíduos modificados aumentou após o tratamento com formaldeído, com exceção da casca interna da castanha e do pomelo. A casca da laranja, por exemplo, passou a remover $96 \%$ do urânio presente em água não salina devido à fixação de compostos polifenólicos por tratamento com o formadeído os quais possuem bastante afinidade pelo urânio. 
A fibra de coco foi estudada como adsorvente de urânio por Parab et al. [80]. A capacidade máxima de adsorção foi observada à $317 \mathrm{~K} \mathrm{em} \mathrm{um} \mathrm{pH} \mathrm{4,3} \mathrm{e} \mathrm{com}$ a concentração inicial de urânio de $800 \mathrm{mg} \cdot \mathrm{L}^{-1}$. Nestas condições a fibra de coco foi capaz de adsorver 235,27 mg de urânio para cada grama de biossorvente.

A eficiência do bagaço de uva como material adsorvedor de Cd(II) e $\mathrm{Pb}$ (II) foi avaliada por Farinella et al. [81]. Adsorção máxima ocorreu em pH 7 e 3 para o $\mathrm{Cd}(\mathrm{II})$ e $\mathrm{Pb}(\mathrm{II})$, respectivamente. O tempo necessário para atingir o equilíbrio foi de $5 \mathrm{~min}$ para ambos os metais. Nestas condições, a capacidade de adsorção encontrada foi de 0,479 e $0,204 \mathrm{mmol} . \mathrm{g}^{-1}$ para o $\mathrm{Cd}(\mathrm{II})$ e $\mathrm{Pb}(\mathrm{II})$, respectivamente.

A remoção de $\mathrm{Cu}(\mathrm{II})$ pela casca de amendoim e grânulos de casca de amendoim foi investigada por Johnson et al. [82]. Os adsorventes removeram $77 \%$ do $\mathrm{Cu}(\mathrm{II})$ nos primeiros $20 \mathrm{~min}$, sendo o tempo de equilíbrio igual a 40min. A diferença na remoção de $\mathrm{Cu}(\mathrm{II})$ não foi significativa entre os adsorventes observando-se uma pequena melhora de remoção com a casca de amendoim em forma de grânulos. A capacidade máxima de adsorção verificada foi de $9 \mathrm{mg} \cdot \mathrm{g}^{-1}$ para a casca de amendoim e de $12 \mathrm{mg}^{-1} \mathrm{~g}^{-1}$ para a casca de amendoim em formato de grânulos.

Saeed et al. [83] investigaram a eficiência na remoção de $\mathrm{Cu}(\mathrm{II})$, de $\mathrm{Cd}(\mathrm{II})$ e $\mathrm{Zn}(\mathrm{II})$ na madeira do pé de mamão. Com um tempo de equilíbrio de 60 min e no $\mathrm{pH}$ ótimo igual a 5, a remoção de $\mathrm{Cu}(\mathrm{II}), \mathrm{Cd}(\mathrm{II})$ e $\mathrm{Zn}(\mathrm{II})$ foi, respectivamente, de 1,93, 1,89 e $1,29 \mathrm{mg}^{-1}$ referentes a $97,3 \%, 95,3 \%$ e $66,6 \%$. Utilizando-se $5 \mathrm{~g}$ de biossorvente para cada litro da solução de íon metálico obtiveram-se valores de $97,8 \%, 94,9 \%$ e $66,8 \%$ de remoção para o cobre, o cádmio e o zinco, respectivamente.

\subsection{Bagaço de Cana-de-açúcar como Material Biossorvente}

Gupta et al. estudaram o uso do bagaço de cana-de-açúcar na remoção de íons de cobre e zinco [47], cádmio e níquel [84] e chumbo e cromo [85]. Em todos os estudos, o bagaço de cana-de-açúcar foi previamente tratado com peróxido de hidrogênio, seco a $60^{\circ} \mathrm{C}$ por $24 \mathrm{~h}$ a fim de remover a matéria orgânica aderida no 
bagaço. O material foi então lavado com água destilada, filtrado e seco a $100^{\circ} \mathrm{C}$, moído, peneirado e armazenado em um dessecador a vácuo.

Para adsorção de cobre e zinco [47] foi encontrado um tempo de equilíbrio de $60 \mathrm{~min}$ e de $75 \mathrm{~min}$, respectivamente, sob as seguintes condições: dose do adsorvente $10 \mathrm{~g} \cdot \mathrm{L}^{-1}$, temperatura fixada em $30^{\circ} \mathrm{C}$ e $\mathrm{pH}$ ótimo 4 para o cobre e 5 para o zinco. Para ambos os metais, a adsorção se tornou constante a partir de dose 25 $\mathrm{mg} \cdot \mathrm{L}^{-1}$. O estudo variando o tamanho da partícula mostrou que quanto menor o tamanho do biossorvente, maior a remoção de íons metálicos presentes na fase fluida.

No estudo de adsorção de cádmio e níquel [84] o equilíbrio de adsorção ocorreu a partir de $60 \mathrm{~min}$ e $80 \mathrm{~min}$, respectivamente. A isoterma de equilíbrio mostrou que a adsorção máxima ocorreu em $14 \mathrm{mg} \cdot \mathrm{L}^{-1}$ para o cádmio e em $12 \mathrm{mg} \cdot \mathrm{L}^{-1}$ para o níquel. O modelo de Langmuir se ajustou melhor aos resultados para os dois tipos de íons. O pH ótimo encontrado foi 6 para o cádmio e 6,5 para o níquel. Os resultados indicaram que uma dose de $10 \mathrm{~g} \cdot \mathrm{L}^{-1}$ de adsorvente foi suficiente para a remoção de $1,18 \mathrm{mg} \cdot \mathrm{g}^{-1}$ e $0,96 \mathrm{mg} \cdot \mathrm{g}^{-1}$ para o cádmio e o níquel, respectivamente. Foi observado um aumento da adsorção com o aumento da temperatura indicando a natureza endotérmica do processo. O estudo do tamanho da partícula do biossorvente apresentou $99,9 \%$ de remoção dos íons metálicos para partículas de tamanho entre 100-150 $\mu \mathrm{m}$, indicando que quanto menor o tamanho da partícula, maior a sua área superficial, aumentando porcentagem de remoção de íons metálicos.

Estudos de remoção de chumbo e cromo [85] apresentaram bons resultados, sendo de $96 \%$ e $98 \%$, respectivamente, para dose de adsorvente de 10 g. $\mathrm{L}^{-1}$. Os tempos de equilíbrio encontrados foram: 60 e $40 \mathrm{~min}$, a máxima adsorção ocorreu nas concentrações iniciais acima de 40 p.p.m. e 20 p.p.m. e os melhores pH foram de 6 e 5, para o chumbo e o cromo, respectivamente. O estudo da influência das temperaturas em $30^{\circ} \mathrm{C}, 40^{\circ} \mathrm{C}$ e $50^{\circ} \mathrm{C}$ mostrou que a melhor remoção de chumbo e cromo ocorreu na temperatura de $30^{\circ} \mathrm{C}$, demonstrando o caráter exotérmico do processo de adsorção. Os modelos de equilíbrio de adsorção de Langmuir e Freundlich se aplicaram ao estudo. 
O bagaço de cana-de-açúcar também tem sido estudado na remoção de compostos orgânicos de efluentes aquosos.

A remoção de hidrocarbonetos tais como hexano, heptano e iso-octano utilizando coluna de leito fixo de bagaço de cana-de-açúcar foi analisada por Silva et al. [86]. As micrografias de MEV revelaram a existência de uma superfície porosa que sofreu ataque dos hidrocarbonetos a que foi submetido, aumentando ainda mais a porosidade das fibras. Os estudos mostraram que ocorreu uma diminuição da quantidade de hidrocarbonetos retidos pelo leito com o passar do tempo. O bagaço de cana-de-açúcar sob as condições estudadas foi capaz de remover no mínimo $30 \%$ dos hidrocarbonetos em altas concentrações (30\% de hidrocarbonetos) e até $100 \%$ destes para baixas concentrações (6\% de hidrocarbonetos).

Ho et al. [87] estudaram a remoção de três corantes básicos: violetas 1 e 10 e verde 4 de soluções aquosas com o bagaço de cana-de-açúcar. O bagaço foi lavado, seco à temperatura de $60^{\circ} \mathrm{C}$ por 96 horas, moído, e então separado em tamanhos entre 351 e $589 \mu \mathrm{m}$. Utilizaram as faixas de concentrações: $30-70 \mathrm{mg} \cdot \mathrm{L}^{-1}$ para o violeta $10,150-250 \mathrm{mg} \cdot \mathrm{L}^{-1}$ para o violeta 1 e $60-130 \mathrm{mg} \cdot \mathrm{L}^{-1}$ para o verde 4 . As capacidades de saturação de adsorção da monocamada segundo o modelo de Langmuir foram 50,4, 20,6 e 13,9 mg.g ${ }^{-1}$ para o violeta 1 , verde 4 e violeta 10 , respectivamente. 


\subsection{Adsorventes Magnéticos}

Pesquisas relacionadas a novas tecnologias para a remoção de poluentes de águas residuárias têm direcionado atenção para o desenvolvimento de adsorventes magnéticos.

Os adsorventes magnéticos são uma combinação de partículas de ferritas superparamagnéticas, como a magnetita, e polímeros sintéticos ou naturais contendo sítios reativos para interagir com os contaminantes. Uma vez carregados de contaminantes, os adsorventes podem ser recuperados do meio aquoso utilizando um imã. Como eles são superparamagnéticos, não se tornam permanentemente magnetizados, de maneira que com a retirada do campo magnético podem ser ressuspensos em outro meio líquido para dessorção dos contaminantes. Conseqüentemente podem ser reutilizados. A estabilidade das partículas superparamagnéticas e dos sítios reativos contribui para o uso e reúso dos adsorventes magnéticos.

As ferritas superparamagnéticas também contribuem com os sítios ativos nos adsorventes magnéticos. Sheha et al. [88] demonstraram o comportamento adsortivo da magnetita natural e a sintetizada para a remoção de césio radioativo. $A$ magnetita sintética foi preparada por precipitação de íons de $\mathrm{Fe}^{2^{+}}$e $\mathrm{Fe}^{3^{+}}$. Por meio do modelo de isoterma de adsorção de Langmuir, estimaram as capacidades máximas de adsorção de $70,77 \mathrm{mg} \cdot \mathrm{g}^{-1}$ para a magnetita natural e de $108,58 \mathrm{mg} \cdot \mathrm{g}^{-1}$ para a magnetita sintética.

Yamaura et al. [89] estudaram um adsorvente magnético contendo magnetita envolvida por silano e uma mistura de agentes extratores CMPO-TBP como os sítios ativos. As partículas de magnetita foram obtidas por precipitação dos íons $\mathrm{Fe}^{2+}$ e $\mathrm{Fe}^{3+}$ (na relação molar 1:2) por adição de hidróxido de sódio até atingir o $\mathrm{pH} 11$, à temperatura ambiente. $\mathrm{O}$ adsorvente magnético foi avaliado para remoção de íons de $E u(I I I)$ de uma solução nítrica e o efeito do campo magnético na separação do metal foi verificado. A separação da fase líquida do adsorvente magnético foi obtida utilizando um campo magnético de um imã. Os estudos 
mostraram que a capacidade de adsorção do adsorvente magnético para o Eu aumentou com a diminuição da concentração de ácido nítrico. Não se observou influência no processo de adsorção na presença e na ausência do campo magnético de $0,1 \mathrm{~T}$.

Um outro adsorvente magnético constituído de nanopartículas de magnetita e goma arábica foi estudado por Banerjee et al. [90] para a remoção de íons de cobre de soluções aquosas. Prepararam-se as nanopartículas de magnetita por precipitação do $\mathrm{Fe}^{2^{+}}$e $\mathrm{Fe}^{3+}$ a uma relação molar de 1:2 com solução de hidróxido de amônia $\left(\mathrm{NH}_{4} \mathrm{OH}\right)$. O precipitado foi aquecido a $80^{\circ} \mathrm{C}$ por 30 min e então lavado por diversas vezes com água e etanol, e seco a vácuo a $70^{\circ} \mathrm{C}$. Para a modificação da superfície com goma arábica, $1 \mathrm{~g}$ de nanopartículas de magnetita foi adicionado em $100 \mathrm{~mL}$ de solução de goma arábica em um frasco fechado. Após um tempo de reação em um banho de ultrassom, o material foi lavado com água e seco a $50^{\circ} \mathrm{C}$ por 24 horas. As nanopartículas magnéticas (MNP) apresentaram um tamanho de cerca de $13 \mathrm{~nm}$ enquanto que as partículas nanomagnéticas modificadas com goma arábica (GA-MNP) resultaram na aglomeração de MNP e tiveram um diâmetro médio estimado em 34,19 nm, contendo cerca de 5,1\% de goma arábica. Por meio da análise de difração de raio-x verificaram que a modificação com goma arábica não resultou em mudança de fase. Do espectro de absorção na região do infravermelho verificaram que a ligação da goma arábica sobre a superfície da magnetita ocorreu devido à interação entre os grupos carboxílicos da goma arábica e os grupos hidroxila da magnetita. Com relação à adsorção de íons de cobre, o equilíbrio foi atingido em 2 min, atribuído à alta área de superfície específica e à ausência de resistência à difusão interna. A capacidade máxima de adsorção encontrada para o MNP foi de $17,6 \mathrm{mg} \cdot \mathrm{g}^{-1}$ enquanto que para o GA-MNP foi de $38,5 \mathrm{mg} \cdot \mathrm{g}^{-1}$. Concluíram que a adsorção sobre a superfície do GA-MNP ocorreu devido à complexação com o grupo amino da goma arábica, enquanto a adsorção sobre a superfície de MNP ocorreu devido ao grupo hidroxila do óxido de ferro. Os dados de adsorção seguiram ambos os modelos: Langmuir e Freundlich. No estudo de dessorção utilizando uma solução de $\mathrm{HCl}, \mathrm{pH}$ 1,5, obtiveram 93\% de recuperação de cobre. Estudos para verificar a reutilização do adsorvente seguiram-se processos de adsorção-dessorção por 3 ciclos. As capacidades de adsorção não tiveram variações significativas indicando que o material pode ser reutilizado. 
Yamaura et al. [91] compararam as propriedades de adsorção entre os adsorventes de quitosana e quitosana magnética para o cromo na forma de íons dicromato. A quitosana é um biopolímero de carboidrato derivado do processo de desacetilação da quitina por tratamento alcalino. A quitosana magnética possui os grupos funcionais da quitosana e nanopartículas de magnetita. A síntese da quitosana magnética (QM) foi obtida por adição de uma solução contendo nanopartículas de magnetita e de $\mathrm{NaOH}$ a $1 \mathrm{~mol} . \mathrm{L}^{-1}$. Comparando-se os espectros de absorção na região do infravermelho verificou-se o aumento da banda na região de $573 \mathrm{~cm}^{-1}$ para a QM, a qual corresponde às vibrações de estiramento de FeO e Fe-O-Fe da magnetita. Além dessa banda, foram encontrados pontos associados às ligações $-\mathrm{OH}$ e $-\mathrm{NH}$ do polímero quitosana e $\mathrm{C}=\mathrm{O}$ proveniente dos grupos amida residuais da quitina. Verificou-se que a condição de equilíbrio foi atingida em 20 min com remoção maior do que $90 \%$. Os dois adsorventes não apresentaram diferenças significativas de adsorção, o que indicou que não ocorreu contribuição significativa das partículas de magnetita como adsorvente. Entretanto, o adsorvente QM apresentou vantagens com relação à separação sólido-líquido mais simples, rápido e eficiente por aplicação de um campo magnético.

A quitosana magnética também foi estudada para remoção de urânio (VI) por Stopa L. C. [92]. O material apresentou forte magnetização, aproximadamente 55 emu. $\mathrm{g}^{-1}$ sem, contudo, apresentar histerese. Notou-se que a adsorção de íons uranilo foi influenciada pelo $\mathrm{pH}$ da solução e dose do adsorvente. A melhor remoção obtida ocorreu em pH 5 e em doses a partir de $15 \mathrm{~g}$ de adsorvente por litro de solução de íons uranilo, atingindo uma remoção próxima de $100 \%$. O tempo para se atingir o equilíbrio foi de $40 \mathrm{~min}$ a uma velocidade de agitação de 360 r.p.m. O modelo de isoterma que melhor se aplicou aos dados experimentais foi o de Langmuir. A energia livre de Gibbs descreveu o processo de adsorção química e espontânea para remoção de íons uranilo. A capacidade máxima de remoção encontrada foi de $41,8 \mathrm{mg} \cdot \mathrm{g}^{-1}$. Do estudo de dessorção com íons carbonato foram recuperados, em 3 estágios de equilíbrio, 94\% de $U$ adsorvido, indicando uma possível recuperação de todo o urânio ao se utilizar vários estágios de equilíbrio.

Nuñez et al. [93] estudaram carregadores superparamagnéticos, comercialmente obtidos, com uma camada de revestimento contendo agentes 
extratores organofosforados, CMPO e TBP, para a separação e recuperação de actinídeos de soluções de rejeito nuclear em baixas concentrações. Notou-se um sinergismo entre a superfície dos carregadores magnéticos e os agentes extratores. Estudos com partículas magnéticas de carvão vegetal poli bis-acrilamida usando 0,75 mol. $\mathrm{L}^{-1}$ de CMPO em TBP demonstraram um coeficiente de partição, $\mathrm{K}_{\mathrm{d}}$, de 3000 a $5000 \mathrm{~mL} . \mathrm{g}^{-1}$ para o amerício. Em contrapartida, utilizando a mesma concentração de extratores para um sistema de extração por solvente obteve um coeficiente de partição de cerca de $80 \mathrm{~mL} \cdot \mathrm{g}^{-1}$. Um comportamento similar foi observado para o plutônio, com um coeficiente de partição com cerca de 5000 a $10000 \mathrm{~mL} \cdot \mathrm{g}^{-1}$.

Em uma revisão bibliográfica apresentada por Ngomsik et al. [94] as propriedades magnéticas das nanopartículas e micropartículas magnéticas foram comparadas no processo de remoção de metais. As nanopartículas possuem a vantagem de apresentar alta resposta magnética, de maneira que se estiverem aglomeradas serão facilmente separadas do meio líquido por aplicação de um baixo gradiente de campo magnético. Devido ao seu tamanho, as nanopartículas são altamente dispersantes no meio e muitas vezes somente o campo magnético não é eficiente para promover a separação do meio, sendo necessário adicionar um agente floculante a fim de proporcionar a aglomeração. A separação de micropartículas do meio líquido seria mais fácil se fossem mais magnéticas. As micropartículas são constituídas de uma matriz polimérica contendo óxido magnético. Dessa forma o processo melhoraria se aumentasse o volume da fração do óxido magnético na matriz polimérica porém levaria à diminuição da capacidade de adsorção das micropartículas.

White et al. [95] estudaram as nanopartículas de $\mathrm{y}-\mathrm{Fe}_{2} \mathrm{O}_{3}$ disponíveis comercialmente e funcionalizadas com Poli-L-cisteína (PLCys $)_{n}(n=20)$ para a remoção seletiva de metais pesados, tais como $\mathrm{Cd}, \mathrm{Ni}, \mathrm{Zn}, \mathrm{Pb}, \mathrm{Cu}$ e As. A adsorção foi comparada às partículas de $\mathrm{Y}-\mathrm{Fe}_{2} \mathrm{O}_{3}$ não funcionalizadas. As nanopartículas funcionalizadas obtiveram um melhor resultado para a maioria dos metais. Utilizando uma solução ácida recuperaram-se mais de $50 \%$ dos metais com exceção do As. Devido ao caráter de proteção da monocamada de PLCys ${ }_{n}$ sobre as nanopartículas 
de $\mathrm{Y}-\mathrm{Fe}_{2} \mathrm{O}_{3}$, a dissolução das nanopartículas foi mínima quando expostas às soluções ácidas que normalmente atacam as partículas de óxido de ferro. 


\section{MATERIAIS E MÉTODOS}

\subsection{Materiais e Equipamentos de Laboratório}

- Vidrarias;

- Filtro, Whatman - 41 ashless;

- Peneiras granulométricas com aberturas de 0,6;0,8; 3,0; 8,5;

- Pipetas automáticas de volume fixo e regulável, Eppendorf;

- Ácido Ascórbico, Merck;

- Ácido Nítrico, Merck;

- Arsenazo III (1,8 dihidroxinaftaleno -3,6- ácido sulfônico - 2,7 bis(azo-2)- ácido arzônico);

- Bagaço de cana-de-açúcar;

- Cloreto de ferro II tetrahidratado, Merck;

- Cloreto de ferro III hexahidratado, Merck;

- Hidróxido de Sódio, Merck;

- Solução estoque de nitrato de uranilo, proveniente do Centro de Química e Meio Ambiente / IPEN;

- Agitadores modelo AD8850, Donner;

- Balança analítica digital, Q500L210C, QUIMIS;

- Espectrofotômetro de UV-Vis, model. B582, Micronal;

- Estufa de Secagem e Esterilização FANEM - model. 315 SE;

- Mufla FANEM - Forno Elétrico model. 412;

- PHmetros, Metrohm, $3 \mathrm{~mol} \cdot \mathrm{L}^{-1} \mathrm{KCl}$;

- Difratômetro de raios-X Rigaku, 40 kV e 20 mA;

- Espectrômetro de absorção na região do infravermelho (FTIR), THERMO NICOLET, modelo NEXUS 670 FTIR e o espectrômetro FTIR BOMEM, modelo MB-100. 
- Magnetômetro de amostra vibrante (MAV), EG\&G PRINCETON APPLIED RESEARCH, model 4500, Instituto de Física (USP/SP);

- Microscópio eletrônico de varredura (MEV), Philips XL-30, acoplado ao espectrômetro de energia dispersiva (EDS), LEO 440i, Instituto de Pesquisas Energéticas e Nucleares (IPEN/SP);

- Termobalança, Mettler Toledo, modelo TGA/SDTA 851.

\subsection{Preparação dos Biossorventes Magnético e de Bagaço}

\subsubsection{Preparação do Biossorvente de Bagaço}

O bagaço de cana-de-açúcar utilizado neste trabalho é o resíduo gerado do processo de obtenção de garapa, em uma feira livre de São Paulo. O material obtido foi lavado em água corrente, seco $(27 \pm 2)^{\circ} \mathrm{C}$, cortado e classificado por tamanhos diferentes (FIG. 5.1). Este material passou a ser chamado de biossorvente de bagaço. Parte do biossorvente de bagaço foi utilizada no estudo das variáveis do processo de adsorção para a remoção de urânio e o restante foi destinado à preparação do biossorvente magnético. 


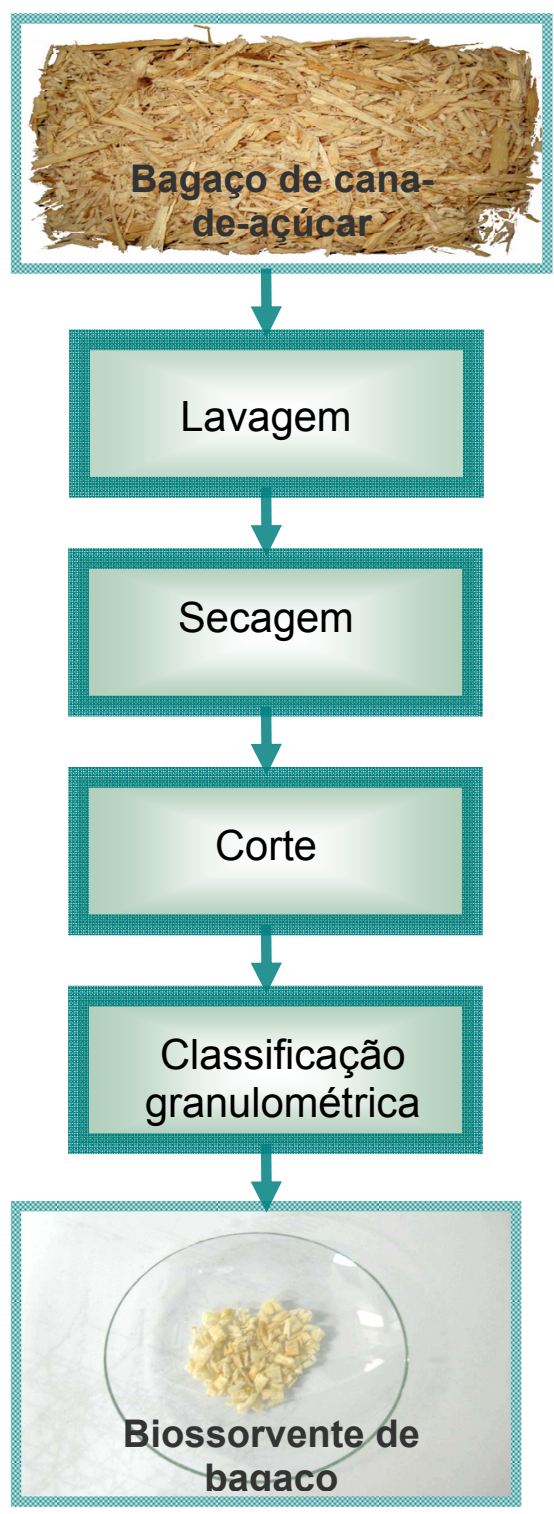

FIGURA 5.1 - Processo de preparação do biossorvente de bagaço.

\subsubsection{Preparação do Biossorvente Magnético}

Para a preparação do biossorvente magnético, parte do biossorvente de bagaço obtido segundo o procedimento descrito no item anterior, foi termicamente tratado na mufla a $300^{\circ} \mathrm{C}$ por 30 min e reservado (FIG. 5.2). 


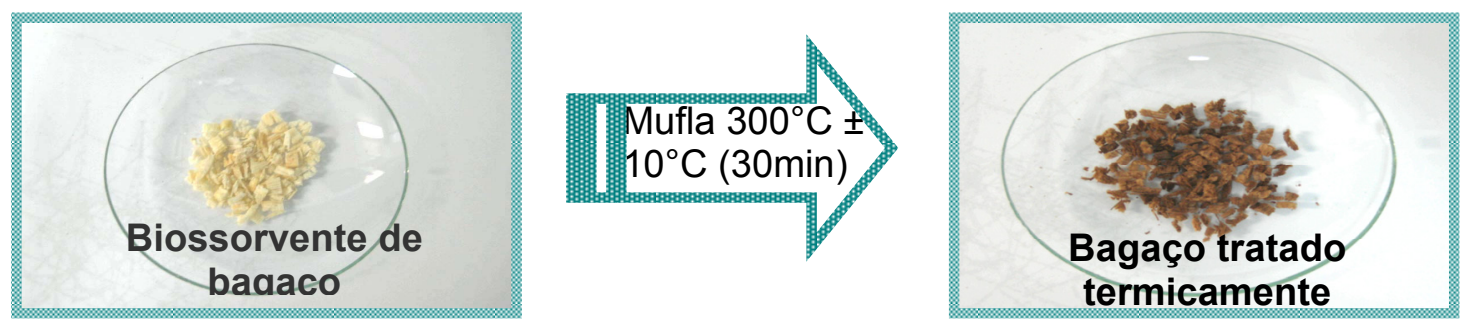

FIGURA 5.2 - Tratamento térmico do biossorvente.

Partículas de magnetita no biossorvente foram obtidas adicionando-se $0,25 \mathrm{~g}$ de material reservado a $50 \mathrm{~mL}$ de solução aquosa contendo $0,21 \mathrm{~g} \mathrm{Fe}$ (cloreto de ferro II tetrahidratado) e $0,31 \mathrm{~g} \mathrm{Fe}^{3+}$ (cloreto de ferro III hexahidratado) em uma relação molar 1:2. O sistema permaneceu sob agitação durante 1 hora. Em seguida, adicionou-se $\mathrm{NaOH} 5$ mol. $\mathrm{L}^{-1}$ até atingir $\mathrm{pH} 11$, à temperatura ambiente, com o objetivo de precipitar a magnetita, $\mathrm{FeO} . \mathrm{Fe}_{2} \mathrm{O}_{3}$, segundo a reação da equação 5.1 .

$$
\begin{array}{r}
\mathrm{Fe}^{2+}+2 \mathrm{Fe}^{3+}+8 \mathrm{OH}^{-} \longrightarrow \underset{\mathrm{FeO}^{-} \mathrm{Fe}_{2} \mathrm{O}_{3}+4 \mathrm{H}_{2} \mathrm{O}}{\longrightarrow} \\
\text { O sistema foi mantido sob agitação e fervura durante } 30 \mathrm{~min} .
\end{array}
$$

Descartou-se o sobrenadante e o bagaço foi lavado com água destilada até atingir o pH 7. Repetiu-se o processo de precipitação. $O$ produto foi seco na estufa a $100^{\circ} \mathrm{C}$. O novo biossorvente foi chamado de biossorvente magnético. Todo o processo de preparação do biossorvente magnético está esquematizado nas FIG. 5.3 e FIG. 5.4 .

A FIG. 5.5 ilustra o arranjo experimental utilizado. A foto mostra a segunda etapa do processo de precipitação da magnetita no biossorvente. O béquer contém as partículas de biossorvente com magnetita incorporada na solução de $\mathrm{Fe}^{2+} / \mathrm{Fe}^{3+}$, sob agitação. 


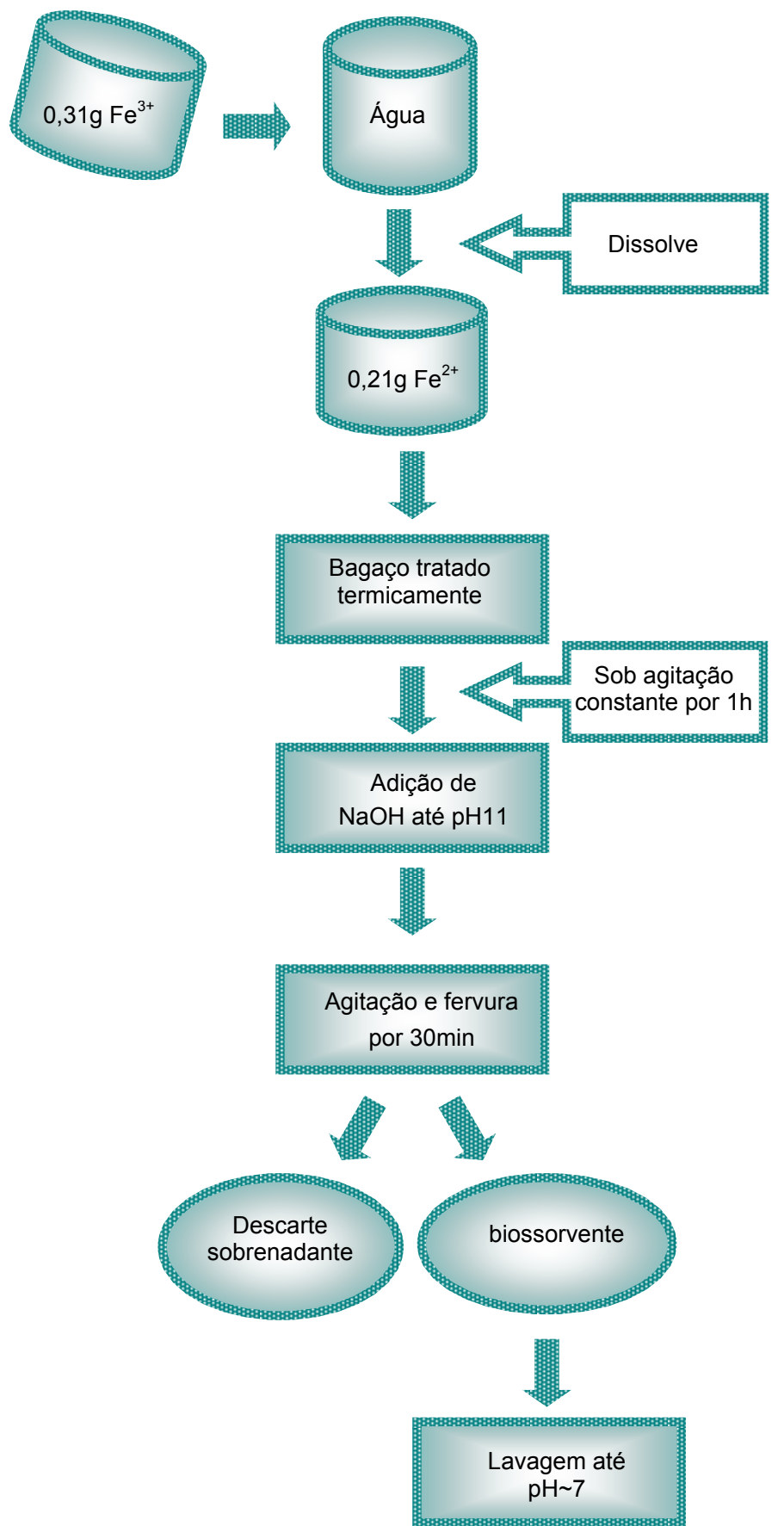

FIGURA 5.3 - Preparação do biossorvente magnético - $1^{2}$ etapa. 


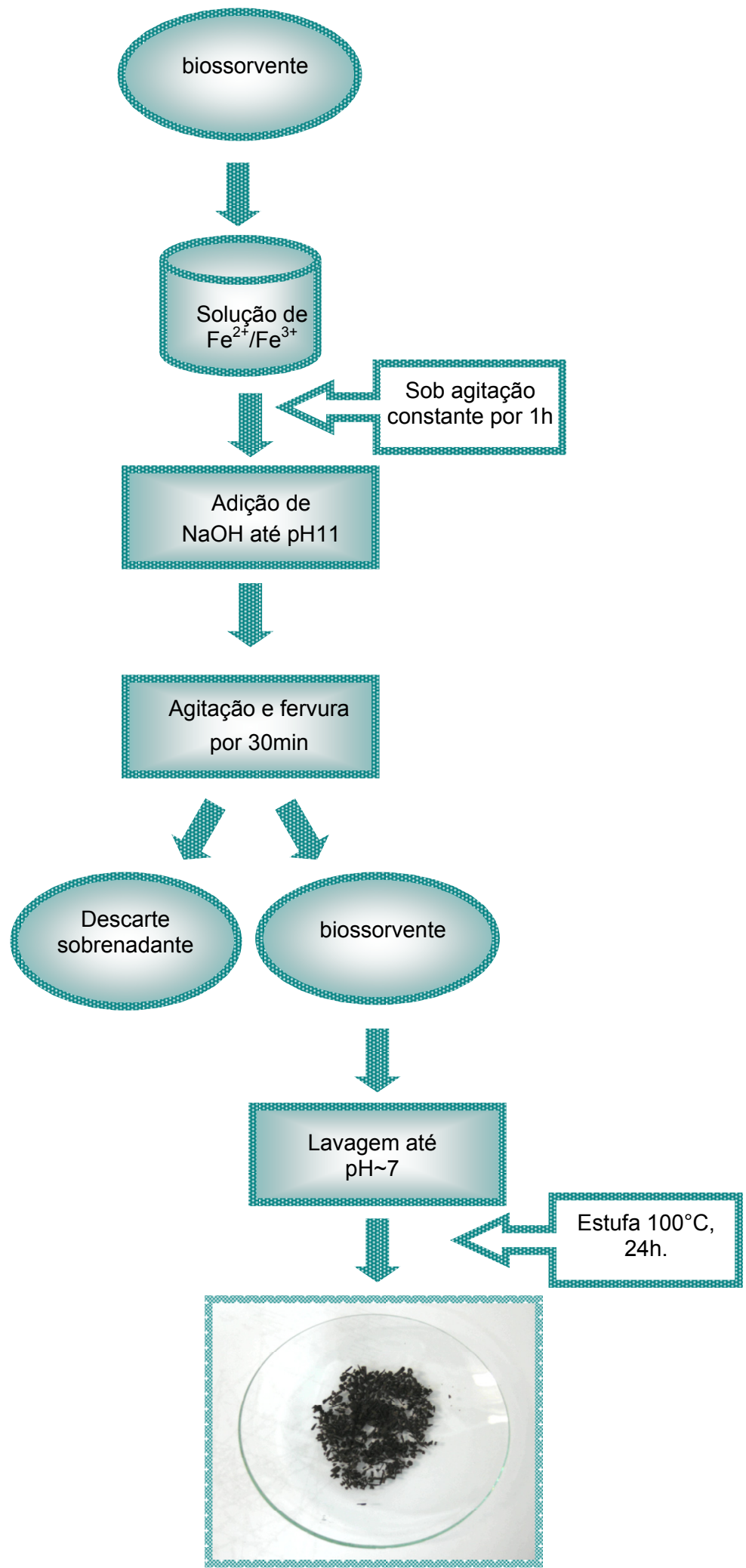

FIGURA 5.4 - Preparação do biossorvente magnético - $2^{a}$ etapa. 


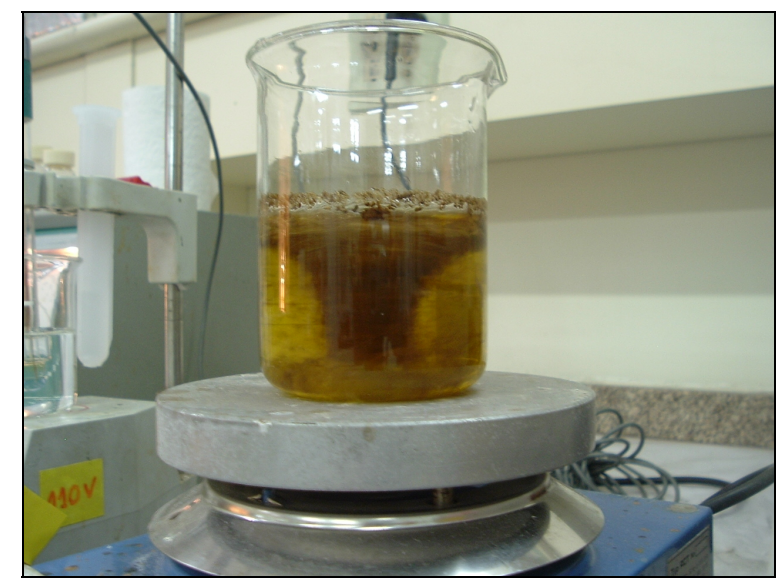

FIGURA 5.5 - Foto da preparação do biossorvente magnético.

\subsection{Preparação das Soluções de Urânio}

\subsubsection{Preparação das Soluções de Urânio em Diferentes Valores de pH}

A partir de uma solução estoque de $U$ (nitrato de uranilo $130,07 \mathrm{~g} \cdot \mathrm{L}^{-1}$ ), de procedência do Centro de Química e Meio Ambiente (CQMA) do IPEN, foram preparadas por diluição soluções com concentração de $U$ de $0,1 \mathrm{~g} \cdot \mathrm{L}^{-1}$, para os $\mathrm{pH} 2$, $3,4,5$ e 10. As diluições foram realizadas com água destilada e o pH ajustado ao valor desejado com adição de $\mathrm{NaOH}$ ou $\mathrm{HNO}_{3}$.

\subsubsection{Preparação das Soluções de Urânio com Concentrações Diferentes}

A partir de uma solução estoque de $U$ (nitrato de uranilo $130,07 \mathrm{~g} \cdot \mathrm{L}^{-1}$ ), foram preparadas soluções de $U$ de $0,05 \mathrm{~g} . \mathrm{L}^{-1}, 0,10 \mathrm{~g} \cdot \mathrm{L}^{-1}, 0,15 \mathrm{~g} \cdot \mathrm{L}^{-1}, 0,20 \mathrm{~g} \cdot \mathrm{L}^{-1}, 0,30$ g. $\mathrm{L}^{-1}$ e de $0,40 \mathrm{~g} \cdot \mathrm{L}^{-1}$. O pH foi fixado e ajustado em $\mathrm{pH} 5$ com solução de $\mathrm{NaOH}$.

\subsection{Caracterização}

Os dois biossorventes magnético e de bagaço foram caracterizados quanto à morfologia utilizando um microscópio eletrônico de varredura, identificaram- 
se os elementos com número atômico igual ou superior a 4 por espectroscopia de energia dispersiva. As amostras foram recobertas com um filme de Au.

Obtiveram-se espectros na região de infravermelho dos dois biossorventes, utilizando o espectrômetro Nesus 670 FTIR da Thermo Nicolet, cujas bandas de absorção correspondentes aos grupos funcionais foram comparadas e identificadas. As amostras foram misturadas com $\mathrm{KBr}$ e prensadas para formar pastilhas.

Os difratogramas de raios-X dos compostos foram obtidos em um difratômetro da Rigaku com auto-alinhamento, acoplado a um monocromador, PHA e a um sistema óptico totalmente automatizado, utilizando radiação $\mathrm{CuK}_{\alpha 1}(\lambda=1,5406$ $\AA$ ), a $40 \mathrm{kV}$ e $20 \mathrm{~mA}$, no intervalo de $2 \theta$ de $10^{\circ}$ a $100^{\circ}$, a uma velocidade de varredura de $1^{\circ}$ por minuto em etapas de $0,02^{\circ}$. Utilizou-se o método do pó para a análise das amostras.

A análise de termogravimetria (TGA) das amostras foi realizada em uma termobalança Mettler Toledo com módulo TGA/SDTA 851 e acoplado a um controlador de fluxo de gases módulo TSO800GC1, com o software Star (gerenciador de sistema). As massas iniciais em torno de $\sim 10 \mathrm{mg}$, foram aquecidas a uma taxa de $10^{\circ} \mathrm{C} \cdot \mathrm{min}^{-1} \mathrm{sob}$ atmosfera de $\mathrm{N}_{2}$ e de $\mathrm{O}_{2}$ com vazão $50 \mathrm{~cm}^{3} \cdot \mathrm{min}^{-1}$ utilizando-se panelinhas de alumínio.

Medida de magnetização do biossorvente magnético foi obtida, à temperatura ambiente, em um campo magnético de até $15 \mathrm{kOe}$, utilizando um magnetômetro de amostra vibrante, marca Princeton Applied Research, modelo 4500.

\subsection{Processo de Adsorção}

Todos os estudos de adsorção com os biossorventes de bagaço e magnético foram realizados segundo o procedimento em batelada (ensaio "batch"). O sistema composto por $2 \mathrm{~mL}$ de solução de nitrato de uranilo e uma dada massa de biossorvente foi mantido em contato sob agitação, com uma determinada 
velocidade, durante um intervalo de tempo, utilizando-se, para tanto, um agitador. Em se tratando do biossorvente magnético, a separação deste da fase líquida (sobrenadante) ocorreu por meio da aplicação de um campo magnético. A FIG. 5.6 mostra o esquema do procedimento utilizado nos estudos de adsorção com o biossorvente magnético. A separação do biossorvente de bagaço da fase aquosa, chamada sobrenadante, foi realizada por meio de filtração.

Determinou-se a concentração de urânio remanescente no sobrenadante por espectrofotometria de UV-vis. Determinou-se a quantidade de U adsorvida pelos dois biossorventes pela diferença entre a concentração de urânio na solução inicial e na fase aquosa do sobrenadante segundo a equação 5.2.. Os experimentos de adsorção foram realizados em triplicata.

$$
\text { \%remoção }=\underline{\left(\mathrm{C}_{0}\right.} \underline{-\mathrm{C})} \times 100
$$

$\mathrm{C}_{0}$

Sendo:

$\mathrm{C}_{0}$ é a concentração $\left(\mathrm{mg} \cdot \mathrm{L}^{-1}\right)$ de íons $\mathrm{UO}_{2}{ }^{2+}$, antes do contato;

$\mathrm{C}$ é a concentração $\left(\mathrm{mg} \cdot \mathrm{L}^{-1}\right)$ de íons $\mathrm{UO}_{2}{ }^{2+}$, após o contato. 


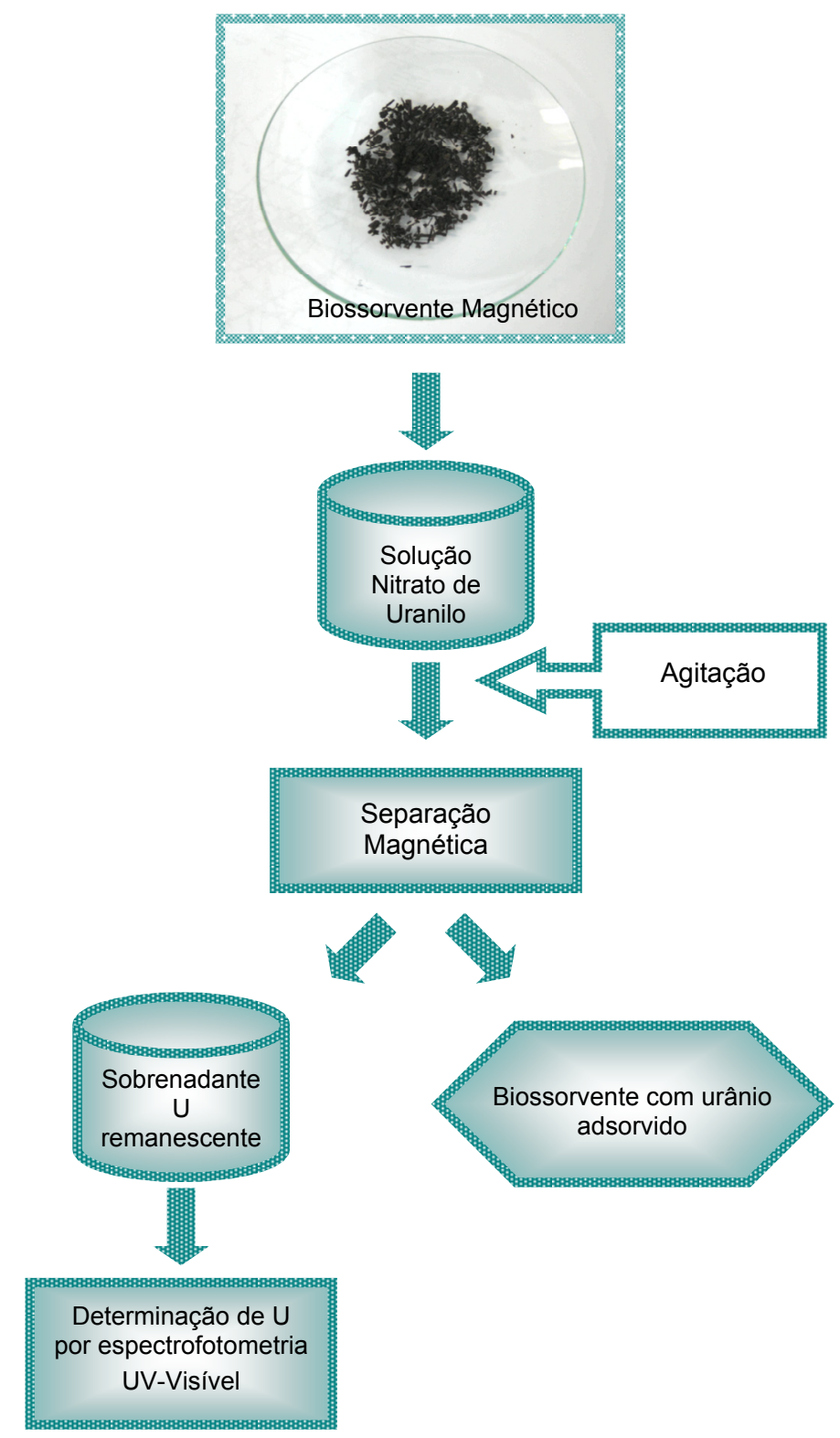

FIGURA 5.6 - Procedimento experimental para estudos de adsorção do biossorvente magnético.

A quantidade de urânio adsorvida por grama de biossorvente, ou seja, a capacidade de adsorção foi calculada pela diferença entre as concentrações encontradas nas soluções inicial e no sobrenadante, multiplicado pelo volume de solução inicial e dividido pela massa do biossorvente. A capacidade de adsorção foi determinada pela equação 5.3 [96]. 


$$
\text { Capacidade de adsorção }\left(m g \cdot g^{-1}\right)=\left(C_{0}-C\right) \times \text { V/M }
$$

Sendo:

$\checkmark$ é o volume da solução de íons uranilo (L) em contato com o biossorvente;

M é a massa (g) de biossorvente.

\subsection{Análise Espectrofotométrica de U(VI)}

Realizou-se a determinação da concentração de $U$ pelo método do Arsenazo III, utilizando o Espectrofotômetro UV-Visível.

Uma alíquota da solução de cada batelada realizada foi colocada em um balão volumétrico de $5 \mathrm{~mL}$. Adicionaram-se, na seqüência, $150 \mu \mathrm{L}$ de ácido ascórbico na concentração de $15 \mathrm{~g} \cdot \mathrm{L}^{-1}, 100 \mu \mathrm{L}$ de ácido nítrico $0,56 \mathrm{~mol} . \mathrm{L}^{-1}, 1,5 \mathrm{~mL}$ de arsenazo III $0,06 \%$ e completou-se com água destilada. O branco foi preparado nas mesmas condições, porém, sem a amostra de U. Realizou-se a leitura de absorbância do complexo $\mathrm{UO}_{2}{ }^{2+}$ - arsenazo III no comprimento de onda igual a 650 $\mathrm{nm}$. A diferença entre duas medidas foi menor ou igual a $5 \%$. Por meio da curva de calibração, cada leitura de absorbância foi convertida em massa de $U$ correspondente. Dessa forma, determinou-se o valor da concentração de $U$ no sobrenadante e na solução inicial.

\subsubsection{Determinação do Comprimento de Onda e Curva de Calibração para o Complexo U-Arsenazo III}

Preparou-se uma amostra de $\mathrm{UO}_{2}{ }^{2+}$ - arsenazo III e realizaram-se as leituras de absorbância da solução no intervalo de comprimento de onda de 600 a $700 \mathrm{~nm}$ a fim de obter o espectro de absorção (FIG. 5.7) do complexo $\mathrm{UO}_{2}{ }^{2+}$ arsenazo III e a leitura de absorbância máxima.

Da figura obteve em máxima absorbância, o valor de comprimento de onda de análise igual a $650 \mathrm{~nm}$. 


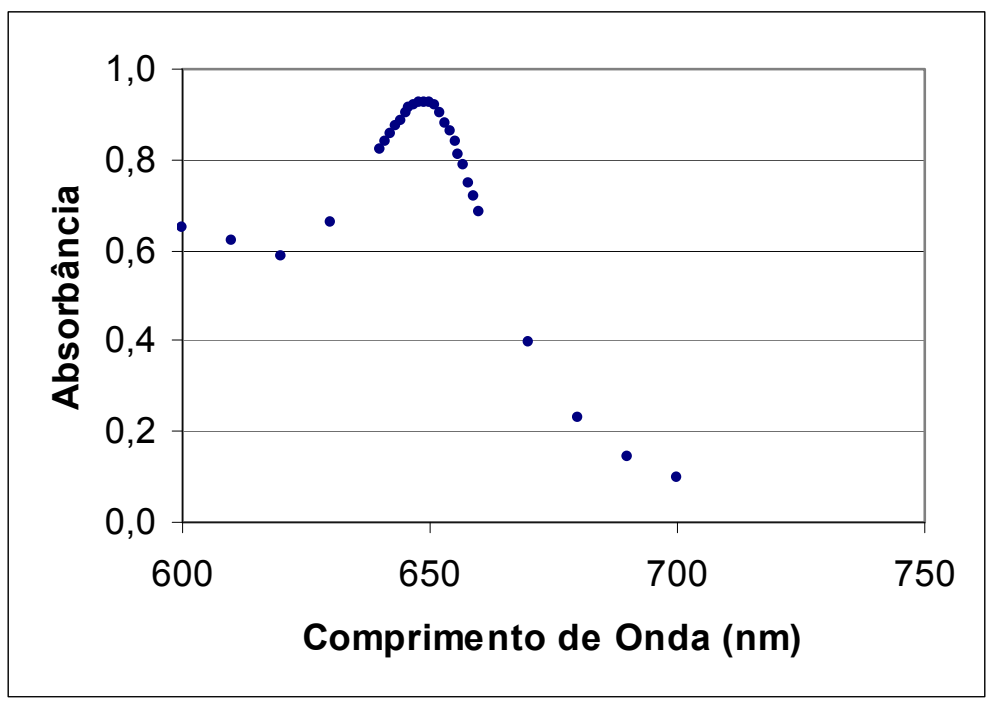

FIGURA 5.7 - Relação entre absorbância e o comprimento de onda ( $\mathrm{nm})$ do complexo $\mathrm{UO}_{2}{ }^{2+}$ - arsenazo III.

Prepararam-se amostras contendo diferentes massas de $U(\mu g)$ e mediram-se a respectiva absorbância em $650 \mathrm{~nm}$. Os valores de absorbância correspondente a cada massa de urânio foram colocados em um gráfico e obteve-se a curva de calibração representada pela equação 5.4:

$$
y=0,0505 x+0,0124
$$

Sendo:

$$
\begin{aligned}
& x=\text { massa de } U(\mu g) ; \\
& y=\text { absorbância. } \\
& r^{2}=0,9994 \text { (coeficiente de correlação linear) }
\end{aligned}
$$

Esta curva de calibração do U foi utilizada para determinar a concentração de $U$ das amostras provenientes de todos os ensaios de adsorção. A precisão considerada para cada medida foi de $7 \%$. 


\section{RESULTADOS E DISCUSSÃO}

\subsection{Caracterização do Biossorvente Magnético e do Biossorvente de Bagaço}

As partículas de biossorvente magnético apresentaram-se na cor preta e magnéticas. Estudo de caracterização foi realizado com a finalidade de comprovar a presença de magnetita e o nível de magnetização do material. A FIG. 6.1 ilustra o biossorvente de bagaço. As FIG. 6.2 e FIG. 6.3 ilustram o biossorvente magnético na ausência e na presença de um campo magnético.

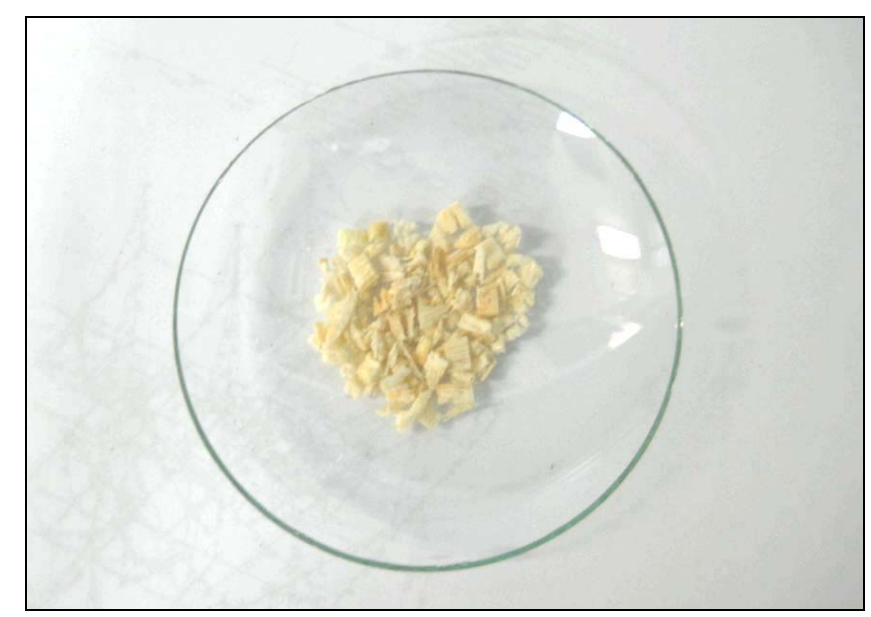

FIGURA 6.1 - Biossorvente de bagaço.

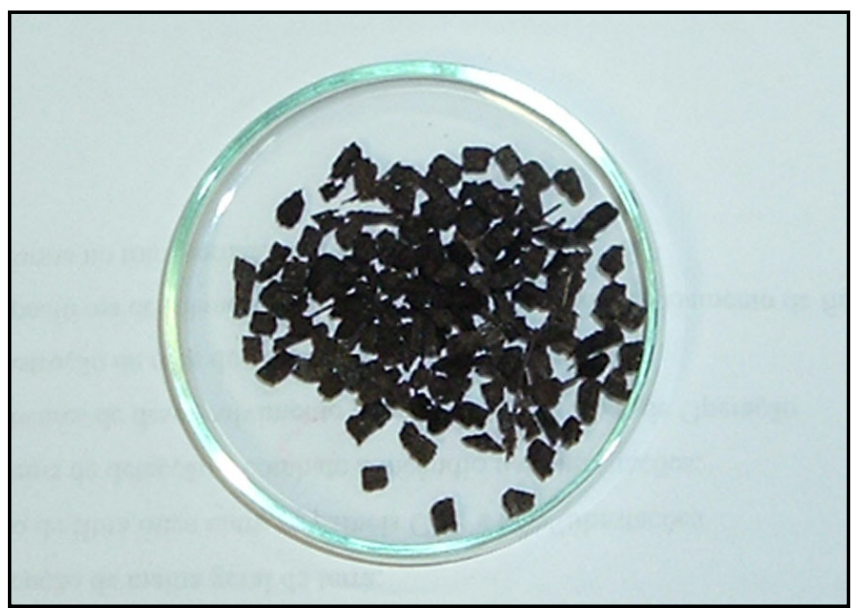

FIGURA 6.2 - Biossorvente magnético. 


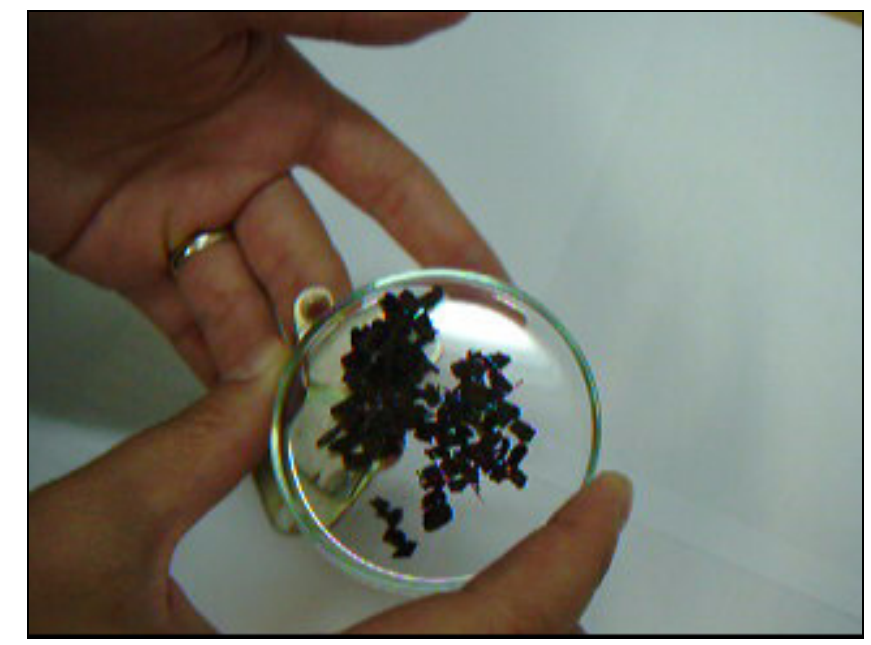

FIGURA 6.3 - Biossorvente magnético sob a ação do campo magnético.

\subsubsection{Microscopia Eletrônica de Varredura}

Uma análise por microscopia eletrônica de varredura foi realiza a fim de comparar a morfologia das partículas de biossorvente magnético e do biossorvente de bagaço.

As FIG. 6.4a e 6.4b ilustram o biossorvente de bagaço como um material tubular e fragmentado, apresentando pressupostos poros e veios. As micrografias ilustradas nas FIG. 6.5a e 6.5b referentes ao biossorvente magnético mostram um material aparentemente danificado com incrustação de particulados nas fibras tubulares possivelmente devido ao tratamento térmico e à presença de partículas de magnetita de tamanhos variados em toda a extensão da superfície do biossorvente. 

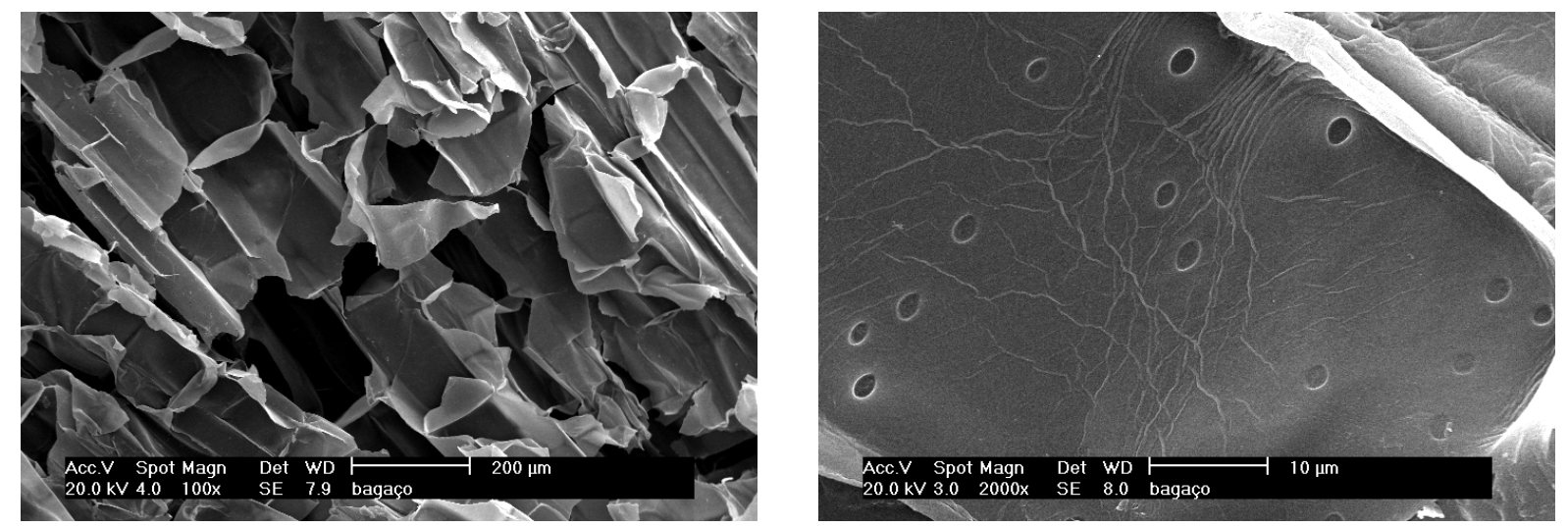

FIGURA 6.4a e 6.4b - Micrografia eletrônica de varredura do biossorvente de bagaço. Aumento de 100 e 2000 vezes.
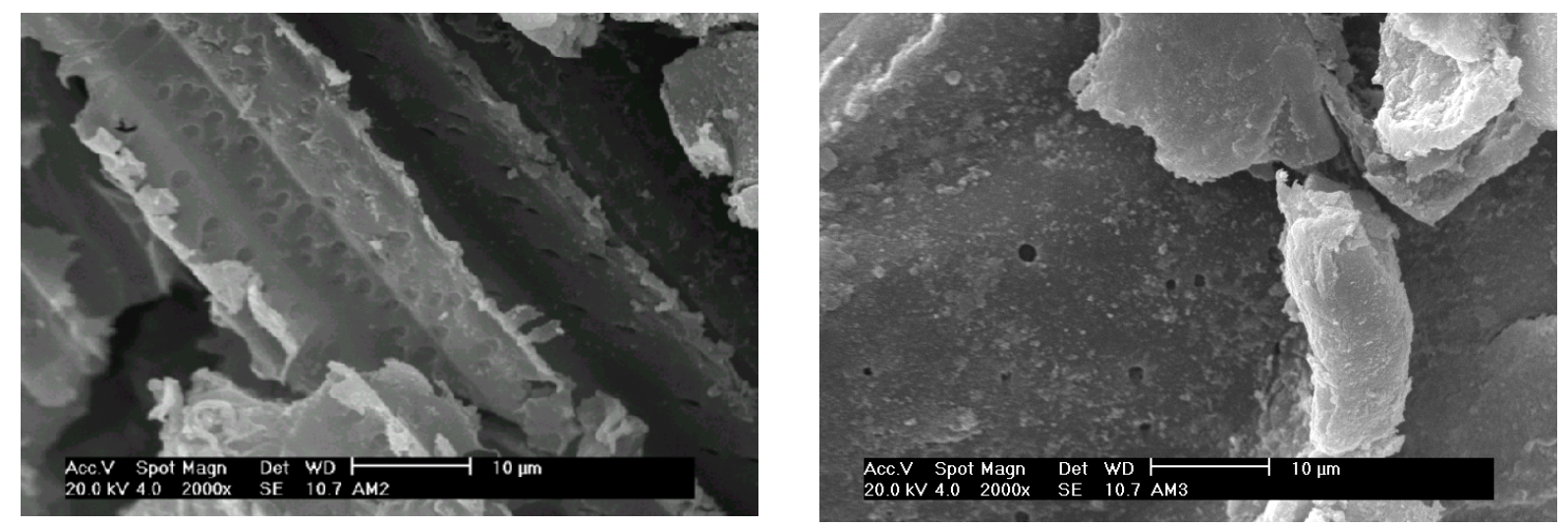

FIGURA 6.5a e 6.5b - Micrografia eletrônica de varredura do biossorvente magnético. Aumento de 2000 vezes.

Os espectros de fluorescência de raios-X obtidos por EDS acusaram a presença de $\mathrm{C}$ e $\mathrm{O}$ de natureza orgânica dos biossorventes observados nas FIG. 6.6 e 6.7. Devido ao tratamento térmico submetido, o biossorvente magnético é composto por menos carbono em relação ao oxigênio como mostra a FIG. 6.6. O pico do elemento Fe foi observado comprovando a presença da magnetita no composto. Ouro é o material utilizado na preparação das amostras para análise por microscopia eletrônica de varredura. 


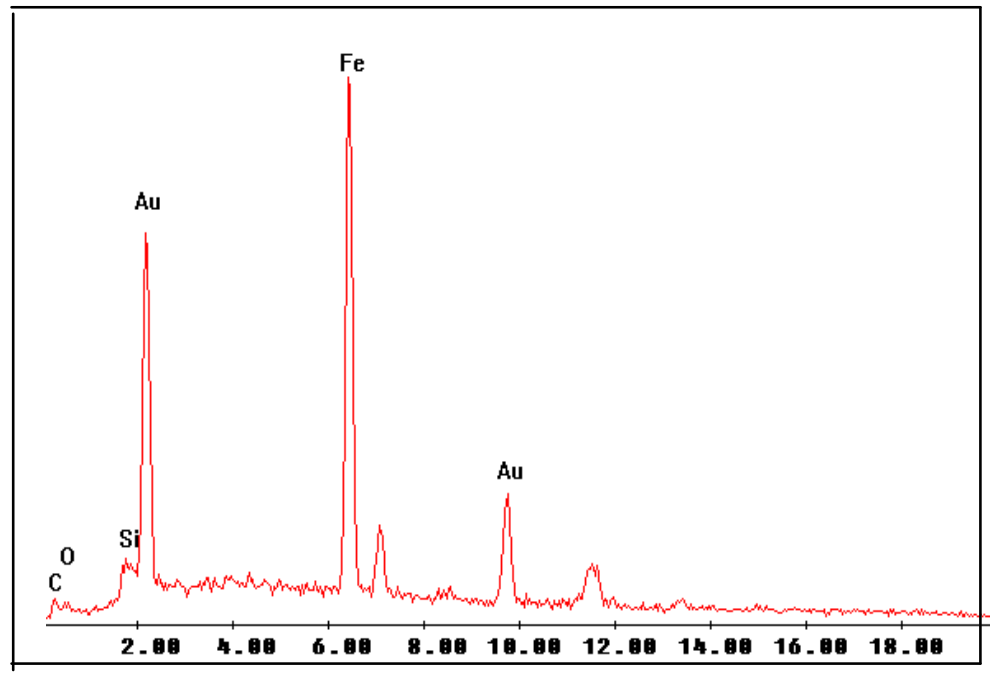

FIGURA 6.6 - Espectro de energia dispersiva do biossorvente magnético.

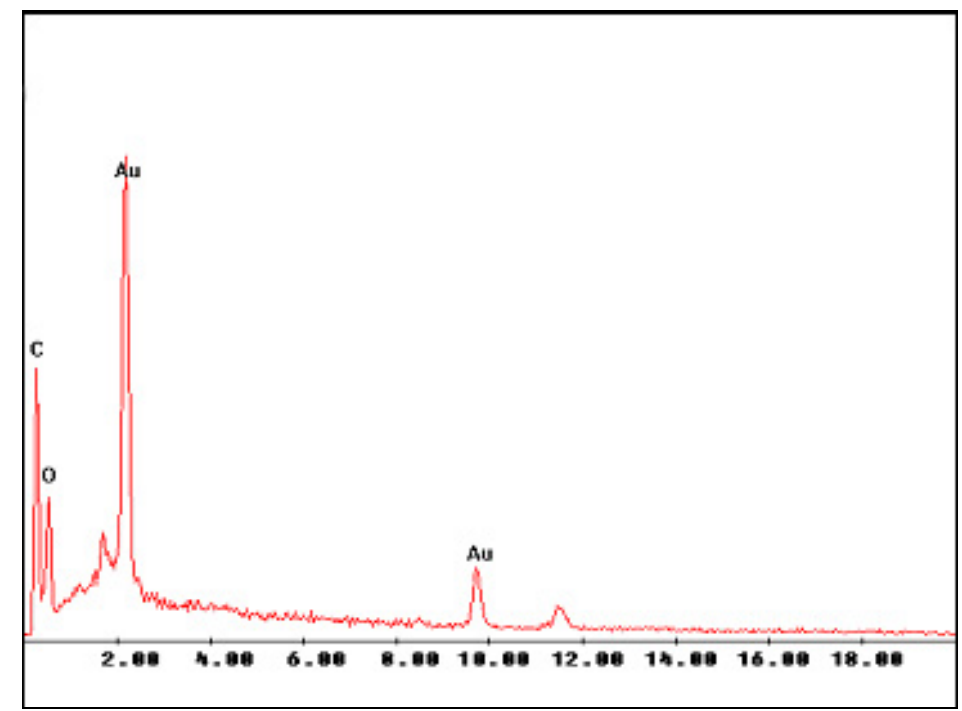

FIGURA 6.7 - Espectro de energia dispersiva do biossorvente de bagaço. 


\subsubsection{Espectro de Absorção na Região do Infravermelho}

Com o propósito de identificar os grupos funcionais do biossorvente magnético e do biossorvente de bagaço obtiveram-se os espectros de absorção na região do infravermelho. O espectro na região do infravermelho do biossorvente de bagaço está mostrado na FIG. 6.8 e do biossorvente magnético na FIG. 6.9. Um breve resumo das atribuições das bandas observadas foi apresentado nas TAB. 6.1 e TAB. 6.2.

Devido à composição química celulósica, constituída principalmente de celulose, hemicelulose e lignina, o biossorvente de bagaço apresenta espectro de absorção no infravermelho muito complexo na região de $1500 \mathrm{~cm}^{-1}$ a $500 \mathrm{~cm}^{-1}$ [97] como pode ser observado na FIG. 6.8.

Da FIG. 6.9, a banda de absorção na região de $604 \mathrm{~cm}^{-1}$ a $565 \mathrm{~cm}^{-1}$ foi atribuída às ligações Fe-O e Fe-O-Fe da magnetita, de forma que, esta observação é a evidência da incorporação de partículas de magnetita no bagaço de cana-deaçúcar, confirmada pela coloração e magnetismo observados.

A carga negativa da estrutura de hidrocarbonetos dos biossorventes pode ser representada pelos grupos funcionais $\mathrm{OH}$ e $\mathrm{C}=\mathrm{O}$ dos álcoois, cetonas, ésteres e anéis aromáticos presentes, os quais são os sítios ativos responsáveis pela propriedade adsortiva.

Comparando-se o espectro de absorção do biossorvente magnético com o do biossorvente de bagaço, notou-se uma redução significativa na intensidade das bandas observadas na região de $3500 \mathrm{~cm}^{-1}$ a $1056 \mathrm{~cm}^{-1}$ relativas às vibrações das ligações $\mathrm{C}=\mathrm{O}, \mathrm{C}-\mathrm{O}$ e $\mathrm{C}-\mathrm{H}$ da estrutura celulósica do bagaço. Esta observação sugere a ocorrência de uma modificação química na estrutura do bagaço durante o tratamento térmico a que foi submetido na obtenção do biossorvente magnético. A redução na intensidade das bandas em $1726 \mathrm{~cm}^{-1}, 1638 \mathrm{~cm}^{-1}$ e $1258 \mathrm{~cm}^{-1}$ do bagaço pode ser atribuída à remoção parcial ou total de lignina e hemicelulose [98] 0 aparecimento da banda em $1037 \mathrm{~cm}^{-1}$ característica do estiramento da ligação C-O da hidroxila, provavelmente, é relativa à formação de grupamentos álcoois e fenóis 
resultantes da clivagem de ligações éter e carbono-carbono no processo de degradação térmica da lignina $[99,100]$.

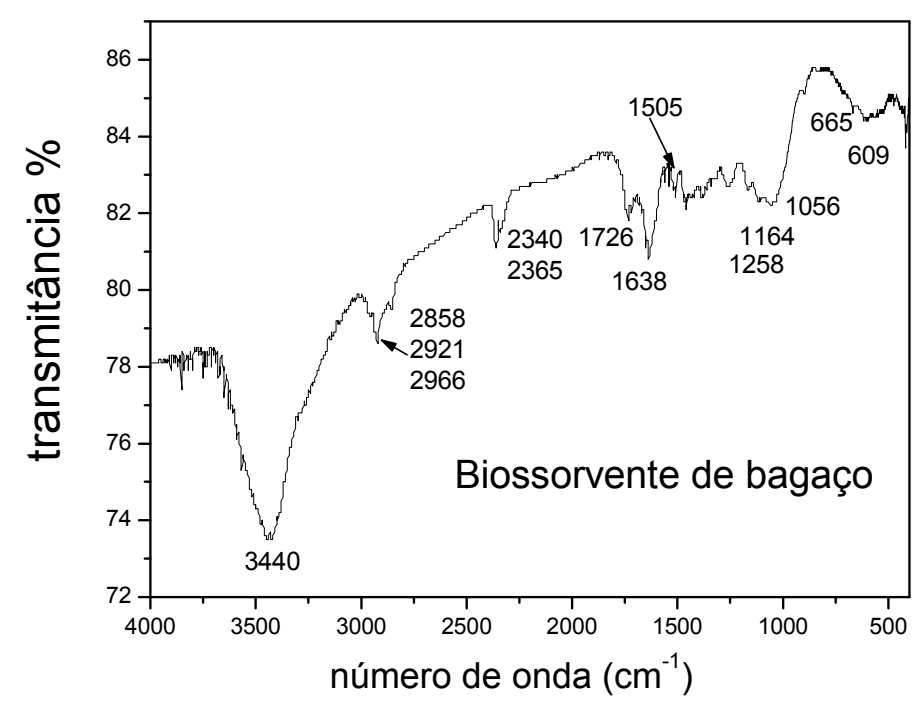

FIGURA 6.8 - Espectro de absorção no infravermelho do biossorvente de bagaço na região de $4000 \mathrm{~cm}^{-1}$ a $400 \mathrm{~cm}^{-1}$. 
TABELA 6.1 - Bandas de absorção na região do infravermelho do biossorvente de bagaço.

\begin{tabular}{ll}
\hline Banda de absorção $\left(\mathbf{c m}^{-1}\right)$ & \multicolumn{1}{c}{ Vibração } \\
\hline 3440 & estiramento $-\mathrm{OH}$ do álcool e fenol, e de \\
& $\mathrm{H}_{2} \mathrm{O}$ adsorvido
\end{tabular}

2966-2858

estiramento $\mathrm{C}-\mathrm{H}$ dos alcanos dos carboidratos (celulose e hemicelulose) e anel aromático da lignina

$2340 / 2365$

contaminação de $\mathrm{CO}_{2}$

1726

estiramento de $\mathrm{C}=\mathrm{O}$ de cetonas não conjugadas, éster da lignina e hemicelulose

estiramento de $\mathrm{C}=\mathrm{O}$ de cetona e aldeído conjugados que podem formar a cadeia de lignina e hemicelulose; deformação $\mathrm{H}$ $\mathrm{O}-\mathrm{H}$ de $\mathrm{H}_{2} \mathrm{O}$ adsorvido, $\mathrm{OH}$ de $\mathrm{C}=\mathrm{O}$ do anel aromático glicose

$665 / 609$ deformação C-H fora do plano dos aromáticos da lignina 


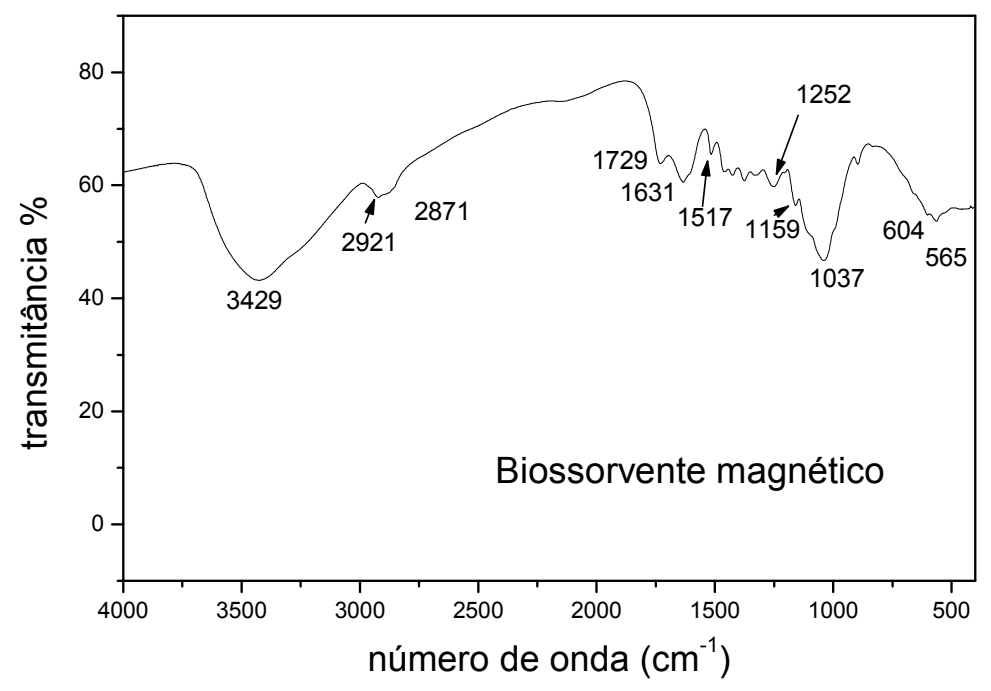

FIGURA 6.9 - Espectro de absorção no infravermelho do biossorvente magnético na região de $4000 \mathrm{~cm}^{-1}$ a $400 \mathrm{~cm}^{-1}$. 
TABELA 6.2 - Bandas de absorção na região do infravermelho do biossorvente magnético.

\begin{tabular}{|c|c|}
\hline Banda de absorção $\left(\mathrm{cm}^{-1}\right)$ & Vibração \\
\hline 3429 & $\begin{array}{l}\text { Estiramento }-\mathrm{OH} \text { do álcool e fenol e } \mathrm{H}_{2} \mathrm{O} \\
\text { adsorvido }\end{array}$ \\
\hline $2921-2871$ & $\begin{array}{l}\text { estiramento } \mathrm{C}-\mathrm{H} \text { dos alcanos dos } \\
\text { carboidratos }\end{array}$ \\
\hline 1729 & $\begin{array}{l}\text { estiramento de } \mathrm{C}=\mathrm{O} \text { de cetonas não } \\
\text { conjugadas }\end{array}$ \\
\hline 1631 & $\begin{array}{l}\text { deformação } \mathrm{H}-\mathrm{O}-\mathrm{H} \text { de } \mathrm{H}_{2} \mathrm{O} \text { adsorvido, } \\
\mathrm{OH} \text { dos álcoois. }\end{array}$ \\
\hline 1517 & vibrações do anel fenol \\
\hline 1252 & estiramento de $\mathrm{C}=\mathrm{O}$ \\
\hline 1159 & $\begin{array}{l}\text { C-C com estiramento de } \mathrm{C}=\mathrm{O} \text { do anel } \\
\text { aromático }\end{array}$ \\
\hline 1037 & C-O da hidroxila dos álcoois e fenóis \\
\hline $604 / 565$ & caracterizadas por $\mathrm{Fe}-\mathrm{O}$, Fe-O-Fe \\
\hline
\end{tabular}




\subsubsection{Difração de Raios-X}

A análise por difração de raios- $X$ foi realizada com o objetivo de identificar a magnetita e comparar os dois materiais biossorventes, segundo os procedimentos descritos no item 5.4 .

A FIG. 6.10 mostra os difratogramas de raios-X do biossorvente magnético e do biossorvente de bagaço.

No biossorvente magnético observaram-se os picos característicos do padrão de referência de magnetita (JCPDS - ICDD19 - 629), ausentes no biossorvente de bagaço confirmando a presença de magnetita. A Tabela 6.3 mostra os picos de difração observados relacionados com os do padrão.

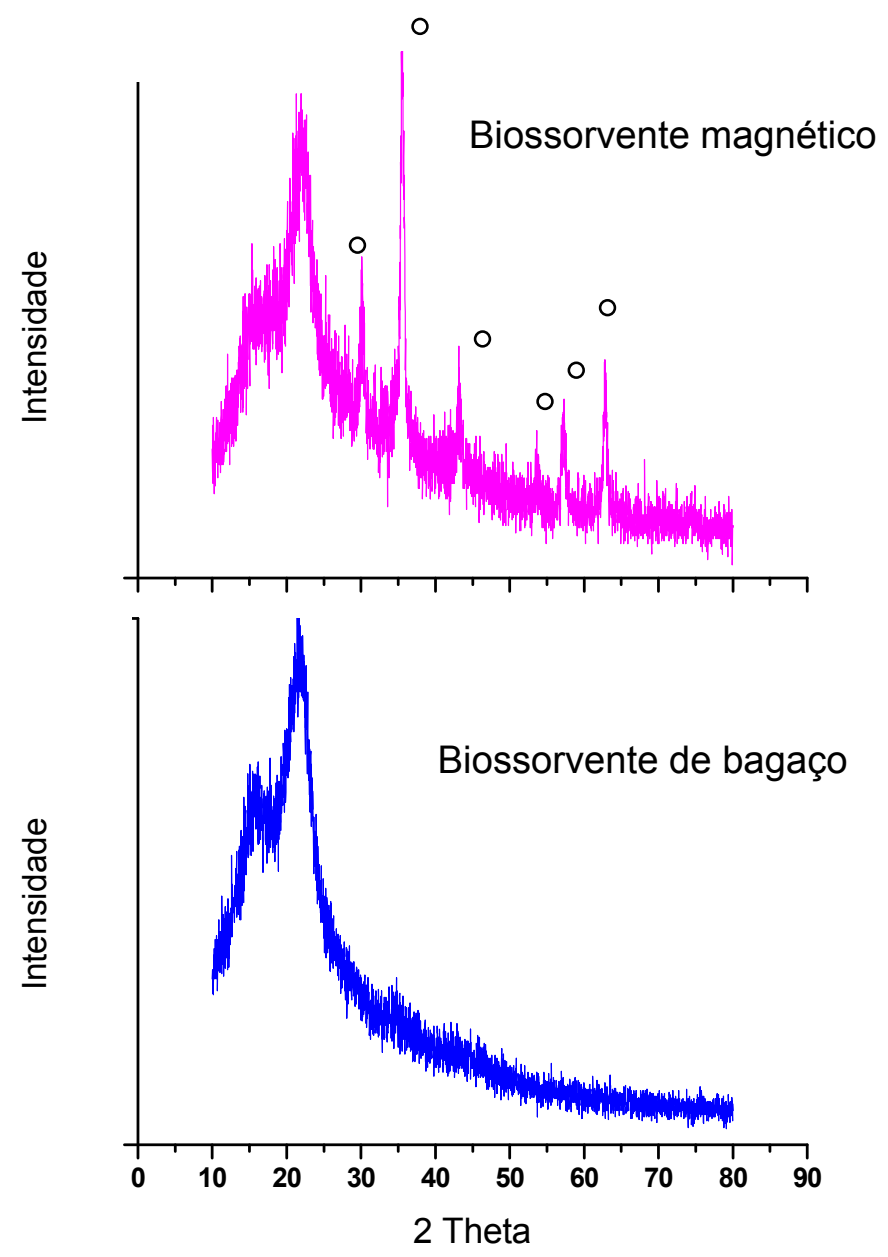

FIGURA 6.10 - Difratogramas do biossorvente magnético e biossorvente de bagaço. $\left({ }^{\circ}\right)$ Picos característicos da magnetita para a radiação incidente CuKa (JCPDS - ICDD 19 - 629). 
Tabela 6.3 - Relação dos picos de difração do biossorvente magnético e do padrão de referência de magnetita (JCPDS - ICDD 19 - 629).

\begin{tabular}{cccc}
\hline $\begin{array}{c}\text { Ângulo 2 } \boldsymbol{\theta} \\
\text { biossorvente magnético }\end{array}$ & $\begin{array}{c}\text { Intensidade } \\
\text { biossorvente magnético }\end{array}$ & $\begin{array}{c}\text { Ângulo 2 } \boldsymbol{\theta}_{\text {padrão de }} \\
\text { referência }\end{array}$ & $\begin{array}{c}\text { Intensidade padrão de } \\
\text { referência }\end{array}$ \\
\hline 35,6 & 100 & 35,422 & 100 \\
30,1 & 39 & 30,095 & 30 \\
62,8 & 40 & 62,515 & 40 \\
43,3 & 32 & 43,052 & 20 \\
57,3 & 29 & 56,942 & 30 \\
53,6 & 17 & 53,391 & 10 \\
\hline
\end{tabular}

\subsubsection{Análise de Termogravimetria (TGA)}

Realizou-se análise termogravimétrica com o objetivo de verificar a diferença na estrutura química entre os biossorventes. Por meio dessa análise é possível prever a estrutura química mediante a destruição térmica dos compostos orgânicos voláteis. As curvas das FIG. 6.11 e 6.12 mostram os termogramas de perda de massa com aumento da temperatura sob atmosfera de $\mathrm{O}_{2}$ e $\mathrm{N}_{2}$.

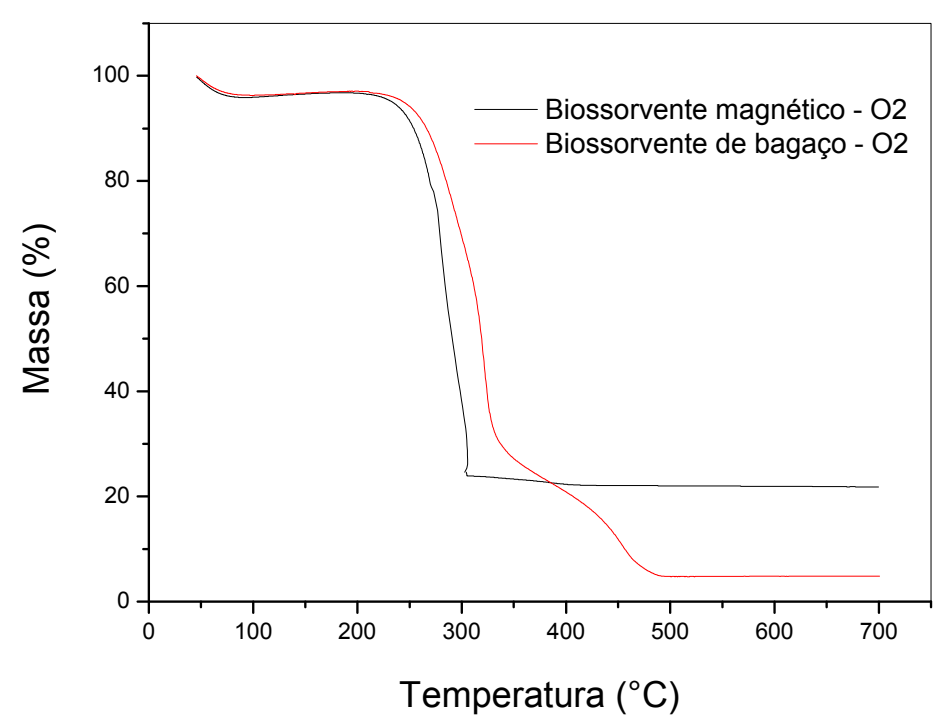

FIGURA 6.11 - Curva termogravimétrica do biossorvente magnético e biossorvente de bagaço sob atmosfera de $\mathrm{O}_{2}$. 


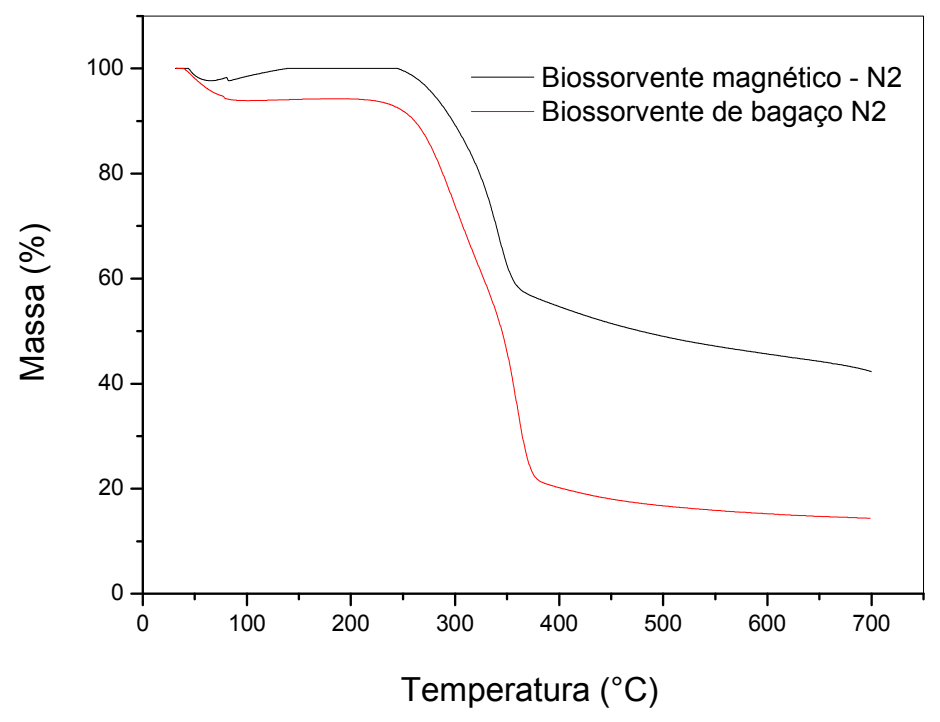

FIGURA 6.12 - Curva termogravimétrica do biossorvente magnético e biossorvente de bagaço sob atmosfera de $\mathrm{N}_{2}$.

No biossorvente de bagaço em atmosfera de $\mathrm{O}_{2}$ (FIG. 6.11) é possível perceber a presença de 3 estágios. O primeiro estágio corresponde ao início da análise até $80^{\circ} \mathrm{C}$, e está relacionado à perda de água da amostra, pode-se observar uma perda de massa de $5 \%$. O segundo estágio inicia a partir de $230^{\circ} \mathrm{C}$ a $330^{\circ} \mathrm{C}$ e corresponde à degradação da hemicelulose e celulose, termicamente menos estáveis que a lignina. Segundo Sousa et al. [101] a rápida degradação térmica da celulose e lenta decomposição da lignina podem ser explicadas pelo fato da celulose apresentar um arranjo linear das unidades de D-glicopiranosídeo- $\beta$ unidas ao modo $1 \rightarrow 4$, ao passo que a lignina é um polímero constituído de $\mathrm{p}-\mathrm{OH}$ fenilpropanol interligadas umas às outras por ligações éter, ésteres e/ou C-C. Neste estágio houve uma perda de massa de cerca de $68 \%$. E o terceiro estágio está entre $330^{\circ} \mathrm{C} \mathrm{e}$ $490^{\circ} \mathrm{C}$, acima do qual não apresentou decomposição até a temperatura estudada de $700^{\circ} \mathrm{C}$. Houve uma perda de massa de $22 \%$, correspondendo à completa degradação da lignina. O gráfico mostra a presença de $4 \%$ a $5 \%$ de resíduos na faixa de temperatura estudada. Estes valores estão próximos daqueles apresentados na literatura. Farinella [81] observou no bagaço de uva, por meio da análise térmica em atmosfera oxidante, a completa degradação da celulose a $300^{\circ} \mathrm{C}$ e a degradação da lignina em $400^{\circ} \mathrm{C}$. Sun [102] verificou a estabilidade térmica da 
hemicelulose do bagaço de cana-de-açúcar sob uma atmosfera de ar seco e verificou que esta é estável em temperaturas abaixo de $200^{\circ} \mathrm{C}$, sendo que a maior perda de massa (cerca de $50 \%$ ) ocorreu em $270^{\circ} \mathrm{C}$.

Para o biossorvente magnético, a curva de TGA em atmosfera de $\mathrm{O}_{2}$ mostra que em temperaturas abaixo de $77^{\circ} \mathrm{C}$ a perda de massa foi de $4 \%$ e corresponde à evaporação da água absorvida. A maior perda de massa, $72 \%$ do biossorvente magnético, ocorreu entre $225^{\circ} \mathrm{C}$ e $305^{\circ} \mathrm{C}$ e está relacionada à decomposição total da parte orgânica do biossorvente. O material não apresentou lignina, a qual é caracterizada com perda de massa em $400^{\circ} \mathrm{C}$ [81], confirmando a ocorrência da clivagem da lignina observada no espectro de absorção de infravermelho (Fig. 6.9). Evangelista et. al do Serviço Brasileiro de Respostas Técnicas [103] verificaram que o tratamento do bagaço de cana-de-açúcar à base de pressão e vapor é uma das formas de se aumentar sua digestibilidade auxiliando na quebra das ligações lignina-celulose a fim de ser utilizado na alimentação de ruminantes. O biossorvente magnético apresentou um resíduo de $21 \%$ da massa inicial, até a temperatura estudada de $700^{\circ} \mathrm{C}$, o qual a maior parte foi considerada sendo de magnetita. Nah [104] estudou a preparação de um compósito de zeólita coberto com magnetita por meio da ligação com uretano. A magnetita mostrou-se termicamente estável com perda de massa desprezível até $1000^{\circ} \mathrm{C}$.

De acordo com as curvas de TGA em atmosfera de $\mathrm{O}_{2}$, a massa de magnetita do biossorvente magnético é cerca de 16 a $17 \%$, considerando que de $4 \%$ a $5 \%$ correspondeu ao resíduo natural do bagaço.

A FIG. 6.12 mostra o termograma de perda de massa do biossorvente de bagaço com o aumento de temperatura em atmosfera de $\mathrm{N}_{2}$. Nesta curva, 2 estágios de perda de massa significativos foram considerados. O primeiro estágio correspondeu do início da análise até $88^{\circ} \mathrm{C}$, e está relacionado à perda de água. Houve uma perda de massa de $6 \%$. O segundo estágio compreendeu de $250^{\circ} \mathrm{C}$ a $370^{\circ} \mathrm{C}$. Neste estágio incluiu-se a decomposição da hemicelulose e celulose seguida de lignina. Houve uma perda de massa de $73 \%$. A decomposição térmica ocorre com a fragmentação da estrutura química do bagaço e emissão de compostos voláteis. Neste estágio ocorreu a completa degradação da matéria orgânica do 
bagaço. Acima de $370^{\circ} \mathrm{C}$ não houve perda de massa significativa, permanecendo $15 \%$ de resíduos à temperatura de $700^{\circ} \mathrm{C}$.

De acordo com a FIG. 6.12 para o biossorvente magnético, a perda de massa em atmosfera de $\mathrm{N}_{2}$ ocorreu em 3 estágios. O primeiro estágio compreendeu do início do experimento até $77^{\circ} \mathrm{C}$ e correspondeu a $2 \%$ de perda de água. $\mathrm{O}$ segundo estágio compreendeu a faixa de temperatura de $248^{\circ} \mathrm{C}$ a $350^{\circ} \mathrm{C}$ e está relacionado à decomposição da parte orgânica que compõe o biossorvente magnético. Devido o tratamento térmico inicialmente submetido ao bagaço na obtenção do biossorvente magnético, este material não é constituído principalmente de celulose, hemicelulose e lignina, como foi verificado no estudo do espectro de absorção de infravermelho e no termograma em atmosfera de $\mathrm{O}_{2}$. O terceiro estágio compreende a faixa de temperatura de $350^{\circ} \mathrm{C}$ ao final da análise térmica, que foi atribuído à lenta perda de água de cristalização da estrutura da magnetita e uma possível modificação química para outra estrutura de óxido, como por exemplo, a maghemita ou uma suposta decomposição por reação química secundária com os resíduos naturais do bagaço. Até a temperatura estudada, $700^{\circ} \mathrm{C}$, a magnetita apresentou uma variação na massa com o aumento de temperatura. $\mathrm{Em} 700^{\circ} \mathrm{C}$ houve uma presença de cerca de $42 \%$ de resíduo, o qual foi atribuído como sendo de magnetita com possível presença de outras espécies de óxidos. O termograma do biossorvente magnético mostrou uma parte orgânica menos estável à temperatura em relação ao biossorvente de bagaço, o que pode ser verificado por meio da FIG. 6.12. A maior porcentagem de perda de massa do biossorvente magnético ocorreu em temperatura inferior $\left(350^{\circ} \mathrm{C}\right)$ ao biossorvente de bagaço $\left(370^{\circ} \mathrm{C}\right)$.

O biossorvente magnético apresentou um resíduo final maior em relação ao biossorvente de bagaço. Isso ocorreu porque a magnetita incorporada é bastante estável [104] e correspondeu a aproximadamente $27 \%$ da massa total. 


\subsubsection{Medidas Magnéticas}

O biossorvente magnético apresentou uma boa resposta magnética de modo que se estudou o seu comportamento magnético por meio da curva de magnetização.

Conforme se observa na FIG. 6.13, a curva de magnetização do biossorvente magnético não apresentou histerese [22], sendo este reversível à temperatura ambiente $\left(27^{\circ} \mathrm{C} \pm 2^{\circ} \mathrm{C}\right)$.

O biossorvente magnético respondeu à ação do campo magnético mas não reteve a magnetização com a retirada do mesmo. Este comportamento está de acordo com o observado em partículas superparamagnéticas [105], partículas magnéticas com tamanho menor que o tamanho crítico, 26 nm [106]. Após a remoção do campo o biossorvente magnético apresentou remanência e coercitividade nulas. O valor de magnetização de saturação foi estimado sendo igual a 6 emu.g . $^{-1}$.

A ausência de histerese e o valor de magnetização de saturação permitiram um controle do movimento do biossorvente magnético sem retenção do magnetismo pelo material tornando o manuseio fácil e rápido. É um processo que agrega dois processos de separação, a separação por adsorção e a separação magnética. A primeira permite a remoção dos íons de urânio os quais ficam retidos na superfície do biossorvente e a segunda permite a remoção desse biossorvente do meio aquoso mediante a aplicação de um campo magnético, tornando desnecessária a utilização do processo de filtragem ou centrifugação. 


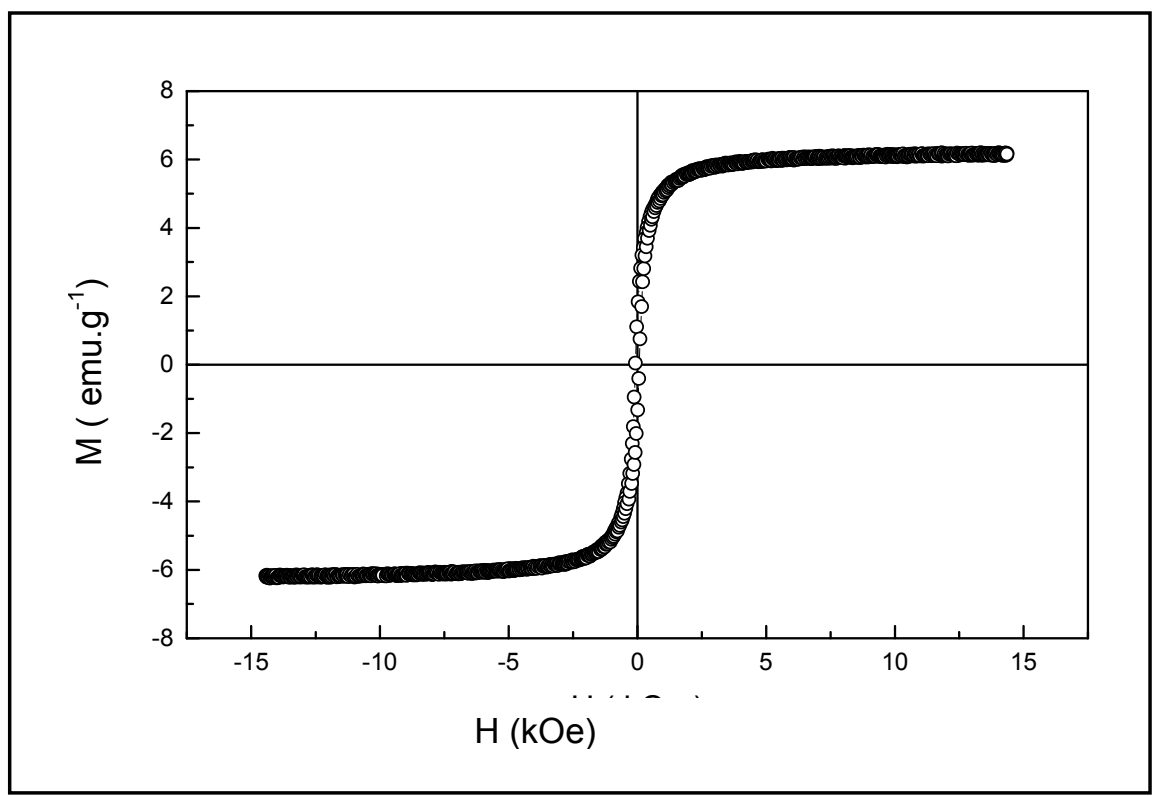

FIGURA 6.13 - Curva de magnetização do biossorvente magnético.

\subsection{Avaliação do Processo de Adsorção}

\subsubsection{Determinação do Tempo de Equilíbrio}

Inicialmente o tempo de equilíbrio foi determinado segundo os ensaios em batelada descritos na metodologia variando-se o tempo de agitação do sistema biossorvente + soluto (U) no intervalo de 20 a 90 min, conforme FIG 6.14. As demais variáveis foram fixadas, como $\mathrm{pH} 3,5$, dose de biossorvente $12,5 \mathrm{~g} \cdot \mathrm{L}^{-1}$, velocidade de 400 r.p.m. e concentração de U em 100 mg. $\mathrm{L}^{-1}$.

Os resultados apresentados na FIG. 6.14 mostram que o menor tempo estudado de 20 min foi suficiente para atingir o equilíbrio no biossorvente magnético. Para o biossorvente de bagaço, 40 min foram necessários para atingir o equilíbrio.

No equilíbrio, a porcentagem de remoção torna-se constante, removendo cerca de $98 \%$ do urânio presente em meio nítrico em se tratando do biossorvente magnético e cerca de $50 \%$ no caso do biossorvente de bagaço. Este patamar, a partir do qual a \%remoção se torna constante em adsorvente derivado de bagaço, também foi observado por Mohan et al. [107]. 
A melhor remoção obtida pelo biossorvente magnético está relacionada aos sítios ativos presentes na magnetita além dos sítios ativos da hidroxila dos álcoois e fenóis presentes no bagaço, o que pôde ser verificado pelo espectro de absorção do infravermelho.

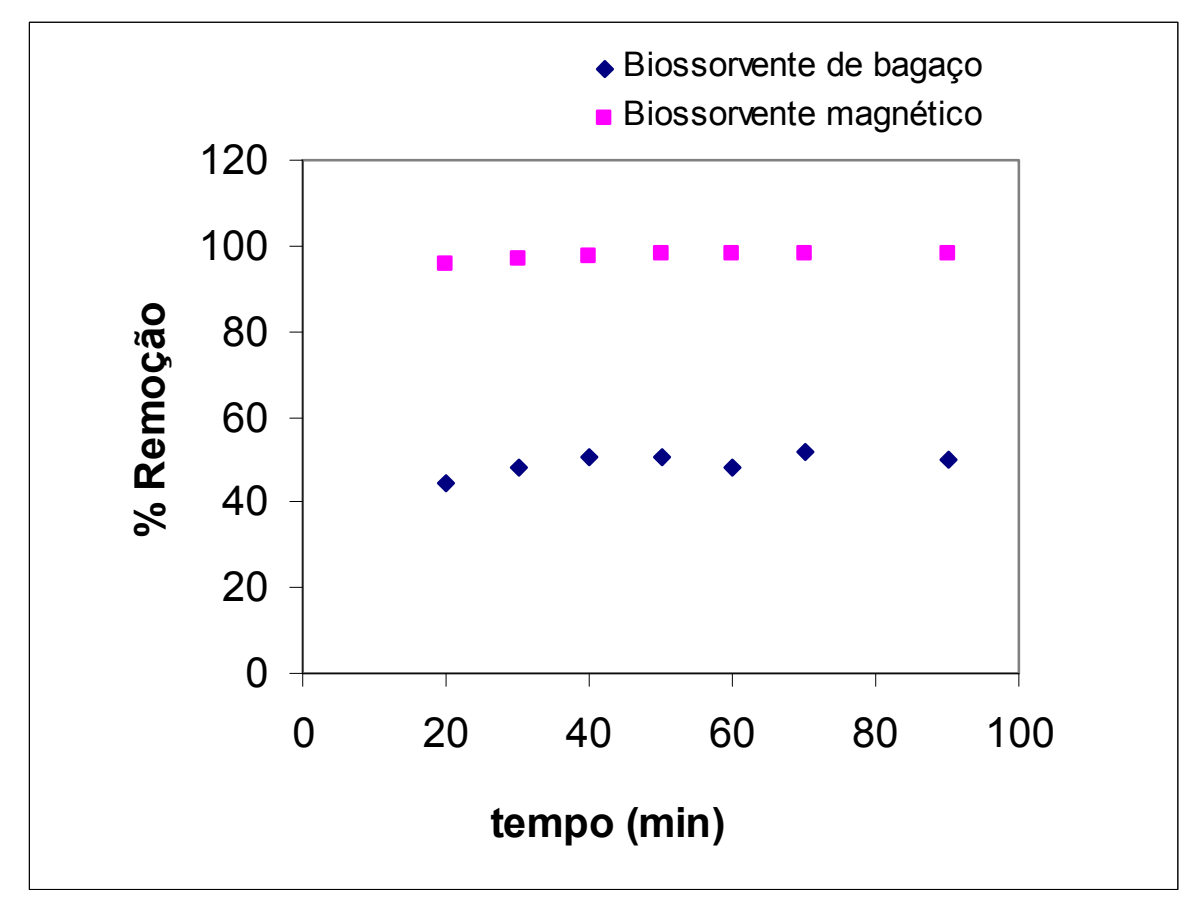

FIGURA 6.14 - Influência do tempo sobre a adsorção de urânio pelo biossorvente magnético e biossorvente de bagaço. Concentração de $U=100$ $m g \cdot L^{-1}, p H 3,5$.

O tempo de equilíbrio de uma reação química é diretamente afetada pela concentração dos reagentes. Quanto maior a concentração dos reagentes maior é o tempo para se atingir o equilíbrio da reação em questão. Portanto, para os próximos estudos fixou-se um tempo de agitação de 50 min a fim de garantir o equilíbrio de adsorção dos sistemas estudados. 


\subsubsection{Estudo do Tamanho dos Biossorventes}

O tamanho do biossorvente é uma variável importante no processo de adsorção. Sabe-se que quanto menor o tamanho maior a área superficial específica e está diretamente relacionado com o desempenho do biossorvente. Porém, a forma, a superfície e a porosidade também influenciam na adsorção.

Para o estudo do tamanho de ambos os biossorventes, magnético e de bagaço, uma peneira cuja abertura de forma quadrada de $3,1 \mathrm{~mm}$ foi confeccionada por meio do qual selecionaram-se os biossorventes por tamanhos. A outra peneira cuja abertura de 0,8 mm, foi comprada. Mediante essas duas peneiras, frações de biossorventes de três intervalos de tamanhos foram obtidas, valores inferiores a 0,8 $\mathrm{mm}$, entre 0,8 e 3,1 e superiores a 3,1 $\mathrm{mm}$ de abertura da malha da peneira. Portanto, o tamanho dos biossorventes refere-se à medida das malhas das peneiras utilizadas. Os tamanhos encontrados desconsideram a porosidade dos biossorventes.

Verificou-se a influência do tamanho do biossorvente no processo de adsorção de íons uranilo. As seguintes variáveis foram fixadas: $\mathrm{pH}$ 5, dose 12,5 g.L' 1 , tempo de equilíbrio de 50 min para o biossorvente magnético e biossorvente de bagaço. A velocidade de agitação adotada foi de 400 r.p.m. Foram estudadas frações de amostras de biossorventes com três tamanhos diferentes, conforme se observa nas TAB. 6.4 e TAB. 6.5:

TABELA 6.4 - Relação entre o tamanho do biossorvente e a adsorção de urânio por meio do biossorvente magnético.

\begin{tabular}{cc}
\hline $\begin{array}{c}\text { TAMANHO } \\
(\mathbf{m m})\end{array}$ & $\begin{array}{c}\text { \% REMOÇÃO } \\
\text { (Biossorvente Magnético) }\end{array}$ \\
\hline$<0,8$ & 100 \\
entre 0,8 e 3,1 & 81 \\
$>3,1$ & 72 \\
\hline
\end{tabular}


TABELA 6.5 - Relação entre o tamanho do biossorvente e a adsorção de urânio por meio do biossorvente de bagaço.

\begin{tabular}{cc}
\hline $\begin{array}{c}\text { TAMANHO } \\
(\mathbf{m m})\end{array}$ & $\begin{array}{c}\text { \% REMOÇÃO } \\
\text { (Biossorvente de Bagaço) }\end{array}$ \\
\hline$<0,8$ & 83 \\
entre 0,8 e 3,1 & 77 \\
$>3,1$ & 69 \\
\hline
\end{tabular}

Segundo as TAB. 6.4 e TAB. 6.5 verificou-se que a eficiência de adsorção varia com o tamanho do biossorvente magnético e de bagaço. Quanto maior o biossorvente menor a porcentagem de remoção devido a menor área superficial específica em contato com o soluto. Comportamento semelhante foi encontrado por Syna et al. [108]. Tamanhos entre 0,8 e 3,1 mm foram selecionados para ambos os biossorventes para os próximos estudos de adsorção em consideração às facilidades de preparação e utilização.

\subsubsection{Estudo do pH}

As espécies de urânio em solução aquosa variam com o pH da solução [109]. Conforme se observa na FIG. 6.15, as formas catiônicas de uranilo são predominantes entre o pH3 e 5,5. Entre o pH 5,5 e 8,5, a forma neutra de uranilo torna-se a espécie predominante. A partir desse $\mathrm{pH}$ há a formação da espécie aniônica e o desaparecimento da forma neutra.

Portanto, neste trabalho avaliou-se a influência do $\mathrm{pH}$ na adsorção de $U$ pelos biossorventes. Realizaram-se estudos de remoção de urânio nos intervalos de $\mathrm{pH}$ de 2 a 5 e em pH 10, das soluções de $100 \mathrm{mg} \cdot \mathrm{L}^{-1}$. Os resultados referentes aos dois biossorventes estão ilustrados na FIG. 6.16. Verificou-se para ambos os biossorventes que a remoção máxima ocorreu em $\mathrm{pH} 5$. A \%remoção de $U$ para o biossorvente magnético aumentou de $5 \%$ em $\mathrm{pH} 2$ para $94 \%$ em $\mathrm{pH} 5$. Para o biossorvente de bagaço aumentou de $12 \%$ em pH 2 para $78 \%$ em pH 5. 
A \%remoção de íons uranilo é máxima no $\mathrm{pH} 5$, quando há o predomínio das espécies catiônicas $\left(\mathrm{UO}_{2}{ }^{2+}\right.$ e $\left.\mathrm{UO}_{2} \mathrm{OH}^{+}\right)$. Isto evidencia a grande afinidade desses compostos pelos sítios ativos do bagaço de cana. $\mathrm{O}$ pH 2 apresentou a menor \%remoção devido ao excesso de $\mathrm{H}^{+}$presente na solução aquosa o qual compete com os sítios ativos de $\mathrm{OH}$ presentes nos biossorventes, diminuindo a remoção. $\mathrm{O}$ biossorvente magnético removeu menos $\mathrm{U}$ em $\mathrm{pH} 2$ em relação ao biossorvente de bagaço e isto é devido à instabilidade das partículas de magnetita em pH ácido, o que também foi observado por White [95]. Em pH 2, a magnetita sofre dissolução ácida, liberando íons de $\mathrm{Fe}^{2+}$ e $\mathrm{Fe}^{3+}$ no meio aquoso o que também pode vir a competir pela adsorção e consequentemente diminuindo a remoção de íons uranilo. Entre os pH 6 e pH 9 a solução inicial de urânio apresentou-se turva e com precipitado amarelo, o que impossibilitou estudo de adsorção nesse intervalo de $\mathrm{pH}$. Em pH 10 observou-se uma baixa adsorção pelo biossorvente devido à formação de hidroxi-uranilo negativamente carregado, pelo qual o biossorvente demonstrou pequena afinidade. Um comportamento semelhante foi encontrado por Gupta e colaboradores [47] para a remoção de cobre e zinco através das cinzas de bagaço. A provável espécie formada nesse $\mathrm{pH}$ é o íon negativo $\mathrm{UO}_{2}(\mathrm{OH})_{3}{ }^{-}$[109], conforme se observa na FIG. 6.15.

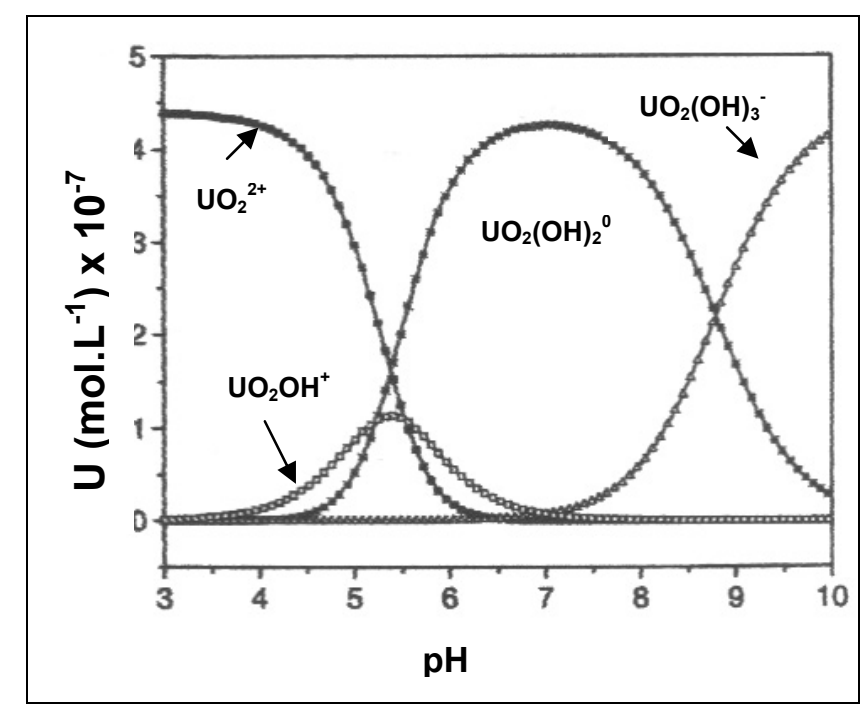

FIGURA 6.15 - Principais espécies aquosas de urânio. Força iônica = 0,1 mol. $\mathrm{L}^{-1}$, $[U]=4,4 \cdot 10^{-7} \mathrm{~mol} \cdot \mathrm{L}^{-1}[109]$. 


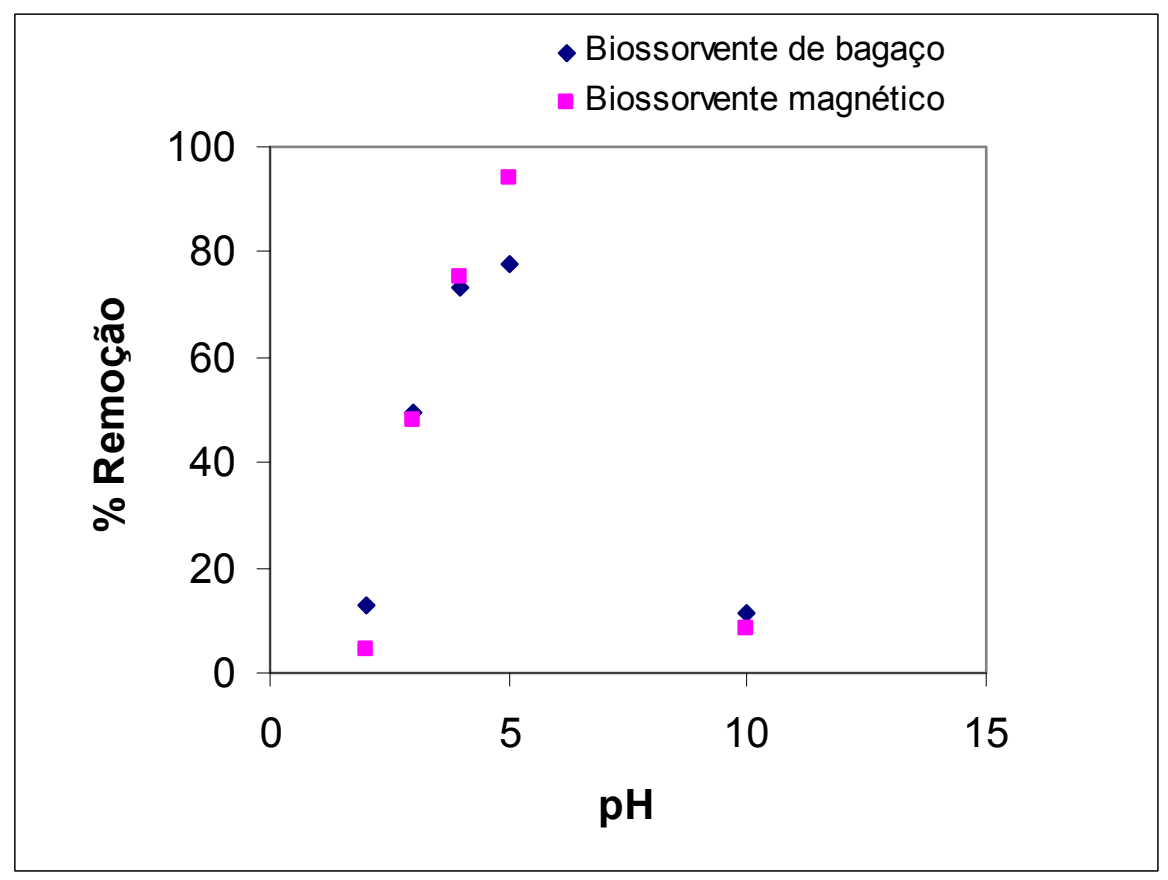

FIGURA 6.16 - Efeito do pH sobre a adsorção de urânio pelos biossorventes magnético e de bagaço. Concentração de íons de $U=100 \mathrm{mg} \cdot \mathrm{L}^{-1}$.

\subsubsection{Estudo da Velocidade de Agitação}

Estudou-se a velocidade de agitação do sistema biossorvente-soluto no intervalo de 240 a 500 r.p.m. mantendo fixos a dose de 12,5 g.L $\mathrm{L}^{-1}$, concentração de $\mathrm{U}$ em $100 \mathrm{mg} \cdot \mathrm{L}^{-1}, \mathrm{pH}$, tamanho dos biossorventes entre $0,8 \mathrm{~mm}$ e $3,1 \mathrm{~mm}$.

Da FIG. 6.17, onde estão apresentados os resultados, verificou-se que o processo de adsorção é favorável com o aumento da velocidade de agitação. Quanto maior a velocidade maior a porcentagem de remoção, atingindo o equilíbrio a partir de 300 r.p.m. Para estudos posteriores fixou-se a velocidade de agitação em 400 r.p.m. a fim de garantir o equilíbrio. Os melhores resultados de adsorção apresentados pelo biossorvente magnético podem ser atribuídos à presença de magnetita a qual também contribui para a adsorção em adição à adsorção promovida pelo biossorvente de bagaço. 


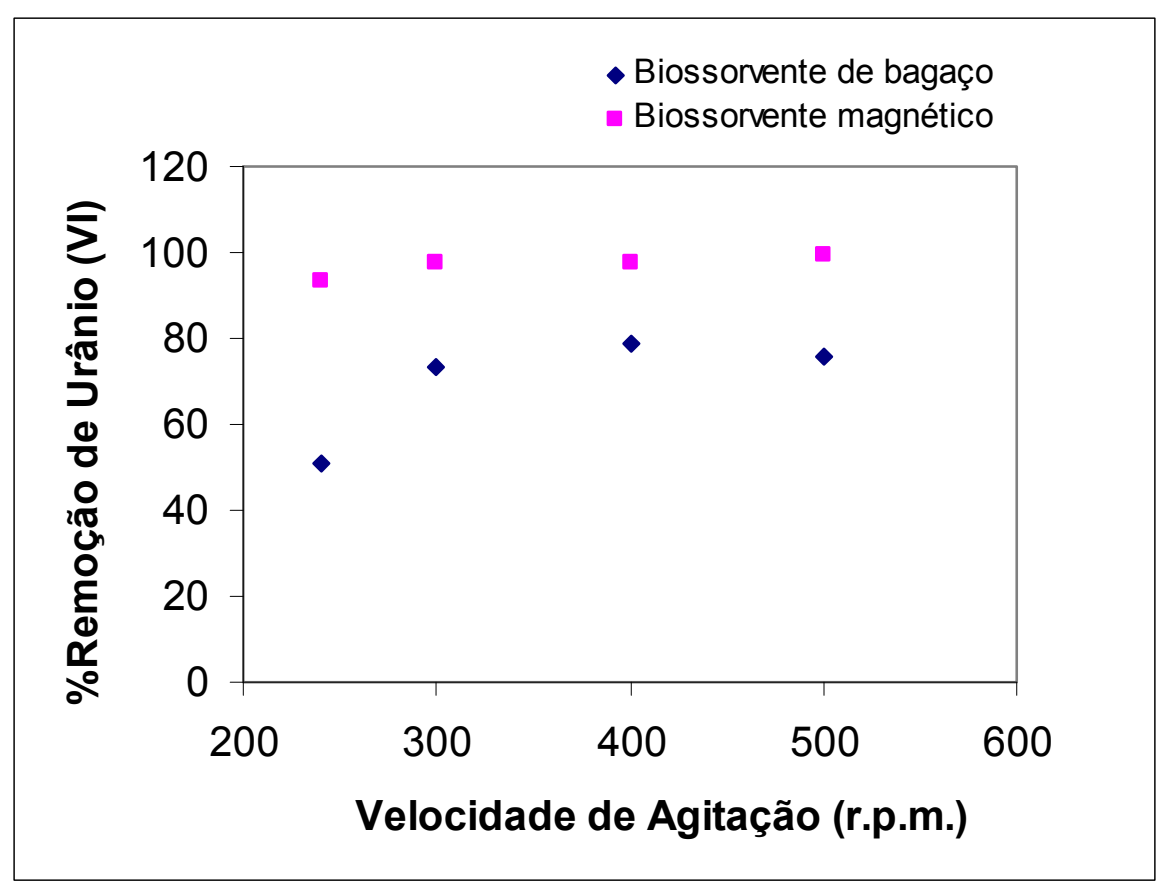

FIGURA 6.17 - Influência da velocidade sobre a adsorção de urânio pelo biossorvente magnético e biossorvente de bagaço. Concentração de ions de $U=100 \mathrm{mg} \cdot \mathrm{L}^{-1}, \mathrm{pH} 5$. 


\subsubsection{Estudo da Dose}

A dose foi definida como a relação entre a quantidade de biossorvente $(\mathrm{g})$ e o volume de solução de urânio (L). Variou-se a quantidade de $4 \mathrm{mg}$ a $50 \mathrm{mg} \mathrm{em}$ um volume de $2 \mathrm{~mL}$ de solução de urânio, pH 5 e a velocidade de 400 r.p.m. Utilizaram-se soluções de $U$ de concentração $100 \mathrm{mg} \cdot \mathrm{L}^{-1}$ para o biossorvente magnético e $177 \mathrm{mg} \cdot \mathrm{L}^{-1}$ para o biossorvente de bagaço. A relação entre os resultados da porcentagem de remoção e a dose de biossorventes encontra-se na FIG. 6.18.

Verificou-se que quanto maior a dose maior a porcentagem de remoção para uma mesma concentração de íons uranilo em contato com os biossorventes. Porém, a partir de uma dose de $10 \mathrm{~g} \cdot \mathrm{L}^{-1}$, o aumento torna-se lento e tende-se a um equilíbrio de remoção. Para dose de $10 \mathrm{~g} . \mathrm{L}^{-1}$ verficou-se uma remoção em torno de $94 \%$ para o biossorvente magnético e de $70 \%$ para o biossorvente de bagaço.

Leal [110] encontrou uma remoção de $85 \%$ de íons de $\mathrm{UO}_{2}{ }^{2+}$, de uma solução de $100 \mathrm{mg} \cdot \mathrm{L}^{-1}$, pela magnetita sintética para uma dose de $15 \mathrm{~g} \cdot \mathrm{L}^{-1}$. Para esta mesma dose e concentração inicial de urânio, a remoção referente ao biossorvente magnético foi de $97 \%$. A remoção de $U$ pelo biossorvente magnético foi maior em comparação ao adsorvente de magnetita porque o biossorvente magnético também possui sítios ativos do bagaço responsáveis pela adsorção de íons uranilo.

A FIG. 6.19 mostra a influência da dose de biossorvente magnético na sua capacidade de adsorção. Observou-se que a capacidade diminui rapidamente com o aumento da dose até $10 \mathrm{~g} \cdot \mathrm{L}^{-1}$. A partir desse valor a diminuição da capacidade de adsorção é lenta com tendência a atingir um equilíbrio. Independentemente de outras variáveis, este estudo mostrou que existe uma relação entre a quantidade de adsorbato adsorvido e o melhor aproveitamento do adsorvente sem desperdício do material, ou seja, a escolha da dosagem de adsorvente no processo de tratamento depende da concentração final de adsorbato que se deseja na solução em equilíbrio. 


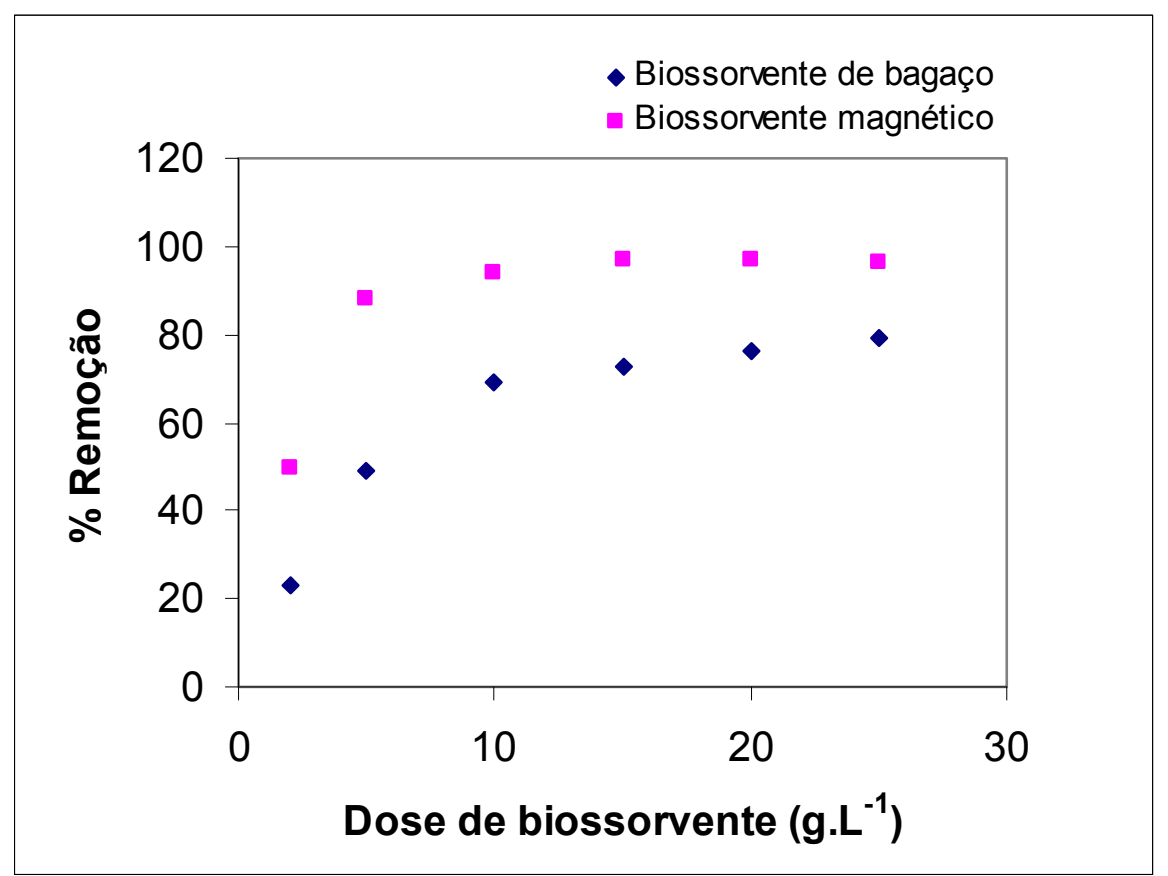

FIGURA 6.18 - Variação da \%remoção de $\mathrm{UO}_{2}{ }^{2+}$ em função das doses do biossorvente magnético e do biossorvente de bagaço, em solução nítrica. $\left[\mathrm{UO}_{2}^{2+}\right]=100 \mathrm{mg} \cdot \mathrm{L}^{-1}$ para o biossorvente magnético. $\left[\mathrm{UO}_{2}{ }^{2+}\right]=177 \mathrm{mg} \cdot \mathrm{L}^{-1}$ para o biossorvente de bagaço.

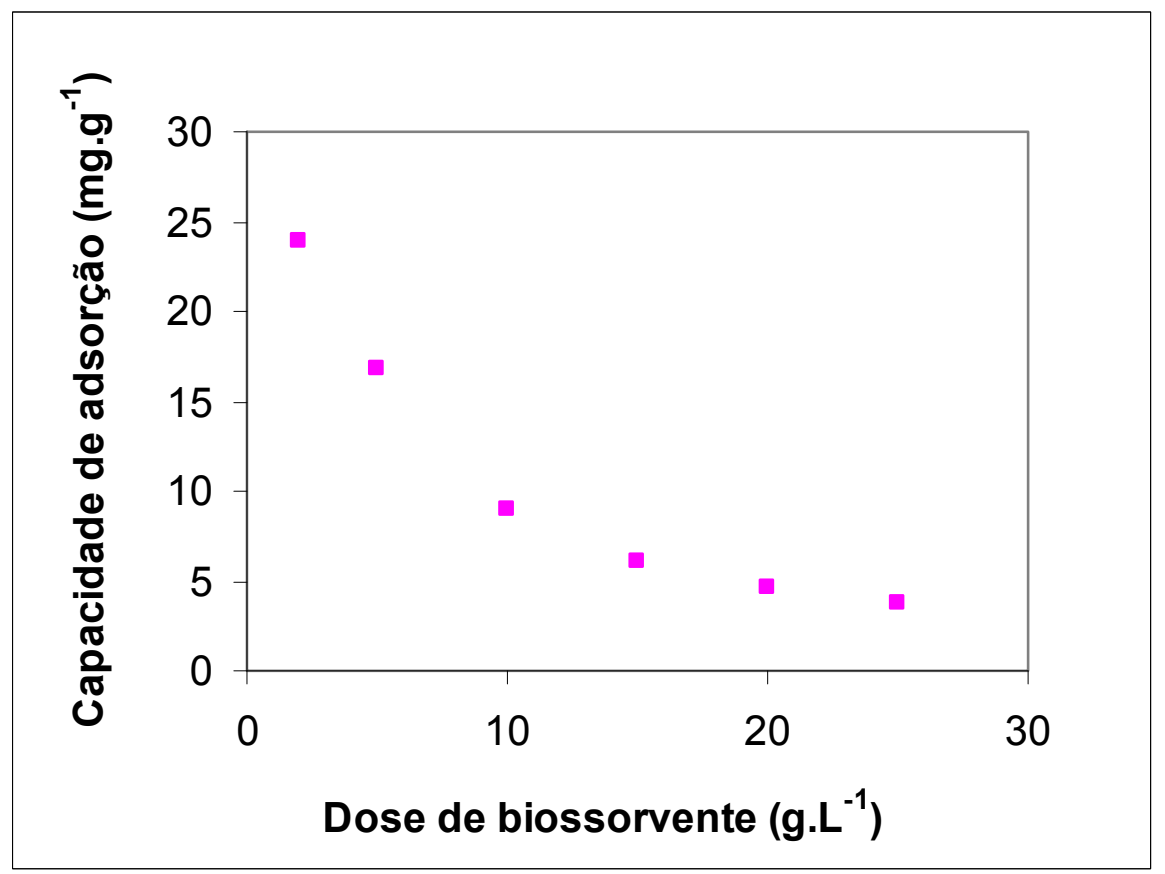

FIGURA 6.19 - Influência da dose de biossorvente magnético na capacidade de adsorção. $\left[\mathrm{UO}_{2}{ }^{2+}\right]=100 \mathrm{mg} \cdot \mathrm{L}^{-1}$. 


\subsubsection{Isotermas de Equilíbrio}

Para a obtenção das isotermas variou-se a concentração da solução de urânio em contato com o biossorvente em $50 \mathrm{mg} \cdot \mathrm{L}^{-1}, 100 \mathrm{mg} \cdot \mathrm{L}^{-1}, 150 \mathrm{mg} \cdot \mathrm{L}^{-1}, 200$ $\mathrm{mg} \cdot \mathrm{L}^{-1}, 300 \mathrm{mg} \cdot \mathrm{L}^{-1}$ e $400 \mathrm{mg} \cdot \mathrm{L}^{-1}$. O tempo de equilíbrio foi fixado em $50 \mathrm{~min}$, o tamanho dos biossorventes variou entre $0,8 \mathrm{~mm}$ e $3,1 \mathrm{~mm}, \mathrm{pH} \mathrm{5}$, velocidade de agitação do sistema 400 r.p.m. e dose do biossorvente $10 \mathrm{~g} \cdot \mathrm{L}^{-1}$.

Para cada experimento realizado de diferentes valores de concentração inicial de urânio obtiveram-se os valores de concentração em equilíbrio entre a solução e o adsorvente.

Com os resultados, as isotermas de equilíbrio de adsorção foram construídas para os dois biossorventes a partir do equilíbrio entre a quantidade de $U$ adsorvido no biossorvente e a concentração de $U$ na fase aquosa, à temperatura ambiente, e ilustradas nas FIG. 6.20 e 6.21.

As isotermas mostram que os íons uranilo foram favoravelmente adsorvidos pelos biossorventes no intervalo de concentração estudado. Para o biossorvente magnético, o processo de adsorção evoluiu rapidamente até um determinado valor de $\mathrm{C}_{\text {eq. }}$. A partir de então, verificou-se uma tendência a um patamar em um valor máximo de $Q_{\text {eq }}$, indicando a saturação do biossorvente. Para o biossorvente de bagaço, a adsorção aumentou continuamente e não se observou um valor de $Q_{e q}$ de saturação, até a concentração de $U$ estudada. 


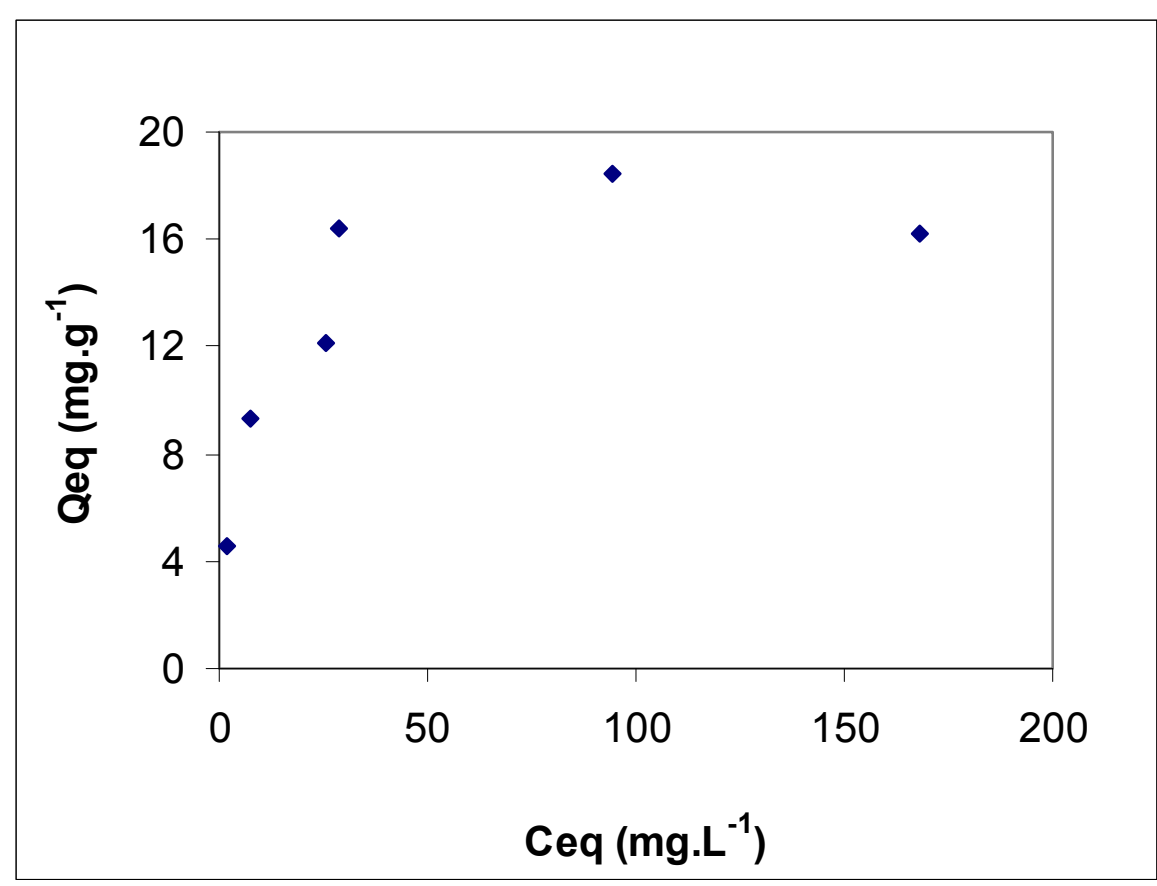

FIGURA 6.20 - Isoterma de equilíbrio de adsorção de íons $\mathrm{UO}_{2}{ }^{2+}$ pelo biossorvente magnético. Temperatura $=27^{\circ} \mathrm{C} \pm 2^{\circ} \mathrm{C}$.

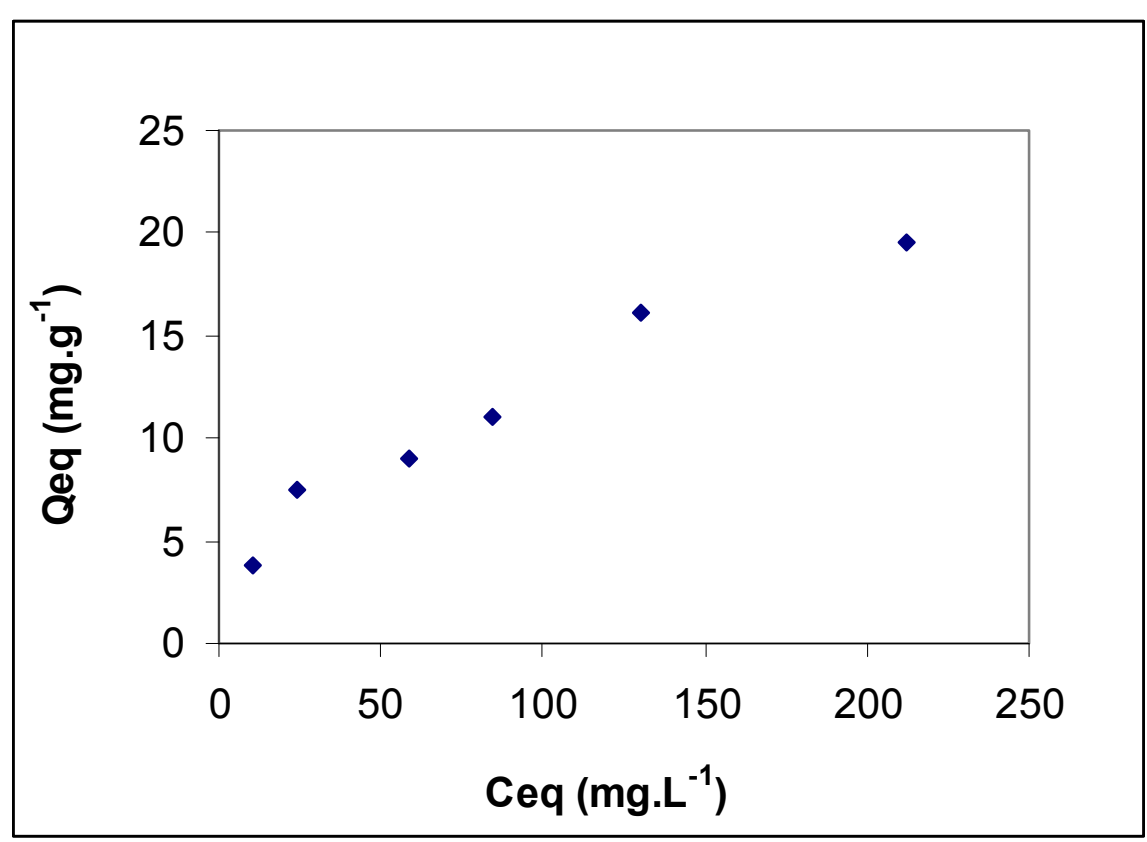

FIGURA 6.21 - Isoterma de equilíbrio de adsorção de íons $\mathrm{UO}_{2}{ }^{2+}$ pelo biossorvente de bagaço. Temperatura $=27^{\circ} \mathrm{C} \pm 2^{\circ} \mathrm{C}$.

As FIG. 6.22 e 6.23 relacionam-se às isotermas lineares dos modelos de Langmuir e Freundlich, respectivamente, do biossorvente magnético. As FIG. 6.24 e 6.25 relacionam-se aos resultados para o biossorvente de bagaço referentes às 
isotermas lineares dos modelos de Langmuir e Freundlich. As isotermas lineares de Langmuir foram obtidas a partir da equação 3.2 e as isotermas lineares de Freundlich, mediante a equação 3.4, aplicados aos resultados de equilíbrio.

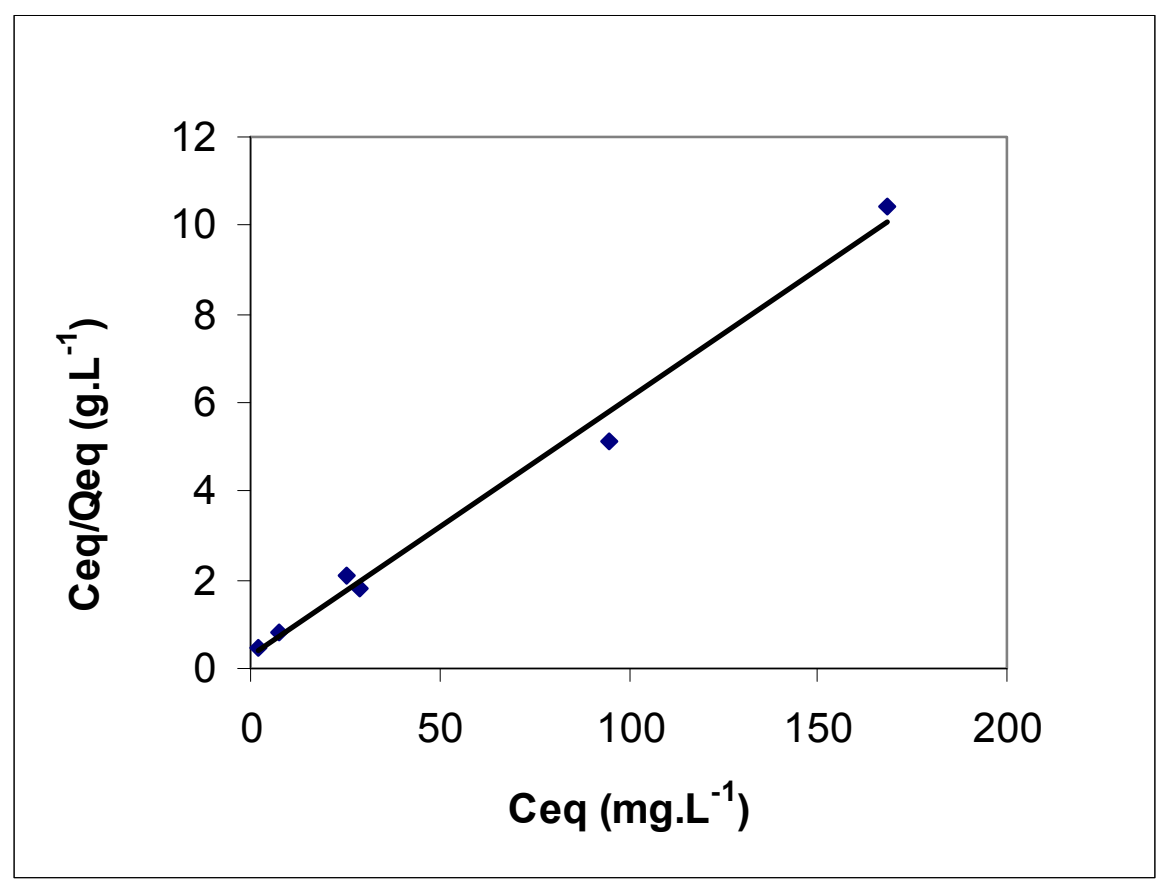

FIGURA 6.22 - Representação da isoterma linear de Langmuir para o processo de adsorção de urânio pelo biossorvente magnético. Temperatura = $27^{\circ} \mathrm{C} \pm 2^{\circ} \mathrm{C}$. 


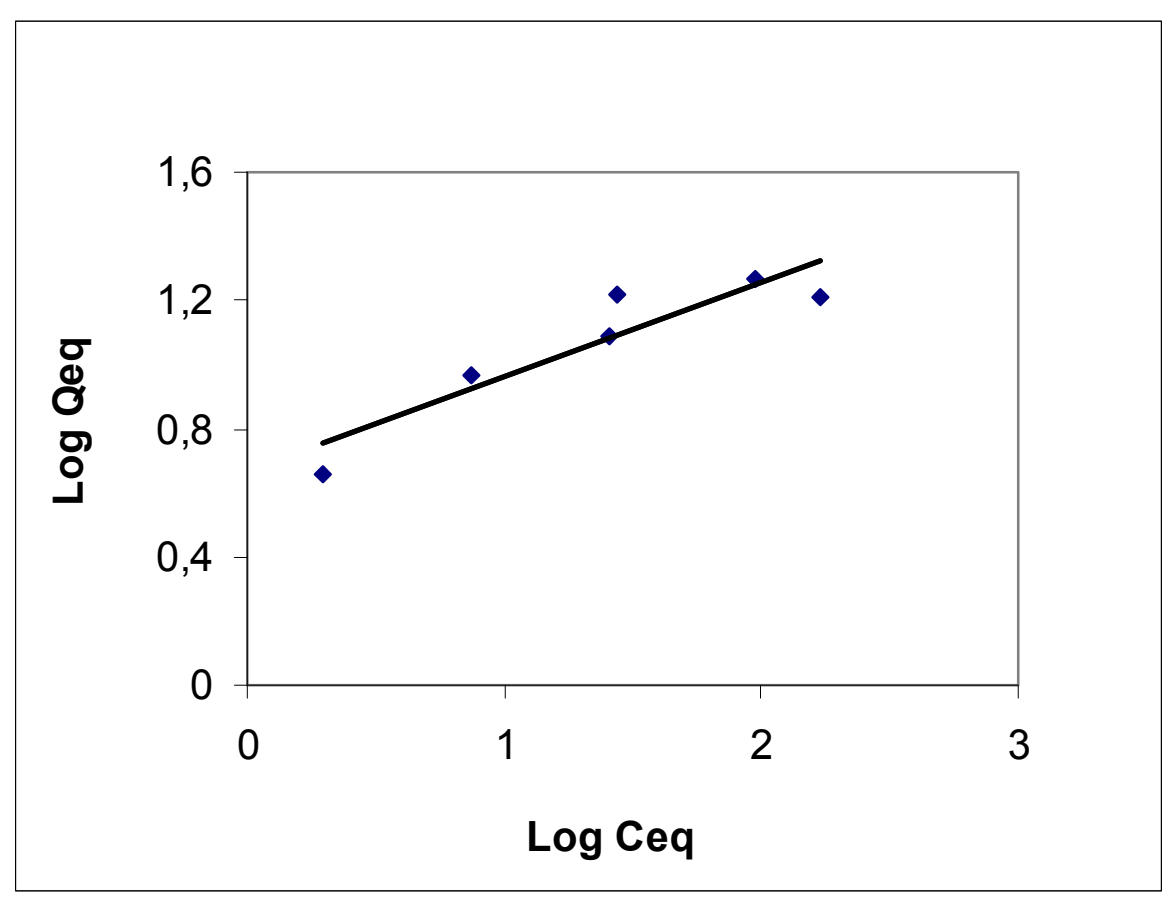

FIGURA 6.23 - Representação da isoterma linear de Freundlich para o processo de adsorção de urânio pelo biossorvente magnético. Temperatura = $27^{\circ} \mathrm{C} \pm 2^{\circ} \mathrm{C}$.

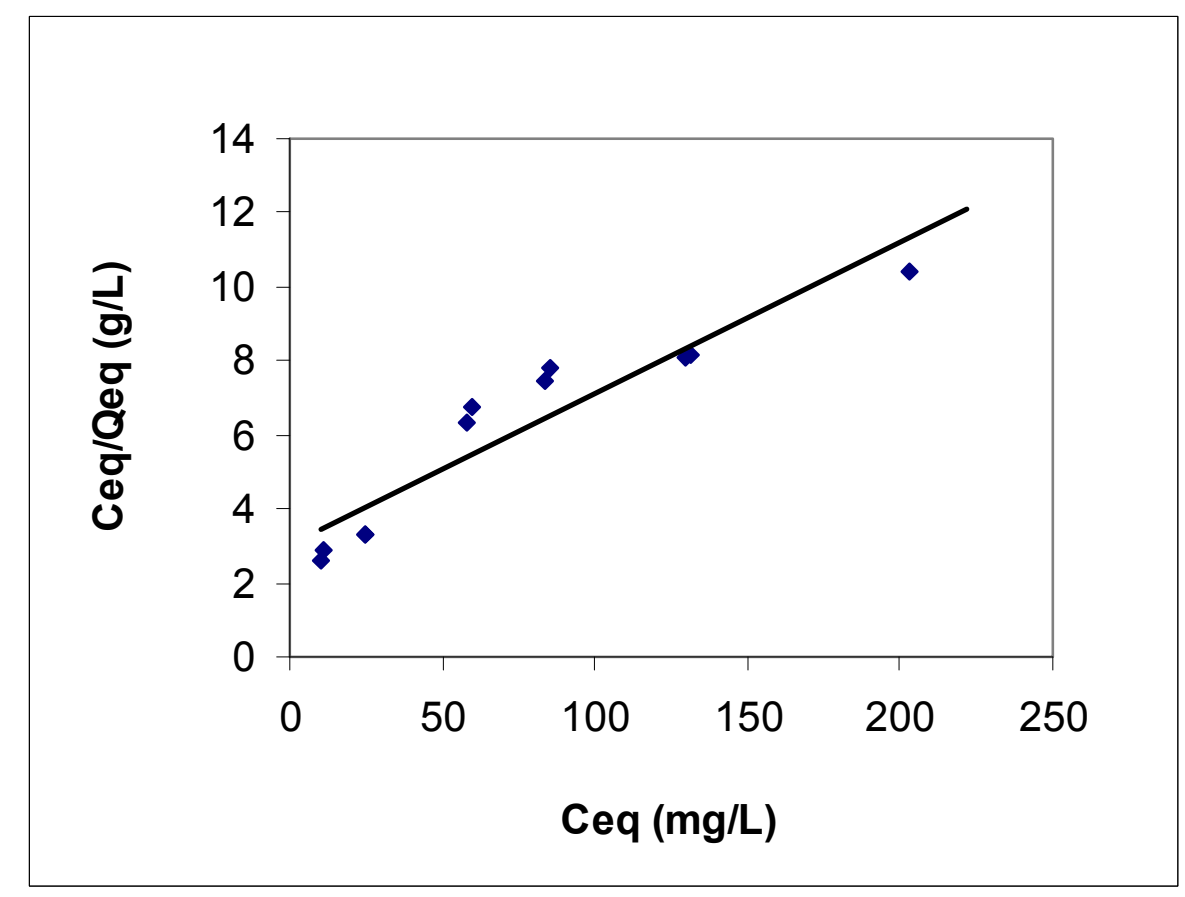

FIGURA 6.24 - Representação da isoterma linear de Langmuir para o processo de adsorção de urânio pelo biossorvente de bagaço. Temperatura = $27^{\circ} \mathrm{C} \pm 2^{\circ} \mathrm{C}$. 


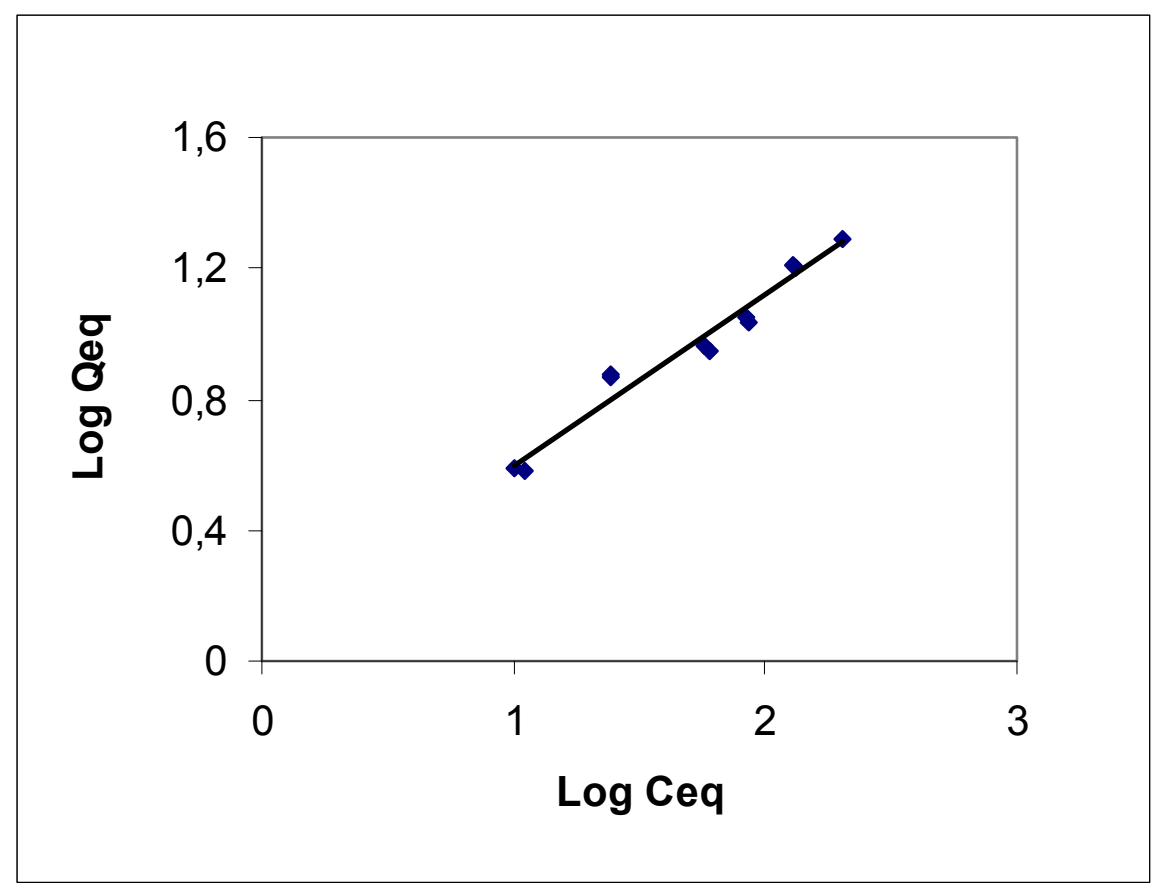

FIGURA 6.25 - Representação da isoterma linear de Freundlich para o processo de adsorção de urânio pelo biossorvente de bagaço. Temperatura $=$ $27^{\circ} \mathrm{C} \pm 2^{\circ} \mathrm{C}$.

A TAB. 6.6 ilustra os valores dos parâmetros dos modelos estimados segundo as equações lineares obtidas para o biossorvente magnético. Os valores de $\mathrm{Q}$ e de $\mathrm{K} \mathrm{L}$ foram calculados para o modelo de Langmuir por meio do coeficiente angular da reta e o coeficiente linear. Os valores de $K_{F}$ e $1 / n$ referem-se ao modelo de Freundlich e foram calculados a partir do valor de coeficiente angular e 0 coeficiente linear da reta.

Por meio do valor do coeficiente de correlação linear, da TAB. 6.6, verificou-se que o modelo de isoterma que melhor se ajustou ao fenômeno de adsorção de urânio foi o de Langmuir, indicando a formação de uma monocamada de íons de U sobre a superfície sólida do biossorvente. Comparando as FIG. 6.22 e 6.23, a FIG. 6.22 mostra a melhor adequação dos pontos experimentais ao modelo linear de isoterma de Langmuir, representada pela reta. Portanto, a capacidade máxima de adsorção foi estimada em $17 \mathrm{mg}$ de $U$ por grama de biossorvente magnético segundo a equação de Langmuir.

A TAB. 6.7 apresenta os parâmetros de Langmuir e Freundlich para a adsorção de íons uranilo pelo biossorvente de bagaço. Estes foram obtidos de 
maneira análoga à TAB. 6.6, porém, utilizando-se valores referentes ao biossorvente de bagaço.

Por meio do valor do coeficiente de correlação linear obtido da TAB. 6.7 verificou-se que o modelo de Freundlich foi o que melhor se aplicou ao processo de adsorção de íons uranilo pelo biossorvente de bagaço. De acordo com as premissas do modelo, isto indica o acúmulo infinito de íons de urânio na superfície do biossorvente em baixas concentrações.

$\mathrm{O}$ valor de $\mathrm{k}_{\mathrm{F}}$ maior do biossorvente magnético, comparado com o do biossorvente de bagaço, indica maior quantidade adsorvida para uma mesma concentração do adsorbato em equilíbrio. Um valor menor de $1 / n$ indica alta variação de capacidade adsortiva com variação de concentração em equilíbrio.

Apesar do modelo de Langmuir não ser o mais adequado para descrever o processo de adsorção no biossorvente de bagaço, este foi utilizado para estimar a capacidade máxima de adsorção. Encontrou-se a capacidade máxima de adsorção igual a $23 \mathrm{mg}$ de $\mathrm{U}$ em solução nítrica por g de biossorvente de bagaço.

TABELA 6.6 - Parâmetros de Langmuir e Freundlich para a adsorção de íons uranilo pelo biossorvente magnético. Temperatura igual a $27^{\circ} \mathrm{C} \pm 2{ }^{\circ} \mathrm{C}$.

\begin{tabular}{lccccc}
\hline & $\mathbf{r}^{2}$ & $\begin{array}{c}\mathbf{K}_{\mathbf{L}} \\
\left(\mathbf{L} \cdot \mathbf{m g}^{-1}\right)\end{array}$ & $\begin{array}{c}\mathbf{Q} \\
\left(\mathbf{m g} \cdot \mathbf{g}^{-1}\right)\end{array}$ & $\begin{array}{c}\mathbf{K}_{\mathbf{F}} \\
{\left[\left(\mathbf{m g}^{-1} \mathbf{g}^{-1}\right) \cdot\left(\mathbf{L} \cdot \mathbf{m g}^{-1}\right)^{1 / \mathbf{n}}\right]}\end{array}$ & $\mathbf{1 / \mathbf { n }}$ \\
\hline Langmuir & 0,9901 & 0,212 & 17,15 & - & - \\
Freundlich & 0,8483 & - & - & 4,61 & 0,295 \\
\hline
\end{tabular}

TABELA 6.7 - Parâmetros de Langmuir e Freundlich para a adsorção de íons uranilo pelo biossorvente de bagaço. Temperatura igual a $27^{\circ} \mathrm{C} \pm$ $2^{\circ} \mathrm{C}$.

\begin{tabular}{lccccc}
\hline & $\mathbf{r}^{2}$ & $\begin{array}{c}\mathbf{K} \mathbf{L} \\
\left(\mathbf{L} \cdot \mathbf{m g}^{-1}\right)\end{array}$ & $\begin{array}{c}\mathbf{Q} \\
\left(\mathbf{m g} \cdot \mathbf{g}^{-1}\right)\end{array}$ & $\begin{array}{c}\mathbf{K}_{\mathbf{F}} \\
{\left[\left(\mathbf{m g} \cdot \mathbf{g}^{-1}\right) \cdot\left(\mathbf{L} \cdot \mathbf{m g}^{-1}\right)^{1 / \mathbf{n}}\right]}\end{array}$ & $\mathbf{1 / n}$ \\
\hline Langmuir & 0,9211 & 0,014 & 23,92 & - & - \\
Freundlich & 0,9635 & - & - & 1,252 & 0,506 \\
\hline
\end{tabular}


As FIG. 6.26 e 6.27 representam os modelos de isotermas de equilíbrio de adsorção para os biossorventes magnético e de bagaço. Foram construídas a partir das equações 3.1 e 3.3 por substituição de cada parâmetro pelo valor estimado nas TAB. 6.6 e 6.7 e considerando os valores de $C_{e q}$ das isotermas experimentais.

A FIG. 6.26 confirmou um melhor ajuste da isoterma de Langmuir aos dados experimentais para a adsorção de urânio por meio do biossorvente magnético. Em relação à adsorção de urânio referente ao biossorvente de bagaço a FIG. 6.27 indicou um melhor ajuste do modelo de Freundlich.

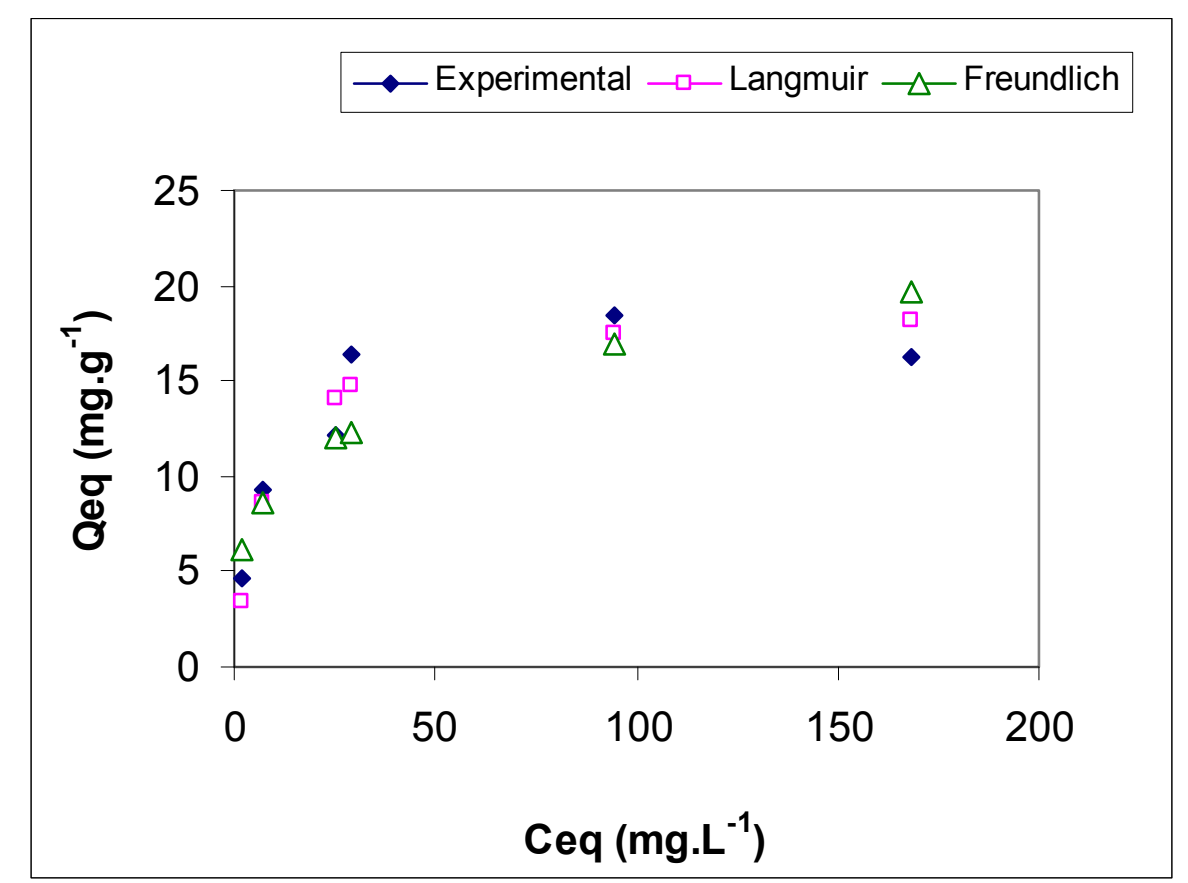

FIGURA 6.26 - Isoterma de equilíbrio de adsorção de íons $\mathrm{UO}_{2}{ }^{2+}$ pelo biossorvente magnético e os modelos teóricos de Langmuir e Freundlich. Temperatura $=27^{\circ} \mathrm{C} \pm 2^{\circ} \mathrm{C}$. 


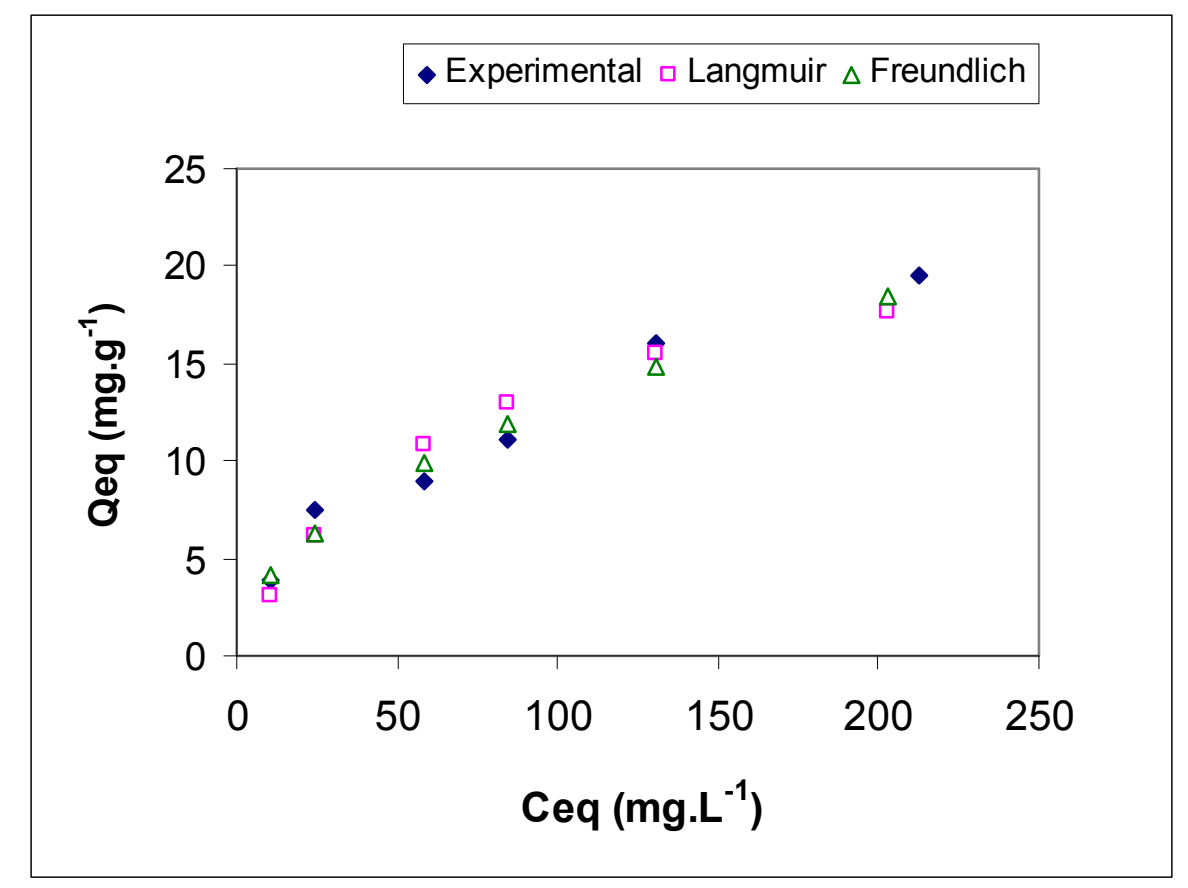

FIGURA 6.27 - Isoterma de equilíbrio de adsorção de íons $\mathrm{UO}_{2}{ }^{2+}$ pelo biossorvente de bagaço e os modelos teóricos de Langmuir e Freundlich. Temperatura $=27^{\circ} \mathrm{C} \pm 2^{\circ} \mathrm{C}$.

\subsubsection{Energia Livre de Gibbs}

Os valores de $\mathrm{K}_{\mathrm{L}}$ indicados nas TAB. 6.6 e 6.7 foram convertidos em L.mol ${ }^{-1}$ [78] para o cálculo da energia livre de Gibbs padrão.

Utilizando-se o valor da constante de Langmuir $\mathrm{K}_{\mathrm{L}}$ de cada biossorvente na equação 3.11 foi possível encontrar os valores da energia livre de Gibbs padrão de -27 kJ.mol ${ }^{-1}$ e $-20 \mathrm{~kJ} \mathrm{~mol}^{-1}$ para os biossorventes magnético e de bagaço, respectivamente, para o processo de adsorção de íons uranilo, em sistema de equilíbrio. O sinal negativo dos valores indicou que o processo de adsorção foi espontâneo para os dois casos à temperatura ambiente. 


\section{CONCLUSÕES}

Este trabalho descreveu o desenvolvimento de um material inédito a partir do bagaço de cana-de-açúcar, um resíduo natural, e com nanopartículas de magnetita, o qual foi chamado biossorvente magnético. Ele apresentou propriedades superparamagnéticas, o que o caracterizou como um material nanotecnológico, possibilitando aplicação da técnica de separação magnética e apresentou sítios ativos cuja funcionalidade permitiu a adsorção de íons $\mathrm{UO}_{2}{ }^{2+}$ e foi comparado com o biossorvente de bagaço.

Pelo espectro de absorção na região do infravermelho verificou-se que o biossorvente magnético é composto por partículas de magnetita e estrutura de carboidratos derivados do bagaço. O difratograma de raios-X confirmou a fase de magnetita. A quantidade de magnetita foi estimada de $16 \%$ a $17 \%$, determinada por meio da análise termogravimétrica em atmosfera de $\mathrm{O}_{2}$. O material desenvolvido não apresentou histerese, ou seja, respondeu à ação do campo magnético, porém não reteve a magnetização com a retirada do mesmo. O biossorvente magnético apresentou um valor de magnetização de saturação igual a 6 emu.g ${ }^{-1}$.

A avaliação do processo de adsorção de íons de $U$ no biossorvente magnético mostrou resultados promissores. De acordo com o estudo realizado, o processo de adsorção é dependente do pH do meio e, para tanto, a melhor adsorção ocorreu em pH 5. A cinética de adsorção é rápida observando-se o estado de equilíbrio de adsorção em 20 min em solução de U $100 \mathrm{mg} \cdot \mathrm{L}^{-1}$, em uma velocidade de agitação de 300 r.p.m. Mantendo-se fixos a concentração da solução de urânio em $100 \mathrm{mg} \cdot \mathrm{L}^{-1}, \mathrm{pH}$, o tempo de contato em $50 \mathrm{~min}$, o tamanho do biossorvente entre $0,8 \mathrm{~mm}$ e $3,1 \mathrm{~mm}$, a velocidade de agitação do sistema em 400 r.p.m. e a dose do biossorvente em $10 \mathrm{~g} . \mathrm{L}^{-1}$, o biossorvente magnético foi capaz de remover $94 \%$ dos íons presentes em solução nítrica em um único estágio.

O modelo proposto por Langmuir foi o que melhor se ajustou ao processo de adsorção de urânio pelo biossorvente magnético. Segundo o modelo observou-se um fenômeno de adsorção química e a capacidade máxima de adsorção do 
biossorvente magnético foi estimada em $17 \mathrm{mg}$ de urânio por grama de biossorvente. A avaliação da energia livre de Gibbs padrão de reação confirmou que o processo de adsorção foi espontâneo.

Do ponto de vista da remoção de $U$ de meio aquoso, o biossorvente magnético apresentou características similares ao do biossorvente de bagaço, porém a presença de magnetita facilitou a separação sólido-líquido, com o uso de um imã.

O biossorvente magnético é uma tecnologia alternativa com potencial de aplicação em tratamento de rejeito radioativo contendo íons de $U$. A técnica possibilita a separação magnética de sólido-líquido, dispensando o uso de centrifugação ou de filtração, normalmente usados no processo de tratamento de efluentes, simplificando o processo.

Novas abordagens serão consideradas em trabalhos futuros como estudo de remoção de outros metais e compostos orgânicos, estudos de dessorção, resistência mecânica, resistência do meio na atenuação do campo magnético, testes preliminares com o efluente real e um projeto de remoção de poluentes em escala maior. 


\section{REFERÊNCIAS BIBLIOGRÁFICAS}

[1] MAUCHAUFFÉE, S.; MEUX, E. Use of sodium decanoate for selective precipitation of metals contained in industrial wastewater. Chemosphere, v. 69, p. 763-768, 2007.

[2] LADEIRA, A. C. Q.; MORAIS C. A. Uranium recovery from industrial effluent by ion exchange-column experiments. Miner. Eng., v.18, p. 1337-1340, 2005.

[3] FERNANDES, T. F.; LEMOS, F. A.; NASCIMENTO, M. Recuperação de cobre de rejeitos industriais aplicando a técnica de extração por solvente. XIII Jornada de Iniciação Científica - CETEM. Disponível em:

<http://www.cetem.gov.br/publicacao/serie_anais_XIII_jic_2005/Telma\%20Fag undes\%20Fernandes.pdf> Acesso em: 12 abr. 2008.

[4] SANTOYO, A. B.; CARRASCO, J. L. G.; GÓMEZ, E. G.; MARTÍN, F. M. MONTESINOS A. M. H. Application of reverse osmosis to reduce pollutants present in industrial wastewater. Desalination, v. 155, p. 101-108, 2003.

[5] TOMA, H. E. O mundo NANOMÉTRICO: a dimensão do novo século. 1.ed. São Paulo, SP: Oficina de Textos, 2004.

[6] Escala Nanométrica. Disponível em:

<http://www.ofitexto.com.br/conteudo/deg_230778.htm> Acesso em 27 dez.. 2008.

[7] Introdução à nanotecnologia. O que é a nanotecnologia? Disponível em: <http://www.euroresidentes.com/futuro/nanotecnologia/nanotecnologia_respons avel/introducao_nanotecnologia.htm> Acesso em 30 mar. 2009.

[8] FEYNMAN, R. P., There's Plenty of Room at the Bottom. Disponível em: <http://www.zyvex.com/nanotech/feynman.html]>. Acesso em: 30 mar. 2009.

[9] VOGOT, C., Admirável Nano - Mundo - Novo. Disponível em: <http://www.comciencia.br/reportagens/nanotecnologia/nano01.htm>. Acesso em: 10 jan. 2009.

[10] CONDE, J. P. Nanomateriais. Sociedade Portuguesa de Química. Disponível em: <http://www.spq.pt/boletim/docs/boletimSPQ_097_057_09.pdf>. Acesso em: 26 set. 2007. 
[11] PIMENTA, M.A. Sociedade Brasileira de Química. Nanotubos de carbono: propriedades eletrônicas e aplicações. Disponível em:

<http://www.sbq.org.br/26ra/nanotubos.htm>. Acesso em: 30 mar. 2009.

[12] CEDECOM - Centro de Informações da UFMG. UFMG leva nanotecnologia à indústria aeroespacial. Disponível em:

<http://www.ufmg.br/online/arquivos/001298.shtml>. Acesso em: 6 mar. 2009.

[13] CHAVES, A. Nanociência e Nanotecnologia. Com Ciência. Disponível em: <http://www.comciencia.br/reportagens/nanotecnologia/nano17.htm> Acesso em 26 jul. 2007.

[14] SILVA, C. G. O que é nanotecnologia. Com Ciência. Disponível em: <http://www.comciencia.br/reportagens/nanotecnologia/16.htm> Acesso em 26 julho 2007.

[15] REZENDE, S.M., Nanomagnetismo. Disponível em: <http://www.comciencia.br/reportagens/nanotecnologia/nano14.htm>. Acesso em: 6 abr. 2009.

[16] KNOBEL, M. Aplicações do magnetismo. Revista Ciência Hoje. Rio de Janeiro, n. 215, maio 2005. Disponível em: <http://cienciahoje.uol.com.br/3359> Acesso em 26 mar. 2008.

[17] RODRÍGUEZ, G. J. B. O porque de estudarmos os materiais magnéticos. Revista Brasileira de Ensino de Física. São Paulo, n. 4, v. 20, dez. 1998. Disponível em: <http://pcsbf1.sbfisica.org.br/rbef/pdf/v20_315.pdf> Acesso em 26 mar. 2008.

[18] MUSSOI, F. L. R. Centro Federal de Educação Tecnológica de Santa Catarina - Fundamentos de eletromagnetismo. Disponível em:

$<$ http://www.scribd.com/doc/16191773/Fundamentos-de-EletromagnetismoCEFETSC> Acesso em: 17 out. 2009.

[19] PADILHA, A. F. Materiais de Engenharia. Editora Hemus, 2000. cap. 19, propriedades magnéticas. p. $317-330$.

[20] Figura: arranjo dos dipolos para diferentes materiais magnéticos. Disponível em: <http://www.geocities.com/castanhola2000/figura.htm> Acesso em: 25 jun 2007. 
[21] HARRIS, L.A. Polymer stabilized magnetite nanoparticles and poly(propylene oxide) modified styrene-dimethacrylate networks. 2002. Tese (Doutorado) - Faculty of the Virginia Polytechnic Institute and State University, EUA. Disponível em: <http://scholar.lib.vt.edu/theses/available/etd05052002-231800/unrestricted/LAH-etd.pdf>. Acesso em: 30 mar. 2009.

[22] CULLITY, B. D. Introduction to magnetic materials. Addison-Wesley Publishing Company, 1972. cap. 6, Ferrimagnetismo. p.181-190.

[23] GUIMARÃES, A. P. Propriedades magnéticas de sistemas granulares. $\boldsymbol{R e v}$. Bras. Ensino de Física. v.22, p. 382-386, 2000.

[24] SANTOS, F.E.P. Propriedades magnéticas de fluidos magnéticos de dupla camada elétrica à base de ferrita de cobalto. 2005. Dissertação (Mestrado) Universidade Federal de Pernambuco, PE. Disponível em:

<http://www.df.ufpe.br/pg/teses\&dissertacoes/pdf/2005/d_francisco.pdf> Acesso em: 19 out. 2009.

[25] SINNECKER, J.P. Materiais magnéticos doces e materiais ferromagnéticos amorfos. Rev. Bras. Ensino de Física. v.22, p. 396-405, 2000.

[26] SILVA, A.T. Estudo de chapas de ferro silício (3,2\% Si) usada em transformadores de média potência por espectroscopia Mössbauer e miscroscopia óptica. 2003. Dissertação (Mestrado) - Universidade Estadual de Maringá, PR. Disponível em:

http://www.pfi.uem.br/mfi/disserta_teses/teses_pdf/Aluizio_torres_2003.pdf>. Acesso em 19 out. 2009.

[27] PANKHURST, Q.A.; CONNOLY, J; JONNES, S.K.; DOBSON, J. Applications of magnetic nanoparticles in biomedicine. J. Phys. D: Appl. Phys. v.36, p. R167R181, 2003.

[28] KNOBEL, M. Os superpoderes dos nanomagnetos. Ciência Hoje, vol. 27, p.32 -38, 2000. Disponível em: < http://www.ifi.unicamp.br/ knobel/pessoal/pdf/cienciahoje.pdf> Acesso em 12 abr 2008.

[29] KNOBEL, M. Aplicações do magnetismo. Revista Ciência Hoje, v. 36. p. 18, 2005.

[30] Cana-de-açúcar. Disponível em: <http://pt.wikipedia.org/wiki/Cana-de-a\%C3\%A7\%C3\%BAcar>. Acesso em 27 jul. 2007. 
[31] CEZAR, G. Sistema de Informações Energéticas. "Produção vai crescer $71 \%$ em 5 anos." Disponível

em:<http://infoener.iee.usp.br/infoener/hemeroteca/imagens/103490.htm>. Acesso em out. 2009.

[32] Universidade Regional Integrada do Alto Uruguai e das Missões. Especialização na cultura de cana-de-açúcar. Disponível em: < http://www.saoluiz.uri.br/index.php?option=com_content\&task=view\&id=24\&lte mid=49> Acesso em 19 out. 2009.

[33] Biocombustíveis - Etanol - Mandioca doce da Amazônia surpreende no teste para etanol. Disponível em:

<http://www.brasilagro.com.br/noticias.php?id=15514> Acesso em: 19 out. 2009.

[34] UNICA - União da Indústria de cana-de-açúcar. São Paulo conta com mais de 120 usinas em operação. Disponível em:

$<$ http://www.unica.com.br/noticias/show.asp?nwsCode=\{2FE3D4C6-2F5549C0-8B23-07DE5CA9E53A\}> Acesso em 19 out. 2009..

[35] SUN, X. F.; SUN, R. C.; TOMKINSON, J.; BAIRD, M. S. Preparation of sugarcane bagasse hemicellulosic succinates using NBS as a catalyst. Carbohydr. Polym., v. 53, p.483-495, 2003.

[36] LANZALUNGA, O.; BIETTI, M. Photo- and radiation chemical induced degradation of lignin model compounds. J. Photochem. Photobiol. B, v. 56, p. 85-108, 2000.

[37] ALMEIDA, J. Indústria: Jalles Machado. [mensagem pessoal]. Mensagem recebida por <Jardel.almeida@jallesmachadosa.com.br> em 26 JAN. 2009.

[38] COELHO, S.T. CENBIO - Centro Nacional de Referência em Biomassa. Biomassa. Disponível em:

<http://cenbio.iee.usp.br/english/download/publicacoes/BIOMASSA.pdf>. Acesso em: 06 abr. 2009.

[39] THIAGO, L.R.L.S. e VIEIRA, J.M. EMBRAPA - Comunicado Técnico. Cana-deAçúcar: Uma alternativa de alimento para a seca. Dez. 2002. Disponível em: <http://www.cnpgc.embrapa.br/publicacoes/cot/COT73.html> Acesso em 10 out. 2007.

[40] COELHO, S.T. Mecanismos para implementação da cogeração de eletricidade a partir de biomassa. Um modelo para o estado de São Paulo, 1999. Tese (Doutorado) - Programa Interunidades de Pós-Graduação em Energia. Instituto de Eletrotécnica e Energia, São Paulo, p. 44. Disponível em: <http://www.iee.usp.br/biblioteca/producao/1999/teses/suani.PDF> Acesso em 12 abr. 2008. 
[41] AGUIAR C.L.,MENEZES T.J.B., Conversão enzimátic a do bagaço de cana-deaçúcar. Biotecnol., Ciência \& Des., v. 5, p. 52-55, 2002. Citado por ALBERTINI S., CARMO L.F., PRADO FILHO L.G. Utilização de serragem e bagaço de cana-de-açúcar para adsorção de cádmio. Ciênc. Tecnol. Aliment. v. 27(1), p. 113-118, 2007. Disponível em:

<http://www.scielo.br/pdf/cta/v27n1/19.pdf> Acesso em: 12 abr. 2008.

[42] DIAS C.M.O., SANTOS R.S., SOUZA R., ALVES T.E., LIMA L.F.M., Aproveitamento do bagaço da cana-de-açúcar na fabricação de papel. Disponível em:

$<$ http://portal.mec.gov.br/setec/arquivos/pdf/mercosul_proj_papel.pdf> Acesso em 27 maio 2009.

[43] MARTINES E., SBRT - Serviço Brasileiro de Respostas Técnicas. Papel artesanal de bagaço de cana. Disponível em:

<http://www.respostatecnica.org.br> Acesso em 15 out. 2009.

[44] MACEDO I.C., NOGUEIRA L.A.H., Agência Paulista de Tecnologia dos Agronegócios. Avaliação da Expansão da Produção de Etanol no Brasil. 2004. Disponível em: <http://www.apta.sp.gov.br/cana/anexos/bc18.pdf>. Consultado em 24 maio 2009.

[45] HO, Y.; CHIU, W.; WANG, C. Regression analysis for the sorption isotherms of basic dyes on sugarcane dust. Bioresour. Technol., v.96, p. 1285-1291, 2005.

[46] YAMAMURA, A. P. G.; YAMAURA, M. Estudo da cinética e das isotermas de adsorção de $U$ pelo bagaço de cana-de-açúcar. In: INTERNATIONAL

NUCLEAR ATLANTIC CONFERENCE (INAC), 28 ago. - 2 set. , 2005, Santos, SP. Anais..., 2005. CDROM, 6 p.

[47] GUPTA, V. K.; ALI, I. Utilisation of bagasse fly ash (a sugar industry waste) for the removal of copper and zinc from wastewater. Sep. Purif. Technol., v.18, p.131-140, 2000.

[48] RAO, M.; PARWATE, A. V.; BHOLE, A. G. Removal of $\mathrm{Cr}^{6+}$ and $\mathrm{Ni}^{2+}$ from aqueous solution using bagasse and fly ash. Waste Mgm., v.22, p. 821-830, 2002.

[49] KEITH, S.; FAROON, O.M.; FOWLER, B.A. Handbook on the Toxicology of Metals 3E. Academic Press, Inc., cap. 45. Uranium. P. 881-903. Disponível em: <http://www.sciencedirect.com/science?_ob=ArticleListURL\&_method=list\&_Arti cleList ID=901088621\&_sort=d\&_st $=4 \&$ acct $=C 000049650 \&$ version $=1 \&$ urlVe rsion $=0 \&$ \&userid $=5671050 \&$ md $5=80 b 1 \overline{1}$ eb37076974b0be20 $\overline{c a 9 f 6 a 3 c 686>}$ Acesso em: 10 jan 2009. 
[50] FRANCO, M. Radioatividade e... muito mais. Associação Juvenil de Ciência. Lisboa, n²0, abr. 2001. Disponível em:

<http://www.ajc.pt/cienciaj/n20/avulso.php> Acesso em: 27 mar. 2008.

[51] INB - Indústrias Nucleares do Brasil. Reservas - Brasil e Mundo Disponível em:

<http://www.inb.gov.br/inb/WebForms/Interna2.aspx?secao_id=48> Acesso em 15 out. 2009.

[52] MACHADO, O. Empresa de Pesquisa Energética. Etanol eleva participação da cana-de-açúcar na matriz energética em 2006. Disponível em:

<http://www.epe.gov.br/imprensa/PressReleases/20070329_1.pdf>. Acesso em: 30 mar. 2009.

[53] DEUTCH J. M.; MONIZ. E. J. Energia de fissão - opção nuclear. Scientific American Brasil, p. ,out. 2006, n. 53, edição especial, Brasil.

[54] INTERNATIONAL ATOMIC ENERGY AGENCY-IAEA. Regulation for the safe transport of radioactive materials. 1985 Edition (As Amend 1990), Viena, 1990. (Safety series 6)

[55] Senado Federal - Secretaria Geral da Mesa. Lei que dispõe sobre os depósitos de rejeitos radioativos. Disponível em:

<http://www.cnen.gov.br/leis/lei_integra.htm> Acesso em 28 mar. 2008.

[56] GONÇALVES, O.D.; ALMEIDA, I.P.S. Energia nuclear e seus usos na sociedade. Revista Ciência Hoje. Rio de Janeiro, n. 220, out. 2005. Disponível em: <http://cienciahoje.uol.com.br/files/ch/220/nuclear.pdf> Acesso em 06 abr 2008.

[57] CNEN - Comissão Nacional de Energia Nuclear. Apostila educativa Aplicações da Energia Nuclear. Disponível em:

<http://www.cnen.gov.br/ensino/apostilas/aplica.pdf> Acesso em: 14 nov. 2007.

[58] SCHNELLRATH, J.; SILVA, A.O.; SHIMABUKURO, N.T. CETEM - Centro de Tecnologia Mineral. Fosfato - Mina de Cajati - Serrana. Disponível em: <http://www.cetem.gov.br/publicacao/CTs/CT2002-187-00.pdf> Acesso em: 19 out. 2009.

[59] FERNANDES, H.M.; RIO, M.A.P.; FRANKLIN, M.R. CETEM - Centro de Tecnologia Ambiental. Série Estudos \& Documentos. Impactos Radiológicos da Indústria do Fosfato. Disponível em: <http://www.cetem.gov.br/publicacao/CETEM_SED_56.pdf> Acesso em 27 abr 2007. 
[60] CPRM. Serviço Geológico do Brasil. Vista das imensas pilhas de rejeito de Cajati (SP). 664. Disponível em:

<http://www.cprm.gov.br/gestao/ppga_valedoribeira/Registros $\% 20$ fotogr\%E1fic os/cajati.htm> Acesso em: 28 mar. 2008.

[61] BERNARDES J., Agência USP de Notícias. Urânio encontrado nos alimentos chega à medula óssea. Disponível em:

<http://www.usp.br/agen/bols/1998_2001/rede808.htm> Acesso em 28 mar. 2008.

[62] SILVA, C.M.; SOUSA, G.H.; AMARAL, R.S. UFPE. Determinação da concentração de urânio em poços de abastecimento público da região uranofosfática de Pernambuco. Disponível em: $<$ http://www.ifi.unicamp.br/physicae/ojs-

2.1.1/index.php/physicae/article/viewFile/91/72>. Acesso em: 6 abr. 2009.

[63] MARQUES, F. Ciência Hoje - On Line. Notícias: medicina e saúde. Ingestão contínua de urânio afeta medula. Disponível em:

<http://cienciahoje.uol.com.br/controlPanel/materia/view/3088>. Acesso em: 06 abr. 2009.

[64] Energia. Nuclear. Radiação e Radioatividade. Disponível em: <http://www.biodieselbr.com/energia/nuclear/radiacao-radioatividade.htm> Acesso em: 13 nov. 2007.

[65] DEPOI, F.S.; POZEBON, D.; KALKREUTH, W.D. Chemical characterization of feed coals and combustion-by-products from Brazilian Power plants. Int. J. Coal Geol.. v. 76, p. 227-236, 2008.

[66] CONAMA. CONSELHO NACIONAL DO MEIO AMBIENTE. № 357, de 17 de março de 2005. Disponível em: <http://www.mma.gov.br/port/conama> Acesso em 21 jul. 2007.

[67] MARQUES F., Ingestão contínua de urânio afeta medula presente em produtos agrícolas, substância imita cálcio e se deposita nos ossos. Disponível em: <http://cienciahoje.uol.com.br/controlPanel/materia/view/3088> Acesso em: 20 out. 2009.

[68] Universidade Federal de Pernambuco. Departamento de Engenharia Química. Disciplinas. Processo Químico de Tratamento de Efluentes. Fundamentos de adsorção. Disponível em:

<http://www.deq.ufpe.br/disciplinas/Processos $\% 20$ Qu $\%$ C3\%ADmicos $\% 20$ de $\% 2$ 0Tratamento\%20de\%20Efluentes/Fundamentos\%20de\%20Adsorcao.doc> Acesso em: 28 mar. 2008. 
[69] KOUYOUMDJIEV M.S. Kinetics of Adsorption from liquid phase on activated carbon. 1992. Tese (Doutorado) - Eindhoven University of Technology, Eindhoven. Disponível em:

<http://www2.enq.ufsc.br/teses/m102.pdf> Acesso em 12 nov. 2009. Citado por - PERUZZO, L. C. Influência de agentes auxiliares na adsorção de corantes de efluentes da indústria têxtil em colunas de leito fixo. 2003. Dissertação (Mestrado) - Universidade Federal de Santa Catarina - UFSC, Santa Catarina. Disponível em: <http://www2.enq.ufsc.br/teses/m102.pdf> Acesso em 11 abr. 2008.

[70] FAUST, S.D.; ALY, O.M. Adsorption Processes for Water Treatment. 1. ed. Boca Raton, Flórida, 1987.

[71] PINO, G.A.H. Biossorção de metais pesados utilizando pó da casca de coco verde (cocos nucífera).2005. Dissertação (Mestrado) - Pontifícea Universidade Católica, Rio de Janeiro.

[72] Molecular Biology Archive, Gibbs's Free Energy. Disponível em: <http://www.newton.dep.anl.gov/askasci/mole00/mole00194.htm> Acesso em 15 dez. 2008.

[73] ATKINS, P. Físico-química - Fundamentos. 3. ed. Oxford, England, 2001.

[74] Gibbs Free Energy and Equilibrium. Disponível em: <http://www.science.uwaterloo.ca/ cchieh/cact/applychem/gibbsenergy.html> Acesso em 15 dez. 2008.

[75] FILHO, J. G., Físico-química - Uma proposta de ensino. 1. ed. São Paulo, SP, 1993.

[76] BENEGUELLA, B.; BENAISSA, H. Cadmium removal from aqueous solutions by chitin: kinetic and equilibrium studies. Water Res., v.36, p. 2463-2474, 2002.

[77] POLAKOVIC, M.; GORNER, T.; VILLIÉRAS, F.; DONATO, P; BERSILLON, J. L. Kinetics of salicylic acid adsorption on activated carbon. Langmuir, v. 21, p. 2988-2996, 2005.

[78] LIU, Y., Some consideration on the Langmuir isotherm equation. Colloids Surf. A. v. 274 , p. 34-36, 2006.

[79] NAKAJIMA, A.; SAKAGUCHI, T. Recovery and removal of uranium by using plant wastes. Biomass, v.21, p. 55-63, 1990. 
[80] PARAB, H.; JOSHI, S.; SHENOY, N.; VERMA, R.; LALI, A.; SUDERSANAN, M. Uranium removal from aqueous solution by coir pith: equilibrium and kinetic studies. Bioresour. Technol., v. 96, p. 1241-1248, 2005.

[81] FARINELLA, N. V.; MATOS, G. D.; ARRUDA, M. A. Z. Grape bagasse as a potential biosorbent of metals in effluent treatments. Bioresour. Tecnol., v. 98, p. 1940-1946, 2007.

[82] JOHNSON, P. D.; WATSON, M. A.; BROWN, J.; JEFCOAT, I. A. Peanut hull pellets as a single use sorbent for the capture of $\mathrm{Cu}(\mathrm{II})$ from wastewater. Waste Manage., v. 22, p. 471-480, 2002.

[83] SAEED, A.; AKHTER, M. W.; IQBAL, M. Removal and recovery of heavy metals from aqueous solution using papaya wood as a new biosorbent. Sep. Purif. Technol., v. 45, p. 25-31, 2005.

[84] GUPTA, V.K., JAIN, C.K., ALI, I., SHARMA, M., SAINI, V.K. Removal of cadmium and nickel from wastewater using bagasse fly ash - a sugar industry waste. Water Res., v. 37, p. 4038-4044, 2003.

[85] GUPTA, V.K.; ALI A. Removal of lead and chromium from wastewater using bagasse fly ash - a sugar industry waste. J. Colloid Interface Sci. v.271, p. 321-328, 2004.

[86] SILVA, V.L.M.M.; GOMES, W.C.; ALSINA, O.L.S. Utilização do bagaço de cana-de-açúcar como biomassa adsorvente na adsorção de poluentes orgânicos. REMAP, v. 2, p. 27-32, 2007. Disponível em:

<http://www.dema.ufcg.edu.br/revista/index.php/REMAP/article/view/28/64 > Acesso em: 17 ago. 2008.

[87] HO, Y.S.; CHIU, W.T.; WANG, C.C. Regression analysis for the sorption isotherms of basic dyes on sugarcane dust. Bioresour. Tecnol., v. 96, p. 12851291, 2005.

[88] SHEHA, R.R.; METWALLY, E. Equilibrium isotherm modeling of cesium adsorption onto magnetic materials. J. Hazard. Mater., v. 143, p. 354-361, 2007.

[89] YAMAURA, M.; CAMILO, R.L.; FELINTO, M.C.F.C. Synthesis and performance of organic-coated magnetite particles. J. Alloys Compd., v. 344, p. 152-156, 2002.

[90] BANERJEE, S.S.; CHEN, D.H. Fast removal of cooper ions by gum arabic magnetic nano-adsorbent. J. Hazard. Mater., v. 147, p. 792-799, 2007. 
[91] YAMAURA, M. ; SHIMA, G.M. Estudo comparativo de adsorção de Cr(VI) pelas fibras de quitosana e quitosana magnética. In: III CONGRESSO BRASILEIRO ICTR2006/GESTÃO AMBIENTAL E DESENVOLVIMENTO SUSTENTÁVEL: RESÍDUO-DESAFIO BRASILEIRO, ago. 6-9, 2006, São Pedro, SP. Anais... 2006. CD-ROM.

[92] STOPA, L.C. Quitosana magnética para remoção de urânio(UI). 2007. Dissertação (Mestrado) - Instituto de Pesquisas Energéticas e Nucleares, São Paulo.

[93] NUÑEZ, L.; KAMINSKI, M. D. Transuranic separation using organophosphorus extractants adsorbed onto superparamagnetics carriers. J. Magn. Magn. Mater., v. 194, p.102-107, 1999.

[94] NGOMSIK, A.F.; BEE, A.; DRAYE, M.; COTE, G.; CABUIL, V. Magnetic nanoand microparticles for metal removal and environmental applications: a review. Chimie, v.8, p. 963-970, 2005.

[95] WHITE, B.R.; STACKHOUSE, B.T.; HOLCOMBE, J.A. Magnetic $\gamma-\mathrm{Fe}_{2} \mathrm{O}_{3}$ nanoparticles coated with poly-L-cysteine for chelation of $\mathrm{As}(\mathrm{III}), \mathrm{Cu}(\mathrm{II}), \mathrm{Cd}(\mathrm{II})$, $\mathrm{Ni}(\mathrm{II}), \mathrm{Pb}(\mathrm{II})$ and $\mathrm{Zn}(\mathrm{II})$. J. Hazard. Mater., v. 161, p. 848-853, 2009.

[96] YAMAMURA, A. P. G.; YAMAURA, M. Estudos de adsorção para remoção de urânio em meio nítrico usando um biossorvente. In: $24^{\circ}$ CONGRESSO BRASILEIRO DE ENGENHARIA SANITÁRIA E AMBIENTAL (ABES), set. 2-7, 2007, Belo Horizonte, MG, Brasil. Anais...,2007. CD-ROM.

[97] PRONIEWICZ, L.M.; PALUSZKIEWICZ, C.; WESELUCH-BIRCZYNSKA, A.; BARANSKI, A.; DUTKA, D. FT-IR and FT-Raman study of hydrothermally degraded groundwood containing paper. J. Mol. Struct., v. 614, p.345-353, 2002.

[98] LU, X.; ZHANG, M.Q.; RONG, M.Z.; SHI, G.; YANG, G.C. Self-reinforced melt processable composites of sisal, Compos. Sci. Technol., v. 63, p.177-186, 2003.

[99] MARCELO, C. R., Determinação da relação siringila/guaiacila em ligninas de Eucalyptus spp. por pirólise associada à cromatografia gasosa e à espectrometria de massas. 2007. Dissertação (Mestrado), Universidade Federal de Viçosa, Viçosa, MG.

[100]RALPH, J.; HATFIELD, R.D. Pyrolysis-GC-MS Characterization of forage materials. J. Agric. Food Chem., v. 39, p. 1426-1437, 1991. 
[101]SOUSA, E.; RAMBO, C.R.; MONTEDO, D.H.; OLIVEIRA, A.P.N.

Vitrocerâmicas porosas do sistema LZSA utilizando resíduos orgânicos como agentes formadores de poros. Exacta, v. 4, p. 289-296, 2006. Disponível em: <http://redalyc.uaemex.mx/redalyc/pdf/810/81040208.pdf> Acesso em: 12 abr. 2008.

[102] SUN, X. F.; SUN, R. C.; TOMKINSON, J.; BAIRD, M. S. Preparation of sugarcane bagasse hemicellulosic succinates using NBS as a catalyst. Carboydr. Polym., v. 53, p. 483 - 495, 2003.

[103]EVANGELISTA, A.R.; ZANETTI, M.; SOUZA, O.; FUKUSHIMA, R.; RAPOSO, S.; SILA, P.R.C. Serviço Brasileiro de Respostas Técnicas. Quebra da lignina. 10 maio 2007. Disponível em: < http://www.respostatecnica.org.br> Acesso em: 11 mar. 2008.

[104]NAH, I.W.; HWANG K-Y, SHUL Y-G, A simple synthesis of magnetically modified zeolite, Powder Technol., v. 177, p. 99-101, 2007.

[105] INSTITUTO DE PESQUISAS ENERGÉTICAS E NUCLEARES. M. Yamaura; A. P.G. Souza; M. HAMAGUCHI; R. L. CAMILO. Biomassa Modificada. BR n. PI0403075-3, 2004.

[106]YAMAURA, M.; CAMILO, R.L.; SAMPAIO, L.C.; MACEDO, M.A.; NAKAMURA, M.; TOMA, H.E. Preparation and characterization of (3-aminopropyl) triethoxysilane-coated magnetite nanoparticles. J. Magn. Magn. Mater., v.279, p.210-217, 2004.

[107] MOHAN, D.; SINGH, K. P. Single- and multi-component adsorption of cadmium and zinc using activated carbon derived from bagasse - an agricultural waste. Water Res., v. 36, p. 2304-2318, 2002.

[108] SYNA, N.; VALIX, M. Modeling of gold(I) cyanide adsorption based on the properties of activated bagasse. Miner. Eng., v. 16, p. 421-427, 2003.

[109] MISSANA, T.; GUTIERREZ, M. G.; FERNNDEZ, V. Uranium (VI) sorption on colloidal magnetite Ander anoxid environment: Experimental study and surface complexation modeling, Geochim. Cosmochim. Acta, v. 67, p. 2543-2550, 2003.

[110] LEAL, R., Estudo da magnetita como material adsorvedor de íons uranilo. 2006. Dissertação (Mestrado) - Instituto de Pesquisas Energéticas e Nucleares, São Paulo. 